Rapport à l'Agence Nationale de Recherches sur le sida - octobre 2002 -

\title{
La gestion spirituelle du VIH-Sida: parcours biographique et construction identitaire
}

Anue-Cécile BéçOT

Groupe de Sociologie des Religions et de la Laïcité (GSRL)

CNRS/ÉPHE/IRESCO

59-61, rue Pouchet

75017 paris 


\section{PLAN}

Introduction

p. 2

\section{Premiere PARTIE : LA CONSTRUCTION DE L'OBJET}

I . Méthodologie

p. 4

1. Les étapes de l'enquête de terrain

p. 4

2 . L'enquête de terrain

p. 5

3 . Les données sociodémographiques

p. 9

II . Problématique

p. 10

1 . Le concept d'identité

p. 10

2 . Les voies de la médicalisation

p. 12

2. 1. Extension du domaine médical

p. 12

2. 1 . 1. L'émergence de politiques de santé publique

p. 12

2. 1 . 2 . La gestion publique du VIH/Sida

p. 14

2.2. Extension du champ de compétence de la médecine

p. 16

2.3. Amplification des préoccupations de santé de la population

p. 17

3. Religion héritée ou choisie ?

p. 19

\section{DEUXIEME PARTIE : CONSTRUCTION IDENTITAIRE ET GESTIONS RELIGIEUSES DU VIH/SIDA}

I . Religions héritées

p. 29

1. Parcours spirituels

p. 29

2 . La dimension « positive » de la maladie

p. 39

3 . Des pratiques thérapeutiques conformes au modèle dominant

p. 41

II . La religion comme lien culturel

p. 46

1. Parcours spirituels

p. 47

2 . Sens de la maladie : modèles exo- et endogène

p. 58

3 . Des pratiques thérapeutiques diversifiées

p. 64

III . Les ruptures religieuses

p. 70

1. Parcours spirituels

p. 70

2. La responsabilité de l'individu

p. 89

3 . Des pratiques thérapeutiques complémentaire et alternative

p. 92

Conclusion

p. 99

Bibliographie

p. 102

Annexes

p. 108

1. Données sociodémographiques

p. 108

2. Grille d'entretien

p. 110 


\section{introduction}

L'acceptation de mon projet de recherche par l'Agence Nationale de Recherches sur le Sida (ANRS) a été, pour moi, une agréable surprise. Je n'imaginais pas qu'un tel sujet puisse être retenu, et ce d'autant plus qu'en apportant mon dossier à l'ANRS, j'ai pu me rendre compte que je n'avais pas été la seule à candidater. En même temps, si j'ai réalisé ce projet, c'est aussi que j'espérais qu'il suscite l'intérêt et qu'il soit choisi.

Passé ces premiers instants, il a fallu que je me rende à l'évidence : réaliser une enquête sociologique en deux ans était un véritable défi. Cela ne tient pas seulement au fait que les études de terrain en sociologie sont, en généralement, relativement longues, mais aussi parce qu'une telle étude n'a jamais été réalisée en France. L'une des questions qui me taraudait, au début de l'enquête, était de savoir s'il me serait possible de rencontrer le public sur lequel je voulais mener mon étude'.

Pour surmonter ce défi, il a fallu faire des choix, notamment restreindre certaines investigations sur le terrain et recherches documentaires. En même temps, je minimise mes regrets au regard des témoignages recueillis au cours de cette enquête. Le parcours des personnes que j'ai rencontrées est tellement riche qu'il compense l'absence de certaines données.

En ce sens, je n'ai pas bien compris ce message, reçu par mail, en mars 2001, où un anonyme me laissait entendre que je vivais de la misère du monde. C'est faire peu de cas des apports des études sociologiques mais aussi des personnes touchées par le VIH-Sida qui estiment être porteuses d'un message, à travers leur témoignage. À ce propos, je repense à cet homme qui, à plusieurs reprises au cours de l'entretien, voulait donner des conseils aux séropositifs. Ou encore, je peux évoquer le cas d'un autre homme qui, ayant souffert du comportement de certaines personnes au sein de son organisation religieuse, du fait de sa séropositivité, tenait à témoigner pour que cela ne se reproduise pas.

Au-delà des motifs retenus par ceux qui ont témoigné dans cette enquête, il est important de considérer que ces personnes s'estiment être porteuses d'un message. Dans la construction de l'objet, il ne m'a pas été possible de restituer l'ensemble des témoignages même si j'ai cherché à les diversifier le plus possible.

Ce rapport est composé de deux parties. La première est consacrée à la construction de l'objet, celle de la construction identitaire à partir d'un référent spirituel. J'y aborde les aspects liés à l'enquête de terrain, la méthodologique et la problématique. La seconde partie est composée des trois formes idéaltypiques de construction identitaire : continuité religieuse, religion comme lien culturel et ruptures religieuses. Chaque forme idéaltypique présente des portraits choisis, les représentations du VIH-Sida et enfin les pratiques religio-thérapeutiques.

\footnotetext{
${ }^{1}$ - F. Nedelec, ayant réalisé une thèse auprès de personnes séropositives au HIV, a également souligné la difficulté de pouvoir s'entretenir avec ce public, « « Notes de terrain », Sociétés, 1993, n 42, p. 369.
} 
Première Partie

La construction de l'objet

3 


\section{I . Méthodologie}

\section{1 . Les étapes de l'enquête de terrain}

Le projet proposé à l'Agence Nationale de Recherches Scientifiques (ANRS), en 2000, concernait le recours à des «thérapies religieuses ${ }^{2}$ par des personnes touchées par le VIH-Sida et l'apport de ces dernières dans la gestion du VIH-Sida.

Il était impossible d'envisager une enquête de terrain approfondie (immersion prolongée sur le terrain) auprès des différents groupes à vocation thérapeutique. Le temps allait me manquer et je n'avais aucune certitude sur la fréquentation de ces groupes par le public qui m'intéressait. J'ai donc pris la décision de créer une annonce de mon étude et de la diffuser auprès de différents associations.

La difficulté a été de trouver des termes pertinents, susceptibles d'interpeller les personnes concernées par l'enquête. Les termes "Thérapies religieuses », "Groupes religieux à vocation thérapeutique », «Religions de guérison», propres à la communauté scientifique, pouvaient difficilement susciter l'attention du public.

En l'absence d'étude sur le sujet, en France, il est difficile de savoir dans quelle mesure ces groupes touchent davantage des personnes affectées par le VIH-Sida que les autres formations religieuses. Une étude réalisée par R. Dericquebourg, souligne que la motivation première, à entrer dans ce type de groupe, n'est pas toujours celle de la maladie ou de la guérison. Ainsi, au sein d'Invitation à la vie (IVI), seuls $17 \%$ des adhérents de ce groupe y sont entrés suite à une maladie ${ }^{3}$, et « $26 \%$ affirment avoir été guéris d'une maladie depuis leur entrée ».

Les différents contacts établis avec des responsables de «religions de guérison » ne laissent pas entrevoir une affinité particulière entre les deux variables (gestion religieuse de la santé et maladie inguérissable). Ainsi, à Mahikari, groupe religieux d'origine japonaise, un responsable m'a affirmé qu'il n'y avait pas de cas de VIH « déclaré », et ce après avoir s'être renseigné auprès de différents responsables de centres (dojo). Cette réponse ne présume en rien la réalité des faits; elle indique que les éventuels contaminés par le VIH ne font pas part de leur situation auprès des dirigeants ou responsables de centres.

Il existe néanmoins un discours sur les rapports éventuels entre Vih-Sida et religiosité. Ainsi, un responsable d'un groupe juif orthodoxe (Loubavitch) estimait que l'absence de personnes touchées par ce virus, au sein de sa communauté, s'explique par les principes éthiques qui les gouvernent (chasteté sexuelle avant le mariage, fidélité conjugale, interdiction de consommer des stupéfiants, ...).

\footnotetext{
2 - Les termes thérapies religieuses renvoient aux «Religions de guérison » étudiées par R. Dericquebourg. Selon cet auteur, ces groupes se caractérisent par divers aspects (centralité du rôle des thérapeutes religieux, la révision de la notion de maladie, des religions peu cérémonielles, ...) dont celui d'accorder une place centrale à la guérison, R. Dericquebourg, «La guérison par la religion », Revue Française de Psychanalyse, 1997, n 3, p. 965-979.

3 - R. Dericquebourg, Croire et guérir. Quatre religions de guérison, Dervy, 2001, p. 112.
} 
Au regard de ces données, le choix a donc été fait de toucher des personnes affectées par le Vih-Sida et s'inscrivant dans une démarche spirituelle ; certaines peuvent fréquenter des religions dite de guérison tandis que d'autres peuvent avoir une démarche religieuse plus « classique ».

\section{2 . L'enquête de terrain}

La localisation du public concerné par l'enquête n'étant pas déterminée, on a décidé de démultiplier les démarches et les contacts auprès de différents groupes et associations.

En premier lieu, on a réalisé une affichette ${ }^{4}$, en couleur, faisant un appel à témoignage. Le texte était le suivant : "Dans le cadre d'une étude de l'Agence Nationale de Recherches sur le Sida (ANRS), je recherche des témoignages $(*)$ de personnes touchées par le VIH-Sida et s'inscrivant dans une démarche spirituelle. (*) L'anonymat de l'entretien est garanti ». Suivaient mes coordonnées et mon rattachement institutionnel.

Cette affichette a été envoyée auprès d'organismes publics tels les Centres de Dépistage Anonyme et Gratuit (CDAG) et les Centres d'Information et de Soins de l'Immunodéficience Humaine (CISIH). Cette démarche a permis de réaliser cinq entretiens. L'annonce qui a eu le plus de «succès », est celle qui était scotchée sur l'ordinateur de la secrétaire délivrant des rendezvous médicaux à l'Hôpital Européen Georges Pompidou.

À propos de cette affichette, une anecdote peut être racontée. Dans l'un des hôpitaux contactés, la secrétaire m'a fait part des réticences du médecin responsable du CDAG pour apposer l'affichette. Les termes « démarche spirituelle » étaient, selon cette responsable, trop connotés d'un point de vue religieux. La secrétaire me laissait entendre que la suppression de ces termes conviendrait mieux et qu'ainsi l'affichette serait « recevable » dans les murs de l'enceinte hospitalière. Malgré mes explications (éliminer les termes « incriminés » reviendrait à retirer la spécificité du public visé), il n'a pas été possible de trouver un terrain d'entente.

La laïcisation de l'institution médicale engagée, en France, dès le début du XIX ${ }^{\mathrm{e}}$ siècle, s'est faite au détriment de l'institution religieuse : les clercs et religieuses ont été progressivement évincés de la sphère médicale pour laisser place à des professionnels de la santé, les officiers de santé et les médecins; de même, les établissements de soins ont progressivement fait l'objet d'une laïcisation dans le sens où tout signe religieux ostentatoire devait être retiré de ces lieux

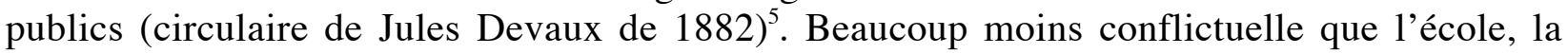
laïcisation de l'institution médicale n'en demeurait pas moins un sujet délicat car elle visait à supprimer les prérogatives des curés et religieuses détenues depuis des siècles. La réaction du médecin-chef du CDAG traduit, d'une certaine façon, une résurgence de cette situation sociohistorique : le malade, inscrit dans la sphère hospitalière $i$. e. publique, est une personne dont les

\footnotetext{
4 - Cette affichette figure en annexe.

5 - On peut également observer que les hôpitaux ou salles d'opération ont été rebaptisés ; les noms de saints et de saintes sont remplacés par des médecins et inventeurs (Trousseau, Jenner, Broca), J. Lalouette, « Expulser Dieu : la laïcisation des écoles, des hôpitaux et des prétoires », Mots. Les langages du politique, juin 1991, n²7, p. 34-35.
} 
croyances religieuses n'ont pas à interférer dans les soins qui lui seront apportés. De fait, une personne extérieure au service médical n'a pas à connaître ces croyances.

L'affichette a été proposée à trente-huit associations de lutte contre le sida. Pour justifier et expliquer la démarche engagée, vingt-six entretiens ont été réalisés avec des responsables de ces associations. Certains d'entre eux ont été intéressées par ma recherche et se sont véritablement investis pour relayer l'information auprès de leur public. Cela s'est avéré fructueux dans certains cas. Je pense notamment à l'association SOS Habitat et Soins dont le personnel (responsables, infirmières et assistantes sociales), directement en contact avec des personnes touchées par le VIH-Sida, s'est vraiment impliqué pour que je puisse rencontrer ces dernières. Malheureusement, dans certains cas de figure, ma requête n'a pas abouti. Ainsi, en est-il de l'Armée du Salut. En dépit de l'engagement du responsable contacté qui a adressé plusieurs courriers auprès des usagers de l'association, je ne suis pas parvenue à obtenir d'entretien. Les caractéristiques du public de cette association, des personnes Sans Domicile Fixe (SDF), peuvent expliquer cette impasse.

De manière plus générale, il est nécessaire d'envisager les conditions de la réalisation d'un entretien ; cette démarche n'est pas accessible à tout le monde. Outre le fait de pouvoir faire un travail d'anamnèse, il y a parfois des souvenirs douloureux que certains ne souhaitent pas raviver. Il faut également ajouter qu'au-delà d'une fragilité psychologique, les usagers de ces associations sont fatigués de devoir systématiquement raconter leur histoire auprès des services sociaux. Certains responsables d'association m'ont ainsi fait comprendre qu'il souhaitaient préserver leur public de toute nouvelle demande d'anamnèse.

Par ailleurs, il a fallu tenir compte de deux écueils possibles dans la réalisation des entretiens. Tout d'abord, celui mentionné par P. Bourdieu, où l'entretien pourrait être une reproduction du « modèle officiel de la présentation officielle de soi, carte d'identité, fiche d'état civil, curriculum vitae, biographique officielle $»^{6}$. Il a été possible d'éviter ce type de présentation de soi en introduisant la variable religieuse ; celle-ci permettait de sortir d'une présentation officielle faite, généralement, auprès des services sociaux. Ensuite, on a pu constater qu'un certain nombre de personnes interviewées avaient été engagées dans une psychothérapie ; elles pouvaient reproduire, dans le cadre de l'entretien sociologique, un discours déjà pensé et construit. La dimension semi-directive de l'entretien (une grille de questions a été élaborée au préalable) a permis, dans une certaine mesure, de « cadrer » un discours pré-construit.

Quelques associations n'ont pas souhaité donner suite à ma demande d'entretien. Si certains arguments étaient recevables (fragilité psychologique des personnes, refus de raconter son histoire devant une inconnue, ...), d'autres l'étaient beaucoup moins. Je pense notamment à une association travaillant auprès de migrants originaires d'Afrique. La responsable avec qui j'ai eu des contacts m'a tout d'abord signifié que les termes « démarche spirituelle » ne convenaient pas au public qu'elle rencontrait. La spiritualité ou la religiosité de ces personnes, m'expliquaitelle, fait partie d'un tout, indivisible, non fragmentable. Face à cet argument, je proposais de changer les termes de mon annonce pour qu'elle soit signifiante au regard de ceux qui étaient susceptibles de la lire ou de l'entendre. Cependant, au cours de l'entretien réalisé avec l'équipe de cette association, ce n'était plus les termes de l'annonce qui posaient problème mais ma propre

${ }^{6}$ - P. Bourdieu, «L'illusion biographique », Actes de la Recherche en Sciences Sociales, 1986, nº 62-63, p. 71. 
personne. En effet, il m'a été dit que réaliser des entretiens avec les usagers de cette association était inutile car je ne comprendrais pas leur univers de sens. Faut-il préciser que la démarche sociologique n'a pas de prétention thérapeutique ; elle poursuit un objectif, celui de comprendre l'autre dans son environnement social.

La réalisation d'une enquête de terrain est toujours faite de rebondissements, d'interrogations, d'échecs, etc. Il me semble toutefois important de mentionner cette expérience car au-delà d'une mise en cause personnelle, c'est la manière d'envisager et de considérer les étrangers qui pose, ici, question. S'inspirant de l'ethnopsychiatrie, cette association prétend avoir la clef ou les outils permettant de comprendre la culture de l'Autre, essentiellement africain, et présuppose que les autres (occidentaux) ne peuvent l'appréhender. Sans aboutir aux conclusions critiques du sociologue D. Fassin ${ }^{7}$, on peut se demander si l'ethnopsychiatrie n'est pas en train de faire de la culture un point de non rencontre entre les hommes.

L'annonce diffusée auprès des associations de lutte contre le sida a permis de récolter dixhuit entretiens. Un autre moyen de rencontre a été celui d'Internet. L'annonce de l'étude a été laissée sur de nombreux sites (homosexualité(s), médecines parallèles, ...) mais deux d'entre eux ont été particulièrement fructueux car elle a été laissée plusieurs mois de suite sur le site (Sida Info Services) ${ }^{8}$, ou parce qu'un courrier électronique a été directement adressé auprès des abonnés du site (Citégay). Ce mode de rencontre a permis d'interviewer cinq personnes.

Par ailleurs, différents contacts ont été établis avec des représentants de différentes confessions, notamment des groupes à vocation thérapeutique. Cette démarche a parfois débouché sur des contacts permettant la réalisation d'entretiens. Ce mode de recrutement pose néanmoins question car en m'adressant aux responsables, je prenais le risque de me voir recommander uniquement les adeptes considérés comme fidèles aux prescriptions du groupe. Ainsi en a t-il été avec l'Alliance Universelle, ex-Christ de Montfavet, où l'un de ses responsables a préféré ne pas me présenter une personne fréquentant leurs réunions en arguant de son absence de respect pour les préceptes du groupe.

Le fait de coopérer à une étude sociologique peut correspondre, pour certains groupes religieux, à une quête de légitimité ; certains d'entre eux sont parfois stigmatisés, qualifiés de « sectes » dans les médias et estiment qu'une étude dite «neutre », sociologiquement, peut leur apporter une image plus « positive ».

\footnotetext{
7 - La critique faite par Didier Dassin, sociologue, à l'ethnopsychiatrie, repose sur le postulat émis d'emblée à propos de l'incompatibilité entre la culture de l'Autre, l'étranger, et plus précisément l'Africain, et la culture du pays d'accueil, la culture occidentale ; cette incompatibilité serait à l'origine, selon les ethnopsychiatres, des désordres psychiques rencontrés par les africains. D. Fassin estime que les désordres sociaux, dès lors qu'ils concernent les immigrés, seraient traités, par les ethnopsychiatres, comme des troubles psychiques. Pour cet auteur, la démarche ethnopsychiatrique repose d'une part sur l'idée que la culture de l'Africain est uniforme (pas de travail de connaissance anthropologique des immigrés rencontrés; il est question de l'Africain, à l'échelle continentale), et d'autre part, que la culture de l'Africain est particulière en ce sens qu'il est impossible de la mélanger à la culture européenne (sans qu'elle soit source de désordre), D. Fassin, «Les politiques de l'ethnopsychiatrie. La psychée africaine, des colonies africaines aux banlieues parisiennes », L'homme, $\mathrm{n}^{\circ}$ 153, 2000, p. 231-250.

8 - Plusieurs réponses à l'annonce déposée sur le site de Sida Info Services n'ont pas pu aboutir car les personnes vivaient en province et je ne pouvais m'y rendre, compte tenu de contraintes financières.
} 
À ces limites méthodologiques, on peut objecter trois aspects. Le premier concerne les contraintes de l'étude. Réalisée sur deux ans, il n'était pas possible d'investiguer les groupes religieux par une immersion prolongée sur le terrain. Cette méthode est trop aléatoire (comment savoir s'il existe des cas de VIH-Sida dans tel ou tel groupe) mais surtout trop longue. Ainsi, en ayant eu connaissance d'un cas de «guérison » de sida dans un groupe pentecôtiste parisien, j'avais décidé de fréquenter ce dernier. Cette démarche n'a pas abouti car elle nécessitait un engagement important pour me familiariser avec les fidèles et établir une relation de confiance avec eux. Dans ce cas de figure, la prise de contact avec les responsables des groupes semble être la voie la plus rapide même si elle pose la question de la « fiabilité » des personnes rencontrées.

Le deuxième aspect consiste à prendre en considération l'objet de l'étude. L'objectif n'est pas de réaliser une monographie sur le groupe religieux fréquenté par la personne interviewée mais de comprendre son parcours biographique. De fait, le rôle et la place occupée par la spiritualité, qu'il s'agisse d'un groupe sectaire ou non, est en soi importante mais ce qui prime c'est le discours de l'individu et son rapport à la religiosité/spiritualité.

Le troisième aspect tient compte d'une situation plus générale, dépassant l'aspect proprement religieux. Le fait de choisir les personnes à interviewer n'a pas été le seul fait des groupes religieux ; certaines associations de lutte contre le sida, dans un souci de représentation d'elles-mêmes, ont également procédé de la sorte. Ainsi, un responsable me disait, en me laissant les coordonnées d'une personne à contacter et fréquentant son association, «oui, allez-y, elle est bien ».

Le dernier moyen de rencontre a été celui du bouche à oreille (six personnes); l'interviewé se faisant l'intermédiaire de l'une de ses connaissances. Ce type de contact est particulièrement intéressant dans la mesure où il concerne des personnes qui n'auraient pas forcément répondu à mon annonce, si elle avait été vue dans un cadre institutionnel. 


\section{3 . Les données sociodémographiques 9}

Au total, trente-huit entretiens ont été réalisés. À l'exception d'un seul, ils ont tous été enregistrés et ont fait l'objet d'une transcription.

Sur ces trente-huit personnes, on a vingt-sept hommes et onze femmes. La répartition par confessions est la suivante : vingt-et-une personnes se trouvent dans la mouvance chrétienne (dix catholiques, six protestantes, deux du groupe Invitation à la Vie, deux orthodoxes et une du groupe Témoin de Jéhovah), trois sont musulmanes, quatre sont dans la mouvance bouddhiste, neuf s'inscrivent dans la mouvance New Age, et un autres cas (personne se définissant comme agnostique). Dix-huit personnes ont engagé une démarche spirituelle après l'annonce de leur séropositivité ; dix-huit autres étaient déjà engagés spirituellement et pour deux cas il n'a pas été possible de savoir ce qu'il en était.

Une large majorité des répondants (vingt-neuf) à l'enquête se trouve dans la tranche d'âge 30-49 ans. Pour la tranche d'âge 20-29 ans, on a quatre personnes, et au-delà (50-60 ans et plus), on a cinq personnes.

Une part importante des personnes interviewées était sans profession au moment de l'entretien (dix-huit). Pour les autres, la répartition par PCS (Profession et Catégories Sociales) est la suivante : deux sont artisans-commerçants, six sont cadres supérieurs ou ont une profession libérale, six sont cadres moyens, un est employé, trois sont personnels de service, et deux sont retraités.

En terme de niveau d'étude, la répartition est relativement homogène : vingt personnes ont un niveau qui va de l'école primaire jusqu'au BAC, dix-sept ont été au-delà du BAC, et un autre cas (sans réponse).

La plupart des personnes rencontrées (vingt-neuf) ont été contaminées avant 1996, date de la mise en place des multithérapies. Les neuf autres ont su leur séropositivité au VIH après 1996. Concernant le mode de contamination, vingt-cinq ont été contaminées par voie sexuelle, six par voie intraveineuse et sept autres $\operatorname{cas}^{10}$. Quant à la sexualité des trente-huit interviewés, vingtquatre se disent hétérosexuels, douze homosexuels, un bisexuel et un cas de non réponse.

Vingt-trois des personnes rencontrées sont françaises et quinze étrangères ou d'origine étrangère (onze sont originaires de l'Afrique subsaharienne, une de l'Afrique du Nord et trois de l'Europe).

\footnotetext{
9 - L'ensemble de ces données figurent en annexe sous forme de tableaux.

10 - Sur ces sept personnes, deux disent ne pas savoir comment elles ont été contaminées et cinq autres ont pu être touchées soit par voie sexuelle, soit par voie intraveineuse.
} 


\section{II . La problématique}

\section{1 . Le concept d'identité}

La mise en place, à partir de 1996, des multithérapies (nouvelle association thérapeutique d'antirétroviraux) a complètement changé les caractéristiques de l'épidémie de Sida, notamment par rapport à la chute du nombre de nouveaux cas de sida et à la baisse du nombre de décès ${ }^{11}$. L'espérance de vie des personnes atteintes du VIH/Sida étant plus longue et l'entrée dans la phase Sida n'étant plus inéluctable, la gestion chronique de la séropositivité a évolué.

L'annonce de la séropositivité peut être envisagée comme un moment de «crise » mais comme toute maladie chronique, cette crise tend à se routiniser, et ce à la différence des maladies aiguës. Deux niveaux de désorganisation sont perceptibles dans le cas de maladies chroniques létales: la personne peut être atteinte dans la plupart de ses insertions sociales (famille, profession, sexualité, ...) et il n'y a pas d'échéance prévisible de la maladie ${ }^{12}$. Dès lors, la question de l'identité se pose car, comme l'écrit M. Pollak, « elle ne va plus de soi » ${ }^{13}$.

La notion d'identité, en tant que concept sociologique, sera appréhendée à partir des travaux de Cl. Dubar ${ }^{14}$. Cet auteur fonde sa théorie de l'identité à partir de différents travaux (psychanalytique, anthropologique, psychologique, sociologique, ...), et l'envisage comme le résultat de divers processus de socialisation qui construisent les individus et définissent les institutions. Il part du postulat qu'il existe une division interne à l'identité : «l'identité pour autrui » et « l'identité pour soi ». L'identité pour autrui se constitue à partir d'actes d'attribution, ceux qui visent à définir 'quel type d'homme (ou de femme) vous êtes, alors que l'identité pour soi apparaît au cours d'actes d'appartenance, ceux qui expriment 'quel type d'homme (ou de femme) vous voulez être ${ }^{15}$.

En dépit de cette dualité, ces deux formes identitaires (la division du Soi) sont inséparables et liées de façon problématique. «Inséparable, écrit-il, puisque l'identité pour soi

\footnotetext{
11 - De 3996 cas de Sida diagnostiqués en 1996, on passe à 1683 pour l'année 2 000, et de 2851 décès au cours de l'année 1996, ils sont évalués à 587 pour l'année 2000. Le nombre total de personnes vivantes ayant développé un Sida a augmenté passant de 17512 cas en 1996 à 22048 cas en 2000. Par ailleurs, les caractéristiques de la population touchée par le Sida ont également changé. En 1997, la contamination hétérosexuelle est devenue le mode de contamination le plus fréquent pour les cas de Sida diagnostiqués (44\% des cas diagnostiqués en 2000 contre $28 \%$ pour les cas de contamination homosexuelle, et $14 \%$ pour les cas de contamination par usage de drogues injectables), alors qu'avant cette date, c'était la contamination homosexuelle qui prévalait. Par ailleurs, parmi les cas de contamination hétérosexuelle, on constate une augmentation chez les femmes (9\% d'augmentation des cas diagnostiqués entre 1999 et 2000). Cette hausse s'explique, entre autre, par une augmentation du nombre de cas diagnostiqués chez les femmes de nationalité africaine (en 1999-2000, 27\% des cas diagnostiqués chez des femmes concernent des femmes de nationalité africaine), «Surveillance du Sida en France. Situation au 31 mars 2001 », Bulletin épidémiologique hebdomadaire, $\mathrm{n}^{\circ} 24,2001$.

12 - I. Baszenger, «Les maladies chroniques et leur ordre négocié », Revue Française de la Sociologie, XXVII, 1986, p. 3-27.

13 - M. Pollak, Une identité blessée. Étude de sociologie et d'histoire, Métailié, Paris, 1993, p. 10.

14 - C. Dubar, La socialisation. Construction des identités sociales et professionnelles, Armand Colin, Paris, 1991, $278 \mathrm{p}$.

15 - Idem, p. 114.
} 
est corrélative d'Autrui et de sa reconnaissance : je ne sais jamais qui je suis que dans le regard d'Autrui. Problématiques puisque 'l'expérience de l'autre n'est jamais directement vécue par soi ... en sorte que nous comptons sur nos communications pour nous renseigner sur l'identité qu'autrui nous attribue ... et donc pour nous forger une identité pour nous-mêmes' ${ }^{16}$.

Cette dualité de l'identité est présente dans d'autres travaux, notamment ceux de Goffman qui évoque «l'identité sociale virtuelle » (celle que les institutions assignent aux individus) et «l'identité sociale réelle » (l'histoire que l'individu se raconte sur ce qu'il est, pour paraphraser R. Laing).

Dans cette perspective, la construction identitaire s'organise autour de deux processus hétérogènes : celle d'une attribution d'identité par les institutions et les agents directement en interaction avec l'individu, et celle de l'incorporation de l'identité par les individus eux-mêmes. Quand un écart existe entre ces deux processus, des transactions sont mises en place pour les réduire : d'un côté, celle de «transaction externe » entre l'individu et les autres significatifs visant à accommoder l'identité pour soi à l'identité pour autrui (transaction objective) ; de l'autre côté, on a la «transaction interne » à l'individu, entre la nécessité de sauvegarder une part de ses identifications antérieures (identités héritées) et le désir de se construire de nouvelles identités dans l'avenir (identités visées) visant à tenter d'assimiler l'identité-pour-autrui à l'identité-poursoi (transaction subjective) ${ }^{17}$. C'est l'articulation de ces deux transactions qui est la clé du processus de construction des identités sociales. "L'enjeu, écrit C. Dubar, est bien celui de l'articulation de ces deux processus complexes mais autonomes: on ne fait pas l'identité des gens malgré eux et pourtant on ne peut se passer des autres pour se forger sa propre identité ${ }^{18}$.

Pour articuler cette théorie sociologique de l'identité au cas des personnes touchées par le VIH/Sida et s'inscrivant dans une démarche spirituelle, il est nécessaire de reprendre ces deux versants de l'identité que sont l'identité virtuelle et l'identité réelle. L'annonce de la séropositivité ou de l'entrée dans la phase sida est, on l'a indiqué, synonyme de crise identitaire. En plus d'être affecté au niveau de ses insertions sociales et d'être dans l'incertitude face à l'échéance de la mort, l'individu se voit assigné/identifié, auprès des services hospitaliers, de son médecin, des services sociaux, mais aussi de sa famille, de ses proches ou collègues, ... comme porteur du VIH. Cette identité de séropositif (identité virtuelle) peut être vécue différemment selon les individus. Pour certains, cette nouvelle identité peut être pleinement acceptée dans la mesure où un sens lui est donné. Pour d'autres, elle peut être problématique dans la mesure où ils ont le sentiment d'être réduits à leur identité de «malade » alors qu'ils ne s'identifient pas (seulement) comme tels. Enfin, d'autres construisent leur identité en opposition à l'identité qui leur assignée.

Par ailleurs, parmi les personnes rencontrées au cours de l'enquête toutes, à l'exception d'une seule, ont eu une religion d'origine. Cette identité religieuse héritée a évolué différemment selon les cas de figure. Ce qui importe, ici, c'est d'envisager le recours à la religion ou la spiritualité (héritée ou non) comme un élément participant à la construction identitaire dans la mesure où il permettrait de résoudre cette tension entre identité virtuelle (séropositif, «malade »

16 - Ibid., p. 112.

17 - Ibid., p. 116.

18 - Ibid., p. 119. 
du sida) et identité réelle (membre de tel groupe religieux, enfant de Dieu, ...). Avant d'étayer cette hypothèse, on dégagera les problématiques propres aux champs médical et religieux, et ce afin de comprendre « le monde » dans lequel ces personnes évoluent.

\section{2 . Les voies de la médicalisation}

Dans l'un de ses articles, P. Aïach envisage différentes caractéristiques du processus de médicalisation $^{19}$. On reprendra certaines d'entre elles pour les examiner à travers le cas du VIHSida.

\section{2 . 1 . Extension du domaine médical}

\section{1 1 1 L'émergence de politiques de santé publique}

Un détour historique permet effectivement de constater une extension du domaine médical. La thèse défendue par D. Fassin concerne les conditions d'émergence d'une politique de santé publique $^{20}$. Pour cet auteur, ce ne sont ni les connaissances scientifiques, ni les concentrations de populations qui permettent d'expliquer la naissance d'une politique de santé publique mais l'émergence d'un pouvoir politique $i$. e. mise en place d'une structure politique et gestion organisée du pouvoir. De fait, ce seront davantage dans des sociétés où les sphères sociales sont différenciées et où existe une organisation du politique que la santé publique prendra toute son envergure.

Durant la première moitié du XIX ${ }^{\mathrm{e}}$ siècle, en France, on décèle une volonté, de la part du monde politique de mettre en place des mesures de santé publique mais les moyens financiers manquent. Des mesures concrètes seront prises au cours de la seconde moitié de ce siècle. Une médecine sociale se met en place dont l'objectif est de réguler la société et de contrôler les conduites. Il faut ajouter, avec le regard de l'historien O. Faure, que « si le ralliement de la population à la médecine scientifique et officielle est bien une révolution culturelle, celle-ci a été au moins autant voulue par le peuple qu'imposée par les médecins et les autorités $»^{21}$ (p. 6).

Quant au $\mathrm{XX}^{\mathrm{e}}$ siècle, il est marqué par une extension du domaine de la santé publique. D'une part, les populations concernées par la loi sont plus nombreuses (cela ne concerne plus seulement les marginaux ou les ouvriers), d'autre part, le corps n'est plus le seul concerné par les mesures mais tous les comportements (entreprise de normalisation), et enfin, on voit une diversification des intervenants dans l'action sanitaire ${ }^{22}$.

\footnotetext{
19 - P. Aïach, « Les voies de la médicalisation », L’ère de la médicalisation. Ecce homo sanitas, P. Aïach, D. Delanoë (éds.), Anthropos, Paris, 1998, p. 15-36.

20 - Cet auteur envisage le domaine de la santé publique de la façon suivante : «l'investissement du politique dans la gestion collective de la maladie détermine la construction d'un espace autonome où se mettent en place les normes et les institutions qui régissent le rapport du corps physique et du corps social », D. Fassin, L'espace politique de la santé. Essai de généalogie, PUF, coll. Sociologie d'aujourd'hui, Paris, 1996, p. 205.

${ }^{21}$ - O. Faure, Les Français et leur médecine au XIX siècle, éd. Belin, Paris, 1993, p. 6.

22 - D. Fassin, L’espace politique de la santé. Essai de généalogie, PUF, coll. Sociologie d'aujourd'hui, Paris, 1996, p. 257.
} 
La politique de lutte contre le Sida, menée en France, repose sur l'idée que l'amélioration de la santé collective passe par une responsabilisation croissante des individus; ainsi, les campagnes de lutte contre le Sida ont surtout mis l'accent sur la responsabilité individuelle. Cette politique est d'autant plus légitime, remarque G. Vigarello, que l'épidémie concerne des pratiques individuelles ${ }^{23}$. Le rejet, par le gouvernement, en 1992, d'une proposition de l'Académie de Médecine visant à rendre obligatoire le test de dépistage pour les femmes enceintes et lors de certificats prénuptiaux, s'inscrit dans cette perspective ; la lutte contre la propagation de l'épidémie tient à la responsabilité de chacun. Néanmoins, indique D. Fassin, l'individualisation de la responsabilité, telle qu'elle s'exprime dans les politiques de santé publique, se manifeste parallèlement au renforcement des dispositions de gestion collective de la santé ${ }^{24}$.

Une politique de santé publique peut être mise en place sans pour autant engager publiquement ceux qui l'impulsent. Un tel cas de figure a été observé par D. Fassin au Congo (Brazzaville) à propos de la lutte contre le sida ${ }^{25}$. Cette politique existe mais elle ne fait l'objet d'aucun discours de la part de la classe politique. Autrement dit, l'épidémie au VIH donne lieu à des programmes et à des mesures de santé publique, sans pour autant apparaître comme un véritable enjeu politique. Les raisons permettant d'expliquer ce silence tiennent d'une part à l'emprise des croyances en la sorcellerie. «C'est dire, écrit cet auteur, combien il est dangereux d'en parler publiquement, puisque ce serait manipuler des forces dont on sait que l'on ne pourra pas ensuite les maîtriser ». D'autre part, le silence des hommes politiques sur la question du VIHSida, tient au fait que ces derniers risquent de s'exposer à la critique ; critique des faiblesses de l'État dans sa politique de prévention, critique des fautes de la classe dirigeante, de ses carences,

À propos des effets des politiques de santé publique, deux aspects peuvent être soulignés. En premier lieu, il s'agit de l'homogénéisation du discours de prévention qui n'empêche pas les exclusions car, comme le souligne B. Hours, les normes intègrent autant qu'elles excluent ${ }^{26}$. Cette analyse peut être complétée par celle de R. Massé qui envisage le respect des prescriptions préventives comme une forme d'intégration sociale : se libérer du joug du déterminisme biologique, maîtrise de soi, contrôle de son destin, ...

En second lieu, il faut circonscrire le cadre dans lequel se mettent en place les politiques de prévention contre le Sida, celui d'une hypervalorisation de la santé. D'un droit à la santé, écrit R. Massé, on est passé à un devoir individuel de maximiser ce potentiel santé ${ }^{27}$. «Il en résulte, écrit cet auteur, un discours moralisateur sur la pratique de comportements connus comme à risque (...) Dans les sociétés libérales, le contrôle social passe par une honte intériorisée de ne pas

23 - G. Vigarello, Le sain et le malsain. Santé et mieux-être depuis le Moyen Âge, Seuil, coll. L'Univers Historique, Paris, 1993, p. 295.

${ }^{24}$ - D. Fassin, L'espace politique de la santé. Essai de généalogie, PUF, coll. Sociologie d'aujourd'hui, Paris, 1996, p. 273.

${ }_{25}$ - D. Fassin, «Le domaine privé de la santé publique. Pouvoir, politique et sida au Congo », Annales, 1994, vol. $49, \mathrm{n}^{\circ} 4$, p. $745-775$.

26 - B. Hours, «Introduction. Pour un anthropologie de la santé en société », Systèmes et politiques de santé. De la santé publique à l'anthropologie, sous la direction de B. Hours, Karthala, Paris, 2001, p. 5-40.

27 - R. Massé, «La santé publique comme projet politique et projet individuel », Systèmes et politiques de santé. De la santé publique à l'anthropologie, sous la direction de B. Hours, Karthala, Paris, 2001, p. 41-64. 
être sain, énergétique et productif, mais surtout une honte de ne pas avoir tout fait en son pouvoir pour maintenir sa santé $»^{28}$. Pour les personnes contaminées au VIH, il peut en résulter un fort sentiment de culpabilité.

Cet auteur tient cependant à souligner la contestation possible des normes édictées par les politiques de santé publique. Il cite le cas des Indiens Montagnais qui stigmatisent, au sein de leur groupe, les personnes qui respectent les directives de l'État canadien. Dans le cadre de l'étude VIH-Sida et Spiritualité(s), on se demandera si le recours à des pratiques religieuses (envisagées comme préventives ou thérapeutiques) ne peut pas être envisagé comme une forme de protestation à l'égard de l'institution médicale.

\section{2 . 1 . 2 . La gestion publique du VIH-Sida}

Il est possible, à travers le cas du VIH-Sida, d'observer une extension du domaine médical. Cette hypothèse apparaît à travers les travaux de O. Borraz et $\mathrm{P}$. Loncle-Moriceau ${ }^{29}$. Ces auteurs contredisent l'hypothèse la plus fréquemment émise selon laquelle les désordres provoqués par l'apparition de l'épidémie de Sida auraient provoqué l'émergence d'une nouvelle politique de santé publique, politique qui entend promouvoir une approche collective des questions sanitaires, avec un objectif de prévention.

Selon ces auteurs, cette hypothèse ne peut tenir, car elle impliquerait que le Sida possède en soi un «ordre propre »: «si la gestion de l'épidémie, écrivent ces auteurs, permet d'établir des liens entre des éléments relevant de secteurs distincts, notamment médical, social et politique, ces liens ne sont pas inscrits dans la structure même de la maladie. Ils sont, au contraire, le produit, d'une part, des décalages, contestations, tensions entre les intervenants dans ces secteurs, qui revendiquent une participation à la lutte contre le sida, voire la maîtrise de celle-ci, d'autre part, des actions entreprises par des structures de médiation pour réduire ces décalages ». Par ailleurs, la gestion du Sida s'inscrit dans des institutions possédant des logiques et temporalités qui leurs sont propres et qui, durant la période de l'expansion de l'épidémie de Sida, ont été soumises à des transformations ; " le sida est un facteur de recomposition, mais il ne saurait être appréhendé indépendamment des évolutions en cours, par exemple dans les dispositifs de lutte contre la toxicomanie, dans la lutte contre la pauvreté et l'exclusion ou encore en matière de financement de l'assurance-maladie voire dans la montée du thème de la responsabilité des élus et fonctionnaires dans la gestion publique $\gg^{30}$.

Pour O. Borraz et P. Loncle-Moriceau, l'épidémie de Sida a permis une recomposition des structures déjà en place se traduisant, notamment, par un renforcement du modèle hospitalier. Pour étayer leur hypothèse, ces auteurs vont examiner le modèle de santé développé en France, modèle qui engage de multiples interactions entre différents intervenants concernés par les questions sanitaires. De fait, ils choisissent de l'appréhender à partir des «matrices institutionnelles ». Celles-ci permettent d'inscrire l'action publique de prévention, de lutte, et de soins contre le Sida à partir des pôles sanitaire (hôpitaux, cliniques, médecins de ville et activités

\footnotetext{
28 - Idem, p. 47 et 48.

29 - O. Borraz, P. Loncle-Moriceau, « Permanence et recompositions du secteur sanitaire. Les politiques locales de lutte contre le sida », Revue Française de Sociologie, n 41-1, 2000, p. 37-60.

30 - Idem, p. 39.
} 
paramédicales), politique (communes, conseils généraux, régionaux) et social (associations, mutuelle, et caisse d'assurance maladie). Il est nécessaire d'étudier chacun de ces pôles à partir de leur organisation interne, des relations qu'ils entretiennent entre eux et de leur insertion dans le secteur sanitaire.

Les auteurs observent que plus le degré de centralité de l'institution hospitalière est élevé (capacité d'intégration de l'hôpital au sein du système local de soins et étroitesse de ses liens avec les institutions politiques et médico-sociales), "plus l'hôpital public est en mesure de déterminer la forme et le contenu des actions de prise en charge des personnes atteintes mais aussi des actions de prévention. À l'inverse, plus ce degré est faible, plus on observe des actions alternatives de prise en charge et de prévention » (p. 48).

Le renforcement de l'institution hospitalière dans la gestion du Sida s'observe par la place et le rôle occupés par les praticiens hospitaliers. Ces derniers vont progressivement prendre le contrôle des structures mises en place par l'État, les Centres d'Information et de Soins de l'Immunodéficience Humaine (CISIH, créés en 1987) ${ }^{31}$ et les Réseaux Ville-Hôpital (RVH, créés en 1991$)^{32}$.

La place grandissante occupée par les praticiens hospitaliers, au sein des CISIH, tient au haut degré de technicité exigé par les multithérapies et à la nécessité d'une coordination dans la définition des traitements. En outre, les praticiens hospitaliers vont se charger des actions de prévention et ce tant pour retrouver une certaine légitimité (due à leur impuissance à traiter le virus pendant plusieurs années) que pour éviter que ne se développe un discours alternatif vis-àvis de la prévention du sida (cf. gestion communautaire).

Quant aux RVH, ils « passent rapidement sous le contrôle des praticiens hospitaliers ». La contestation de l'institution hospitalière ne pourra pas vraiment s'engager dans la mesure où toute action alternative sera évincée, et parmi les acteurs restants, ils « prendront soin de reproduire dans la forme et le contenu de leurs associations, les règles institutionnalisées légitimes dans le secteur sanitaire, témoignant ainsi de leur souci de crédibilité aux yeux de l'institution hospitalière » (p. 46).

Les auteurs de cette étude notent une ouverture de l'hôpital sur la ville mais aussi l'impossibilité, pour des initiatives marginales, de se développer de manière autonomes ; à terme, celles-ci devront soit se rapprocher de l'institution hospitalière, soit en reproduire les traits dominants. La prédominance d'un seul modèle de santé étant légitimé par les valeurs véhiculées par le système de santé, celles de l'égalité d'accès aux soins.

Les actions engagées par des associations de lutte contre le Sida, la prise en compte des revendications de certains acteurs sociaux, la participation de ces derniers à des processus

31 - Les CISIH sont censés renforcer les recherches sur le VIH, améliorer le suivi épidémiologique, renforcer l'organisation et l'exploitation des essais thérapeutiques et soutenir l'effort de formation des personnels médicaux et paramédicaux.

32 - Quant aux RVH, ils visent à une meilleure collaboration entre médecins hospitaliers et médecins de ville et à mobiliser l'ensemble des personnels (médicaux, paramédicaux, travailleurs sociaux) prenant en charge des personnes séropositives. 
décisionnels (campagne de lutte contre le Sida) ${ }^{33}, \ldots$ ne sont pas mis en cause par les auteurs de cette étude. Inscrivant leur étude dans la durée, ils ont suffisamment de recul pour envisager les effets introduits par les multithérapies dans la gestion publique du Sida.

Cette étude présente l'intérêt de contrevenir à un certain discours sur l'émergence d'une nouvelle politique publique en matière de gestion du Sida mais aussi d'envisager le cadre médico-institutionnel dans lequel s'inscrivent les personnes touchées par le VIH-Sida. Le monopole exercé par la médecine hospitalière peut être, après plusieurs années d'impuissance thérapeutique, un motif de rejet et de recherche de voie thérapeutique alternative.

\section{2 . 2 . Extension du champ de compétence de la médecine}

La légitimité acquise par l'institution hospitalière dans la gestion du VIH-Sida tient essentiellement aux progrès réalisés dans le domaine thérapeutique ; l'apparition de nouvelles associations médicamenteuses (les antiprotéases) a permis de diminuer le nombre de décès et d'allonger, la durée de vie des personnes touchées par le Sida.

L'arrivée de ces nouvelles molécules a contribué à une relégitimation de certains professionnels de santé (praticiens hospitaliers) et à susciter de nouveaux espoirs. Ce type de découverte n'est pas sans conséquence car, comme le note le sociologue J. Maître, « en reculant les frontières de la connaissance et de l'efficacité pratique, la rationalité scientifico-technique balise ses frontières et dément ainsi les prétentions sans bornes par lesquelles nous enchante le langage du désir $»^{34}$. Et d'ajouter, « la modernité suscite plus d'espoir en la réalisation des désirs qu'elle ne peut en réaliser effectivement, ce qui induit un surplus pour lequel les promesses ne peuvent venir que d'ailleurs ». Cet ailleurs peut provenir de la «nébuleuse d'hétérodoxie » (terme employé par cet auteur pour qualifier différentes croyances et pratiques, notamment l'astrologie) mais aussi d'autres formes religieuses illégitimes ou légitimes.

L'autre conséquence de l'extension du champ de compétence de la médecine concerne l'évolution du statut des immigrés. Il faut rappeler la polémique qui a surgi, dans le courant des années 1990, à propos de la quasi absence d'étude sur les étrangers touchés par le Sida, vivant en France. Les données épidémiologiques existaient dans la mesure où dans la déclaration obligatoire des cas de Sida doit figurer la nationalité de la personne et son pays d'origine.

L'absence de publication systématique autour de cette question (études ponctuelles du Réseau National de Santé Publique à partir de 1995), avant l'année 1999, doit être mise sur le compte du principe républicain préconisant l'intégration des étrangers, modèle censé être égalitaire $^{35}$. Les chiffres démentent ce principe : alors que les étrangers représentent $6 \%$ de la population adulte en France métropolitaine (données de l'INSEE du recensement de 1990), ils représentent $14 \%$ des cas de sida déclarés depuis le début de l'épidémie en France ${ }^{36}$. Le lien entre

\footnotetext{
33 - Ph. Adam, «Lutte contre le sida : vers une redistribution des rôles ? », Panoramiques, Sois patient et tais-toi. Le pouvoir médical, dirigé par R. Lenoir et M. Tsikounas, 4ème trimestre 1994/II, n 17, p. 105-111.

${ }^{34}$ Maître, «Régulations idéologiques officielles et nébuleuses d'hétérodoxies. À propos des rapports entre religion et santé », Social Compass, vol. XXXIV, n 4, 1987, p. 360.

35 - D. Fassin, «Santé et immigration. Les vérités politiques du corps », Cahiers de l'URMIS, 1999, n 5, p. 69-76.

36 - A. Savignoni, F. Lot, J. Pillonel, A. Laporte, Situation du Sida dans la population étrangère en France, Institut de Veille Sanitaire, Avril 1999, 16 p.
} 
sida et immigration devient pensable, écrit D. Fassin, probablement «parce qu'à la place de la seule question du risque, il est désormais abordé surtout du point de vue des inégalités ${ }^{37}$.

Pour autant, note cet auteur, la santé est devenue, pour les étrangers, l'un des derniers refuge du droit ; de plus en plus d'étrangers demandent une autorisation provisoire de séjour pour soins à la suite d'une demande d'asile déboutée. Il existe « une perspective d'un statut juridique précaire de malade en lieu et place de l'asile politique espéré $»^{38}$. Et d'ajouter, « la maladie et la souffrance offrent une base minimale pour un consensus politique de tolérance et même de reconnaissance de l'étranger ${ }^{39}$. Cette situation n'est pas sans susciter certaines interrogations concernant l'identité de ces étrangers et leur place au sein de la société française.

\section{2 . 3 . Amplification des préoccupations de santé de la population}

L'étude réalisée par G. Vigarello permet d'observer un engouement pour la santé ${ }^{40}$. Ainsi, alors que le nombre de magazines consacrés à la santé étaient de deux dans les années 1970, il est passé à quinze dans les années 1990. Santé Magazine est devenu, en 1991, le deuxième magazine lu (4 285000 lecteurs) parmi les 120 mensuels français. "Ces magazines, écrit cet auteur, révèlent encore une extension inépuisable des maux pris en compte (...) Le processus de civilisation déplace depuis longtemps les frontières entre le supportable et le non-supportable, approfondissant le sensible, rendant moins tolérés des 'mal-être' auparavant acceptés » ${ }^{41}$ Et, audelà de ce constat de l'engouement pour la santé, c'est un rapport consumériste à la santé qui doit être posé. «Le marché de cette santé consommée, poursuit G. Vigarello, propose 'toujours plus', étendant son territoire, comme l'a fait avant lui le marché des biens domestiques ${ }^{42}$.

La gestion du corps s'accompagne d'un discours hédoniste ; il ne s'agit plus de « vieilles gymnastiques » mais de choisir de se faire du bien. Mais, que ces normes apparaissent plus séductrices ou plus libres ne les déchoient pas de leurs contraintes.

Cette nouvelle moralité et ce nouvel engouement pour la santé est envisagé, par G. Vigarello, à partir de la chute des transcendances, politiques, morales et religieuses. Un tel parallèle semble plausible mais est réducteur dans le sens où les intrications entre religiosités et santé ont toujours existé. Ainsi, tout un courant spirituel, le Nouvel Age, a porté des pratiques et techniques corporelles visant un mieux-être, et ce depuis les années 1960-70. De même, certains groupes des Nouveaux Mouvements Religieux (NMR) ont accordé une place centrale à des techniques de mieux-être (cf. Mahikari, Scientologie, ...). Il semble plus raisonnable d'envisager cette question non pas comme un transfert de « compétences » (de la religion vers la santé) mais

37 - D. Fassin, «Sida, immigration et inégalité : nouvelles réalités, nouveaux enjeux », Sida, immigration et inégalités. Nouvelles réalités, nouveaux enjeux, publication ANRS, coll. Sciences sociales et sida, Paris, 2002 , p. 1.

38 - D. Fassin, «Santé et immigration. Les vérités politiques du corps », Cahiers de l'URMIS, 1999, n 5, p. p. 73.

39 - Idem., p. 74.

40 - G. Vigarello, Le sain et le malsain. Santé et mieux-être depuis le Moyen Âge, Seuil, coll. L'Univers Historique, Paris, 1993, p. 306.

41 - Idem.

42 - Ibid., p. 307. 
comme un rapports de force d'une part, entre champs religieux et médical, et d'autre part à l'intérieur même de ces champs ${ }^{43}$.

Les sphères religieuse et médicale se sont progressivement différenciées, notamment avec la professionnalisation des médecins. Ces derniers ont obtenu, en France, le monopole sur l'exercice de la médecine, non pas tant en raison de l'efficacité de leurs pratiques, mais parce que cela permettait à une profession (médecins) de s'affirmer contre une autre (religieux). Les médecins n'ont cependant pas pu s'imposer comme le seul recours légitime face à la maladie. Les curés et guérisseurs étaient également dépositaires d'une certaine légitimité, tirée de l'efficacité de leur pratique et de leur position illégale.

Aujourd'hui, la position hégémonique occupée par la profession médicale est mise à mal par une « crise » révélant une concurrence au sein de la même profession ${ }^{44}$. Un auteur va même jusqu'à établir un parallèle entre la situation occupée par les officiers de santé et les médecins du $\mathrm{XIX}^{\mathrm{e}}$ siècle et les médecins généralistes et les praticiens hospitaliers d'aujourd'hui. Cette « crise » peut également être envisagée au regard du nombre de généralistes qui se spécialisent dans l'homéopathie (dont l'efficacité thérapeutique, rappellent O. Faure, est toujours contestée) mais aussi auprès de ceux qui s'inspirent, dans leurs pratiques, d'une démarche spirituelle. Autrement dit, la différenciation des sphères sociales n'a pas provoqué une rupture entre champs religieux et médical mais une exacerbation des rapports de pouvoir entre ces champs.

Pour revenir à la notion de santé, on reprendra les propos de P. Aïach qui indique que la santé n'est plus un état d'être mais une finalité en soi. Ainsi, la définition adoptée par l'Organisation Mondiale de la Santé, en 1946, de la santé, comme état de bien-être physique, mental et psychique, se rapproche beaucoup de la notion de bonheur.

Cet aspect est d'autant plus important à prendre en considération qu'il s'ajoute à une hyper valorisation de la jeunesse. De fait, si la norme dominante est d'être beau, jeune et en bonne santé, les personnes touchées par le VIH, souvent jeunes (au niveau national, la plus grande proportion des cas de sida diagnostiqués en 2001 concerne les 30-39 ans ${ }^{45}$ ), peuvent vivre difficilement cet écart entre les valeurs de la société globale et leur propre vécu ${ }^{46}$.

\footnotetext{
43 - On reprend, ici, le sens donné par P. Bourdieu du champ, à savoir un espace dans lequel se jouent des intérêts et une lutte pour le pouvoir entre différents acteurs sociaux. Le problème d'une définition préalable d'un champ, souligne P. Bourdieu, c'est qu'il est le lieu où se joue justement une lutte pour sa définition, c'est à dire de la délimitation de la compétence des uns et des autres, «Champ religieux dans le champ de manipulation symbolique », in Histoire et société. Les nouveaux clercs. Prêtres, pasteurs et spécialistes de la santé, éd. Labor et Fides, Genève, 1985, n $^{\circ}$ 6, p. 261.

44 - P. Aïach, D. Fassin et J. Saliba, «Crise, pouvoir et légitimité », Les métiers de la santé. Enjeux de pouvoir et quête de légitimité, P. Aïach et D. Fassin (éds.), Anthropos, Paris, 1994, p. 40.

45 - « Surveillance du sida en France. Situation au 30 septembre 2001 », Bulletin Épidémiologique hebdomadaire, Institut de Veille Sanitaire, $n^{\circ}$ 47, 2001.

46 - Il faut savoir qu'entre 1992 et 1995, le sida était la deuxième cause de décès chez les hommes âgés entre 25 et 44 ans. Aujourd'hui, l'âge moyen au moment du diagnostic de sida augmente : 38 ans pour les hommes contaminés par injection de drogue (contre 30 ans en 1990) et 37 ans chez les femmes, 43 ans pour les hommes contaminés par rapports hétérosexuels, 39 ans pour les femmes (contre 39 ans et 35 ans en 1990), 40 ans pour les homosexuels (contre 38 ans en 1990), Situation du Sida en France. Données de l'Institut de Veille Sanitaire. Département des maladies infectieuses, Données du 31 décembre 2001.
} 
La médicalisation de l'existence, l'importance accordée à la notion de santé, l'association faite entre santé et bonheur, la place grandissante prise par l'hôpital et les médecins hospitaliers dans la gestion du VIH-Sida, ... sont des éléments qui vont jouer un rôle plus ou moins important dans le vécu de la maladie et la construction identitaire.

\section{3 . Religion héritée ou choisie?}

Le paysage religieux contemporain peut être appréhendé à partir du concept de sécularisation. Celui-ci permet d'envisager un double mouvement de fond au sein de l'Europe occidentale: d'une part l'effondrement des institutions religieuses englobantes, et plus précisément des églises instituées, et d'autre part, le renouveau spirituel observé depuis les années 1970, et ce avec en toile de fond, un renouvellement pour des questions touchant à la définition de la religion.

L'histoire du concept de sécularisation est en soi intéressante car révélatrice de l'évolution des interrogations portées par les sociologues sur le fait religieux. Dans les années 1970, la sécularisation désignait le processus inéluctable par lequel passaient les sociétés dites modernes, celui de la fin des religions. Provenant des Lumières ${ }^{47}$, le concept de sécularisation portait en lui une certaine idéologie dans la mesure où il était admis que la modernité, source de progrès, allait mettre fin aux religions.

Le contexte de l'époque (1960-70) était celui d'une perte d'emprise des religions instituées et l'émergence de ce qui a été nommé les Nouveaux Mouvements Religieux (NMR). En fait, cette appellation recouvrait des réalités fort différentes : des groupes nouvellement constitués (La Famille, Krishna) à des plus anciens mais récemment apparus sur la scène religieuse occidentale (Moon, Scientologie) en passant par des courants plus classiques mais apparus à cette période (hindouisme, bouddhisme). Des mouvements parareligieux mais aussi des formes de renouveau religieux (renouveau charismatique, nouvelle vague pentecôtiste) ont également fait partie des NMR.

Différentes typologies ont été élaborées pour caractériser ces groupes religieux. Pour avoir un aperçu de la diversité des groupes concernés, on retiendra celle de J. Beckford qui envisage trois types de groupes en fonction de leur mode d'insertion au sein de la société globale, et ce à partir de groupes non chrétiens. On trouve les groupes refuges (ils offrent à leurs membres la protection d'une communauté et d'un mode de vie entièrement intégré), les groupes dont le but est la réforme de la société, et enfin, les groupes de libération (ils offrent à leur clientèle un ensemble de services de développement personnel $)^{48}$. À cette typologie, G. Davie et D. HervieuLéger ajoutent d'autres groupes et courants. En premier lieu, il y a le courant spirituel où les adeptes recherchent un accomplissement intérieur, un autoperfectionnement et un sentiment d'unité intérieure (la nébuleuse mystique ésotérique, analysée par Fr. Champion et le bouddhisme s'inscrivent dans ce premier courant). Le second courant est qualifié de conversionniste. Il met l'accent sur la rupture individuelle vécue par le converti. La vie de ce dernier est complètement

\footnotetext{
47 - P. Berger, «La désécularisation du monde : un point de vue global », Le ré-enchantement du monde, sous la direction de P. Berger, Bayard, Paris, 2001, p. 15.

48 - Cité par D. Hervieu-Léger, G. Davie, «Le déferlement spirituel des nouveaux mouvements religieux », Identités religieuses en Europe, D. Hervieu-Léger, G. Davie (éds.), La Découverte, Paris, 1996, p. 269-289.
} 
réorganisée selon les nouvelles normes du groupe dans lequel il s'est inséré (cela concerne le protestantisme évangélique, les mouvements charismatiques, les Témoins de Jéhovah, les Mormons, ...). Le troisième courant concerne les groupes prémillénaristes et postmillénaristes ; les premiers visent une réforme de la société dans l'attente d'un monde nouveau tandis que les seconds veulent restaurer un ordre ancien en vue d'anticiper ce monde nouveau ${ }^{49}$.

Dans les années 1970, l'ensemble de ces groupes présentaient la particularité de toucher des jeunes, issus des classes moyennes (les thèses défendues par M. Weber montrent une affinité élective entre les sectes et les classes populaires), provenant de la contre-culture. Les groupes auxquels ils adhèrent sont porteurs d'une protestation et s'inscrivent, en cela, dans le mouvement de la contre-culture.

«Les jeunes qui adhèrent aux NMR, écrivent Fr. Champion et L. Hourmant, sont des 'produits' de ces logiques de désintégration sociale. Leur adhésion même montre combien ils en sont pétris puisqu'il s'agit d'adhésion strictement individuelle (...) et en rupture avec toutes les 'structures sociales' peu ou prou contraignantes, à commencer par la famille ${ }^{50}$. Et pourtant, les NMR offrent des structures sociales qui rompent avec la dislocation sociale, notamment ces « communautés chaudes et intégrées » proposant un mode de vie communautaire permanent ou temporaire. Autrement dit, les NMR apparus dans le courant des années 1960-70, s'inscrivent dans le sillage de la contre-culture et en réaction contre elle.

G. Davie et D. Hervieu-Léger, constatent que le rapport que les adeptes entretiennent avec la modernité occidentale est un rapport, différencié selon les cas, mais qui s'inscrit sur un continuum de la protestation socioreligieuse. Les critiques de la modernité prennent des formes diverses mais toutes se rejoignent par rapport au fait qu'elles gèrent les effets de la modernité (fonctionnalité technique, disjonction, séparation, spécialisation, atomisation) ${ }^{51}$ Ces mêmes auteurs précisent qu'il est impossible de quantifier le poids des Nouveaux Mouvements Religieux $^{52}$ au sein des sociétés occidentales et que cela n'est pas sans poser de problème lorsqu'il s'agit de traiter de sujets aussi épineux que celui des sectes; que représentent ces groupes au sein de la société française ? Combien réunissent-ils d'adeptes ?...

Aujourd'hui, les NMR (même si cette appellation n'est pas très féconde d'un point de vue heuristique dans le sens où on en reste à une description des groupes en question) caractérisent une constellation inédite, historiquement située, qui permet de trouver des liens entre divers mouvements liés au contexte de la contre-culture américaine des années $1965-70^{53}$. Ils traduisent l'émergence d'un ferment religieux, d'une prolifération de croyances; cette évolution s'accompagne de la perte d'emprise des religions instituées. Autrement dit, le développement de

\footnotetext{
49 - Idem.

50 - Fr. Champion, L. Hourmant, «'Nouveaux mouvements religieux’ et sectes », Sectes et démocratie, Seuil, Paris, 1999 , p. 63.

51 - D. Hervieu-Léger, G. Davie, «Le déferlement spirituel des nouveaux mouvements religieux », Identités religieuses en Europe, D. Hervieu-Léger, G. Davie (éds.), La Découverte, Paris, 1996, p. 269-289.

52 - Cette entreprise est difficilement réalisable dans la mesure où certains groupes ne délivrent pas leurs nombres d'adeptes tandis que d'autres comptabilisent les simples sympathisants ou encore parce que le «nomadisme » religieux (aller d'un groupe à l'autre) rend difficile toute tentative comptable.

53 - F. Champion, L. Hourmant, «'Nouveaux mouvements religieux' et sectes », Sectes et démocratie, Seuil, Paris, 1999, p. 69.
} 
ces Nouveaux Mouvements Religieux coïncide avec la perte d'emprise culturelle et sociale des religions instituées.

De fait, la sécularisation, revisitée à l'aube du $\mathrm{XXI}^{\mathrm{e}}$ siècle, n'apparaît plus comme un processus linéaire (la perte ou la déprise des religions en Occident). Pour D. Hervieu-Léger, la sécularisation désigne «l'ensemble des processus de réaménagement du croire qui se produisent dans une société dont le moteur est l'inassouvissement des attentes qu'elle suscite et dont la condition quotidienne est l'incertitude qui résulte de la recherche interminable des moyens de satisfaire ces attentes ${ }^{54}$. Autrement dit, la sécularisation ne désigne plus seulement le déclin des religions instituées mais aussi l'apparition de nouvelles formes de religiosités susceptibles de surmonter les tensions nées de la modernité, notamment les attentes suscitées par un progrès toujours illimité et les incertitudes liées à un monde toujours en changement. Cette thèse rejoint celle défendue par J. Maître à propos de la rationalité technique ; celle-ci, à travers les « miracles » de la science, génère un surplus (de désirs, d'attentes, ...) qui ne peut être satisfait qu'ailleurs, notamment par des hétérodoxies.

Un lien peut être établi entre la dynamique de certains groupes religieux et le fait qu'ils accordent une place centrale au bien-être ou à la guérison. Deux de ces mouvements que, apparemment, tout oppose, peuvent être pris en exemple : le pentecôtisme et la Nébuleuse Mystique Ésotérique (NMÉ).

Le premier est né au début du $\mathrm{XX}^{\mathrm{e}}$ siècle aux Etats-Unis sous l'impulsion de Ch. Parham (pasteur méthodiste Blanc), en 1901, et de W. J. Seymour (pasteur baptiste Noir), en 1906. Très rapidement, ce mouvement va prendre une ampleur importante en se propageant sur l'ensemble des continents. Depuis le début du siècle, le mouvement a connu des vagues de renouveau et n'a cessé de croître. On évalue le nombre de pentecôtistes, dans le monde, à 320 millions dont 200000 en France. Puisant ses sources dans un courant protestant américain (Holiness Movement, mouvement de sanctification de la seconde moitié du XIX ${ }^{\mathrm{e}}$ siècle) $)^{55}$, le pentecôtisme se caractérise par quatre aspects : la conversion (changement de vie suite à l'expérience de foi en Jésus) ; le biblicisme (accent mis sur la Bible comme parole de Dieu); le crucicentrisme (importance cardinale du thème de la croix) et l'activisme (fort engagement des militants) ${ }^{56}$. Selon P. Williams, le pentecôtisme exprimerait un rejet du discours logique et un désenchantement à l'égard de toutes les structures et conditions imposées par le monde industrialisé, et à l'aspiration à une réalité plus simple où ces conventions ne comptent pas ${ }^{57}$. La guérison pentecôtiste anticipe l'arrivée du millénium dans le sens où elle en annonce et en signe la venue ${ }^{58}$.

\footnotetext{
54 - D. Hervieu-Léger «La religion des Européens : modernité, religion, sécularisation », Identités religieuses en Europe, D. Hervieu-Léger, G. Davie (éds.), La Découverte, Paris, 1996, p. 19.

55 - J.-P. Willaime, «Le pentecôtisme : contours et paradoxes d'un protestantisme émotionnel », Archives des Sciences Sociales des Religions, 1999, 105, janvier-mars 1999, p. 5-28.

56 - S. Fath, «L'autorité charismatique au cœur de l'église : pentecôtisme et débat sectaire », Etudes théologiques et religieuses, 2001, n 3 , p. 371-390.

57 - Cité par S. Fath, Idem, p. 381-382.

58 - A. Corten, «Miracles et obéissance. Le discours de la guérison divine à l'Église Universelle », Social Compass, 1997, n 44 (2), p. 283-303.
} 
Au sein des nouveaux groupes pentecôtistes (nouvelle vague émergent dans les années 1970), et notamment au sein de l'Église Universelle du Royaume de Dieu, l'anthropologue M. Aubrée écrit, « la relation du fidèle au divin est que le premier n'attend plus que Dieu lui accorde une grâce en récompense d'une vie ascétique mais exige cette grâce tant pour la foi qu'il professe que pour les dons en monnaie sonnante et trébuchante qu'il fait (...) $\gg^{59}$.

Quant à la Nébuleuse Mystique Ésotérique, ses origines remontent aux années 1960-70, celle des Nouveaux Mouvements Religieux. Étudiée par Fr. Champion, puis par V. Rocchi, la NMÉ « est un ensemble hétérogène de groupes, de réseaux, très divers. Ceux-ci peuvent se rattacher à des religions : religions orientales (hindouisme, bouddhisme) ou plus 'exotiques' (notamment chamanisme). Ils peuvent aussi réactiver diverses pratiques ésotériques, tout particulièrement le Tarot et l'astrologie, ou bien correspondre à de nouveaux syncrétismes psycho-religieux telle la 'psychologie transpersonnelle'. Fait aussi partie de la 'nébuleuse mystique ésotérique' le Nouvel Age qui se donne actuellement à voir principalement sous la forme d'une subculture qui parle de 'méditation', de 'guérison spirituelle', de 'rebirth', d' 'astrologie transpersonnelle', de Tarot, etc. ${ }^{60}$.

La NMÉ se caractérise par plusieurs traits : transformation de soi par des techniques psychologiques (salut mystique), conception moniste du monde, optimisme certain, éthique d'amour, expérience de réalité non ordinaire, recherche du bonheur ici-bas. Les adeptes fréquentant cette mouvance privilégient l'expérientiel. L'appartenance aux groupes constituant la NMÉ est souple et mobile; les individus vont d'un groupe à un autre, « expérimentent » différentes techniques, et refusent tout contrôle institutionnel de leurs croyances. Ne sont validées que les croyances et techniques apportant un mieux-être ou une réponse considérée comme signifiante aux questions posées.

Cette mouvance s'inscrit dans la protestation socio-religieuse des années 1970 (cf. Nouveaux Mouvements Religieux) mais avec ceci de particulier qu'elle annonce une alliance possible entre science et religion. Cette alliance ne repose pas sur des contenus spécifiques de la science contemporaine, considérée comme fragmentée, déterminée, mécaniste, quantifiée, et en quelque sorte indifférente à l'homme mais sur l'émergence d'un nouveau paradigme permettant de prendre en considération la dimension spirituelle de l'homme ${ }^{61}$.

Tout semble séparer le pentecôtisme de la Nébuleuse Mystique Ésotérique. Tout d'abord, leurs formes organisationnelles sont radicalement différentes. Avec le pentecôtisme, on est plutôt face au type secte décrit par M. Weber et E. Troeltsch. Autrement dit, on est face à une association volontaire de personnes religieusement qualifiées, qui est plus ou moins en rupture avec le monde environnant et où il y a reconnaissance et soumission à une autorité religieuse

\footnotetext{
59 - M. Aubrée, «La diffusion du pentecôtisme brésilien en France et en Europe : le cas de 1'I.U.R.D. », Les mutations transatlantiques des religions, sous la direction de C. Lerat et B. Rigal-Cellards, PUB, Bordeaux, 2000 , p. 153.

60 - F. Champion, « À propos des courants mystiques et ésotériques », Sortie des religions, retour du religieux, Astragale, coll. L'œuvre au Bleu, Lille, 1992, p. 151.

61 - F. Champion, «La croyance en l'alliance de la science et de la religion dans les nouveaux courants mystiques et ésotériques », Archives de Sciences Sociales des Religons, 1993, 82 (avril-juin), p. 219.
} 
absolue $^{62}$. À l'inverse, la Nébuleuse Mystique Ésotérique se rapproche plus du modèle associatif de type mystique. Selon J. Séguy, qui reprend les propos de E. Troeltsch, le type mystique " même 'pur' demeure flou, réticent qu'il est devant toute organisation, toute formalisation dogmatique ou culturelle ». «La mystique, poursuit cet auteur, se définit comme une expérience religieuse directe, personnelle, non médiatisée (...) Elle s'oppose, tendanciellement au moins, à l'objectivation de l'expérience en des actes cultuels régulés, en des rites valant pour eux-mêmes, en mythes ou en dogmes sanctionnés comme obligatoires $»^{63}$.

De la même façon, tendanciellement, alors que le pentecôtisme recrute plutôt dans les couches sociales défavorisées, la NMÉ touche essentiellement les classes moyennes et supérieures.

Ces deux groupes partagent néanmoins deux caractéristiques communes : la première est leur vitalité religieuse. Sans pouvoir chiffrer le poids de la NMÉ, elle semble occuper une place importante et grandissante. Il n'est que de regarder la place prise par le rayon «Ésotérisme », au sein de grandes librairies, pour s'en rendre compte. Acheter un livre au rayon Ésotérisme ne signifie pas « appartenir » à cette mouvance mais c'est déjà, quelque part, manifester un certain intérêt pour la question et voire plus si affinités. Quant au pentecôtisme, on mentionnait l'existence de 320 millions de fidèles dans le monde ${ }^{64}$.

Quant à la seconde caractéristique commune, il s'agit de l'importance accordée à la guérison. Il faut toutefois préciser que les termes employés par les deux mouvements ne sont pas semblables : au sein des groupes pentecôtistes, il est question de guérison spirituelle, et ce en référence à la bible, tandis que dans la NMÉ, il est question de mieux-être ou bien-être. Cette nuance permet d'apprécier deux conceptions distinctes du corps et du rapport à l'institution médicale. Dans le premier mouvement, la guérison spirituelle s'opposerait à la guérison médicale dans le sens où cela tendrait à prouver la suprématie d'un ordre divin, tandis que dans le second, le mieux-être correspondrait à un état conçu en dehors des normes bio-médicales (ce qui n'empêche pas de prendre ces dernières comme critère d'évaluation de la guérison).

Au-delà de ces nuances terminologiques, on peut s'interroger sur un lien éventuel entre cette dynamique religieuse et la place occupée par la guérison spirituelle au sein de ces mouvements. De manière générale, on peut envisager ce type de pratique comme une forme de protestation. Dans le cas pentecôtiste, cette protestation signifie d'abord le refus d'un rapport de domination à l'égard de l'institution médicale. Ainsi, chez les tziganes pentecôtistes, J. Baubérot note que le recours à la guérison spirituelle permet à cette communauté de se préserver d'une intrusion, d'une mainmise sur le corps de la société des «gadgés » par le biais de la médecine ${ }^{65}$. Quant à A. Corten, il indique que si l'Église Universelle du Royaume de Dieu engage ses fidèles

62 - J.-P. Willaime, «Les définitions sociologiques de la secte», Les sectes et le droit, sous la direction de F. Messner, P.U.F., Paris, 1999, p. 29.

${ }_{63}$ - J. Séguy, Christianisme et société. Introduction à la sociologie de Ernst Troeltsch, Cerf, Coll. Sciences Humaines et Religoins, Paris, 1980, p. 128-129.

${ }^{64}$ - Ce mouvement, note H. Cox, a connu une expansion considérable puisqu'en 1908, deux ans après ses débuts, il s'était implanté dans cinquante pays, in H. Cox, Le retour de Dieu. Voyage en pays pentecôtiste, éd. Desclée de Brouwer, Paris, 1995, p. 99.

${ }^{65}$ - J. Baubérot, «Changements socio-religieux et restructuration identitaire : le protestantisme pentecôtiste et les tziganes », Ethnologie des faits religieux en Europe, C.T.H.S., Paris, 1993, p. 427-432. 
à recourir à la médecine, c'est, en fait, pour mieux en souligner les limites. Ainsi, l'incapacité de la médecine à diagnostiquer une maladie vient valider la thèse de l'existence de "maladies spirituelles », tandis que le diagnostic établi au préalable par un médecin va confirmer l'existence de la guérison spirituelle ${ }^{66}$.

Dans le cas de la NMÉ, la protestation vise d'abord le fonctionnement de l'institution médicale, trop morcelée et ne prenant pas assez en compte l'individu dans sa totalité. Différentes techniques et pratiques sont offertes aux adeptes pour améliorer leur capital santé ou leur bienêtre. Pour V. Rocchi, ces groupes ont évolué en accentuant leur dimension thérapeutique, c'est pourquoi elle leur a donné l'appellation de Nébuleuse Psycho-Mystique ${ }^{67}$.

Le lien entre vitalité religieuse et guérison spirituelle semble d'autant plus pertinent qu'il s'inscrit dans un contexte où la santé occupe une place centrale. Même si l'existence de thérapies alternatives tient en partie à la recherche d'une efficacité thérapeutique, dans le présent cas de figure, ce sont des rapports de force qui en fondent l'existence et le dynamisme. Cela n'est pas, en soi, une coïncidence si on tient compte, d'une part de la situation de crise que traverse l'institution médicale, d'autre part, des préoccupations de santé, et enfin des attentes et désirs inassouvis suscités par la modernité.

Pour revenir à un point de vue plus général, la situation religieuse contemporaine, envisagée d'un point de vue historique, s'explique notamment par la montée en puissance de la modernité. Pour D. Hervieu-Léger, celle-ci se caractérise par trois dimensions. La première concerne la rationalité dans tous les domaines de l'action où prédomine l'impératif de l'adaptation cohérente des moyens aux fins poursuivies. La deuxième fait référence au type de rapport au monde qui se caractérise par l'autonomie de l'individu-sujet capable de faire le monde dans lequel il vit et de construire lui-même les significations qui donnent un sens à sa propre existence. Enfin, la troisième se caractérise par la différenciation institutionnelle où l'on observe les sphères sociales se séparer et se dissocier (le religieux du politique, l'économique du domestique, ... $)^{68}$.

Le développement des sociétés modernes ne conduit pas à l'éviction sociale et culturelle des religions de même que les religions peuvent, elles-mêmes, être porteuses de modernité. Ainsi, l'Alliance conclue entre le peuple Juif et Dieu pose le principe de l'autonomie du sujet ; celui-ci a le choix de son devenir. Le christianisme étendra cette alliance à l'ensemble de l'humanité. Quant au protestantisme, M. Weber a souligné les affinités électives entre l'éthique calviniste et le développement du capitalisme ${ }^{69}$.

Le caractère inédit de la situation contemporaine ne tient pas seulement à la prolifération des croyances. Au XVI siècle, le christianisme était porteur d'un courant ésotérique ; il faisait partie de la théologie, de la religion officielle, précisent Fr. Champion et L. Hourmant. En fait, ce caractère inédit tient essentiellement au fait qu'il pousse à l'extrême l'accomplissement de soi et

\footnotetext{
66 - A. Corten, « Miracles et obéissance. Le discours de la guérison divine à l'Église Universelle », Social Compass, $1997, \mathrm{n}^{\circ} 44$ (2), p. 283-303.

67 - V. Rocchi, «Du Nouvel Âge aux réseaux psychomystiques », Ethnologie Française, XXX, 2000, 4, p. 583-590.

68 - D. Hervieu-Léger, Le pèlerin et le converti. La religion en mouvement, Flammarion, Paris, 1999, p. 29-32.

69 - M. Weber, L'éthique protestante et l'esprit du capitalisme, Plon, coll. Agora, Paris, 1990, 286 p.
} 
l'incorporation de la quête spirituelle ${ }^{70}$. Vouloir définir la religion ou la spiritualité est une tâche ardue car la dimension collective, fondatrice du fait religieux, tend à disparaître au profit d'une quête strictement individuelle. On peut néanmoins se demander si la difficulté de définir le religieux ne tient pas à la difficulté de saisir des formes sociales inédites.

Dans le cadre de cette étude, on retiendra une définition relativement « classique » de la religion, celle donnée par le sociologue Y. Lambert. Pour cet auteur, la religion se définit à partir de trois caractéristiques : l'existence d'une réalité se situant au-delà de la réalité supraempirique c'est à dire des limites objectives de la nature et de l'homme telles que les saisit la démarche scientifique qui caractérise en propre le point de vue des sciences sociales. La deuxième caractéristique prend en compte l'existence d'une relation entre l'homme et ces réalités supraempiriques par des moyens symboliques (rites, prière, méditation). Enfin, dernière caractéristique : l'existence de formes rituelles collectives. Une religion, écrit Y. Lambert, se définit comme un système de croyances et pratiques se rapportant à des réalités - être(s), entité(s), force(s) - supraempiriques en relation avec l'homme par des moyens symboliques (rites, prière, méditation) et donnant lieu à des formes communautaires ${ }^{71}$.

Quant à la spiritualité, on l'envisagera, à l'instar de R. Campiche, qui lui-même reprend les travaux de Roof, comme « la dimension interne, expérientielle de la religion par opposition avec ses formes établies et institutionnelles. Qui plus est, ajoute cet auteur, la spiritualité est parfois considérée comme une alternative immédiate, personnelle à la religion conçue en termes de dogmes et de traditions $\gg .{ }^{72}$.

Les modalités du croire contemporain peuvent être envisagées à partir de trois aspects : le pragmatisme, la subjectivation et l'individualisation. Le pragmatisme se caractérise par le fait que les pratiques et croyances adoptées doivent être efficaces au regard de ceux qui les adoptent. Celles-ci sont validées à partir du moment où elles apportent un bien-être et/ou une réponse signifiante aux attentes formulées au départ. La subjectivation conduit « l'individu à choisir, à évaluer, à trier, à séparer entre les objets de croyances ceux qui lui conviennent et ceux qui ne lui conviennent pas ${ }^{73}$. Quant à l'individualisation du croire, il caractérise l'autonomie du sujet à l'égard des croyances et pratiques choisies. Le sociologue R. Campiche précise que cette autonomie n'est pas illimitée mais « pilotée » ${ }^{74}$, fruit d'une socialisation et d'expériences issues de la socialisation secondaire. En ce sens, la notion de «marché de biens religieux » est à relativiser; on ne choisit pas des croyances et pratiques sans être plus ou moins déterminé par un habitus.

L'émergence des Nouveaux Mouvements Religieux est un phénomène dont la visibilité sociale est attestée dans la mesure où les médias s'en saisissent assez régulièrement. La question

\footnotetext{
70 - Idem, p. 175.

71 - Y. Lambert, «Une définition plurielle pour une réalité en mutation », Cahiers Français, 1955, n 273 , p. 5.

72 - R. Campiche, «Entre l'exemple et l'expérience : de la transmission par la famille d'une tradition à celle d'un éthos religieux », Figures des Dieux. Rites et mouvements religieux. Hommage à Jean Rémy, De Boeck, Coll. Ouvertures sociologiques, Paris-Bruxelles, 1996, p. 151.

73 - J.-M. Donegani, La liberté de choisir. Pluralisme religieux et pluralisme politique dans le catholicisme français contemporain, éd. Presses de la Fondation des Sciences Politiques, Paris 1993, p. 351.

74 - R. Campiche, "Individualisation du croire et recomposition de la religion », Archives de Science Sociales des Religions, janvier-mars 1993, $\mathrm{n}^{\circ} 81$, p. 119.
} 
des « sectes », souvent traitée de manière unilatérale, en est un signe. Pour autant, au sein même de traditions religieuses instituées, on retrouve certaines caractéristiques du croire contemporain. Ainsi en est-il de ces $34 \%$ de catholiques, qui croient en l'existence d'un Dieu personnel mais aussi en la réincarnation ${ }^{75}$. De la même façon, la figure du pèlerin décrite par D. Hervieu-Léger, caractérise la mobilité de la modernité religieuse. Cette figure renvoie à la fluidité des parcours, à une construction biographique effectuée par l'individu au gré de ses expériences religieuses ; il y a une fluidité des contenus de croyance et une incertitude des appartenances. Le nouveau pratiquant, poursuit cet auteur, veut faire des choix personnels et ne pas vivre d'obligation institutionnelle.

Les chiffres concernant les pratiquants catholiques réguliers attestent de ces changements : ils sont $17 \%$ à se rendre régulièrement à 1 'office (une fois par mois à l'Église) ${ }^{76}$ alors que 64\% des Français se déclarent catholiques. Quant aux jeunes (18-25 ans), ils sont entre 3 et $4 \%$ à se rendre régulièrement à la messe tous les mois. Dans ces conditions, la question de la transmission religieuse se pose. Pour D. Hervieu-Léger, qui fonde sa définition de la religion ${ }^{77}$ autour de la question de la transmission religieuse et de la mémoire, aujourd'hui, on est moins face à une identité religieuse héritée qu'à une construction personnelle de sens (expérience personnelle et recherche d'authenticité). En d'autres termes, la religion est davantage choisie qu'héritée.

Dans le cadre de l'étude ANRS, cette question de la transmission religieuse est fondamentale. Pour appréhender les liens entre VIH-Sida et spiritualité(s), trois types de questions ont retenu l'attention :

1) le parcours spirituel : observe-t-on une démarche de conversion, de recherche, de résurgence, ou de continuité religieuse à l'annonce de la séropositivité ? Quel est le facteur déterminant d'une démarche spirituelle?

2) le rôle du religio-spirituel : la démarche spirituelle poursuit-elle des visées thérapeutiques? Si tel est le cas, qu'en est-il de cette dimension thérapeutique : se montre-t-elle compatible avec le modèle bio-médical ? Observe-t-on des pratiques 《religio-thérapeutiques ${ }^{78}$ distinctes selon le stade de la maladie (cf. protection symbolique pour empêcher le virus de se répliquer, rites pour améliorer les performances du traitement médical, etc.) ? 3) la place du spirituel : la dimension thérapeutique s'exprime-t-elle à travers des pratiques spécifiques - magification du religieux - et/ou l'accent est-il mis sur la dimension éthique ? Existe-t-il des différences, au niveau des pratiques religio-thérapeutiques, selon que l'individu s'inscrit dans un groupe structuré ou dans une démarche spirituelle individualisée?

Au travers de ces questions se pose la question de l'identité : comment et dans quelle mesure le référent spirituel ou religieux est-il susceptible de participer à la construction

\footnotetext{
75 - D. Hervieu-Léger, Le pèlerin et le converti. La religion en mouvement, Flammarion, Paris, 1999, p. 49.

76 - Y. Lambert, «Une définition plurielle pour une réalité en mutation », Cahiers Français, n 273, 1995 , p. 3-12.

77 - «Une religion, écrit cet auteur, est un dispositif idéologique, pratique et symbolique par lequel est constitué, entretenu, développé et contrôlé le sens individuel et collectif de l'appartenance à une lignée croyante particulière », Idem, p. 24.

78 - On entend, par pratiques religio-thérapeutiques, des pratiques religieuses/spirituelles ayant une finalité thérapeutique ou une visée préventive à l'égard de la maladie.
} 
identitaire. C'est à ces différentes questions que l'on tentera de répondre au cours de la prochaine partie. 


\title{
Deuxième Partie
}

\author{
construction identitaire et \\ gestion religieuse du VIH-Sida
}


Pour comprendre le rôle joué par la spiritualité dans la construction identitaire, on a envisagé d'articuler le parcours des individus avec leur démarche spirituelle. Trois groupes ont été constitués. Pour chacun d'entre eux, on présentera, dans un premier temps, des portraits typiques (rassemblant un certain nombre de caractéristiques capables d'illustrer la problématique générale de la construction identitaire). Puis, il sera question, à partir d'une lecture transversale des entretiens, de s'intéresser aux représentations de la maladie et aux pratiques (religio)thérapeutiques (rapport à l'institution médicale, pratiques religieuses à visée thérapeutique, ...).

\section{I . Religions héritées}

Deux ensembles de personnes appartiennent à ce groupe : le premier regroupe celles qui ont connu un « retour » vers leur religion d'origine et qui ont une pratique religieuse relativement importante au regard de la moyenne nationale ; l'autre groupe réunit des individus restés « fidèles » à leur héritage religieux tout en ayant des pratiques religieuses se manifestant sur un mode « mineur».

\section{Parcours spirituels}

Trois parcours vont être présentés en fonction d'une part, du rapport entretenu à la religion d'origine et, d'autre part de l'annonce de la séropositivité. Le retour à la religion d'origine peut être directement lié à l'annonce du VIH-Sida mais n'est pas immédiat ; plusieurs années de quête spirituelle sont nécessaires avant de se «convertir» à son héritage religieux. Dans le cas où le retour à la religion héritée est lié à d'autres évènements, l'engagement des personnes est maintenu voire renforcer, suite à l'annonce de la séropositivité. Et, pour les personnes restées fidèles à leur religion d'origine, cette annonce tend à modifier leur rapport à l'institution religieuse (rapport plus distancié) sans toutefois changer leurs croyances.

\section{Retour vers la «normalité »?}

Pour certaines personnes, le retour à la religion héritée est envisagé comme un retour à la « normalité ». Le cas de Marius ${ }^{79}$, la quarantaine, va illustrer ce cas de figure. Touché par le VIH dans les années 1980 (il apprend sa séropositivité en 1984-85), cette annonce ne retentit pas vraiment sur son quotidien. En fait, à cette époque, la vie de Marius est marquée par d'autres évènements qui le bouleversent davantage : son mariage malheureux qui débouche sur un divorce, la rencontre d'un compagnon, le vécu de son homosexualité, ... De cette époque, il disait :

«j'avais trouvé un travail fixe dans l'export, je travaillais énormément et c'est une époque où je me suis beaucoup investi dans le travail et les questions de santé ne me préoccupaient pas énormément bien que j'avais des problèmes de santé quand même, j'ai eu un début de tuberculose, y'a eu quelques problèmes comme ça, mais déjà j'étais très content de pouvoir sortir de ce problème, de

79 - Les prénoms des personnes interviewées ont été modifiés et ce afin de préserver leur anonymat. 
sortir de ce mariage qui était quand même assez catastrophique et donc finalement j'en ai récolté un vrai bonheur que rien ne pouvait entamer »

À la fin des années 1980, les choses évoluent; la vie commune avec son compagnon se dégrade et il ressent un mal être qui déborde de toute part.

«C'était l'année 1989, dit-il, fin 1989, c'était vraiment la déprime, vraiment, là, j'ai plongé dans quelque chose qui était de l'ordre de la dépression permanente, et je faisais tout pour qu'on vive le mieux possible (avec son compagnon), d'être sympa, et pour être opérationnel sur le plan boulot, et en même temps, je ramais comme un fou sur le plan moral donc j'ai terminé en thérapie, et puis c'est cette année-là que j'ai commencé à faire face à mon malêtre mais dans toute sa profondeur parce que finalement, cette embellie qu'il y a eu en 1987 quand je me suis séparé (de sa femme) et que je me suis retrouvé libre, ça avait quelque chose de pas artificiel mais comme un poisson qui est tombé de son bocal et qu'on remet dans l'eau, et puis y'a des tas de pesanteurs qui dataient de l'enfance, de l'adolescence, finalement des raisons très perverses qui m'avaient fait faire un mariage qui n'était pas juste, que je n'avais pas vraiment voulu mais que j'avais accepté »

Pour mettre fin à ce mal être, Marius décide de suivre une thérapie et des cours de yoga. Le professeur qui donne ces cours s'inspire de différents courants spirituels. Par ce biais, Marius va rencontrer le groupe Partage International, groupe fondé par Benjamin Creme. Il dit ne pas s'être tellement investi dans ce groupe mais avoir été enthousiasmé par leur croyance en Metreya, manifestation divine en différents lieux de la planète. Il décide, fin 1992, de partir au Mexique dans l'un des lieux où Metreya se serait manifesté. Il s'agit d'une ferme d'où aurait surgi une source d'eau miraculeuse. Il ramène à Paris l'eau de cette source pour en faire profiter différentes connaissances.

Marius poursuit son cheminement spirituel et ira, à diverses reprises, rencontrer Mère Meera. Cette femme, d'origine indienne, vivant en Allemagne, pratique le darsha, un enseignement silencieux. Il estime qu'elle est à l'origine de son retour vers l'Église catholique.

« moi, dit-il, je suis allé la voir une bonne douzaine de fois, 10-12 fois, entre 1990 et 1998, et c'était aussi une aide et un fil conducteur très fort, qui m'a beaucoup aidé à la fois physiquement, moralement, et spirituellement, d'autant plus que c'était vraiment quelqu'un qui laisse totalement libre, y'a des gens de toutes obédiences qui allaient la voir, y'avait des agnostiques, (...) c'était pour moi une nourriture importante (...) (ça se passait dans) un silence total, je dirais que c'est même le fondement de sa discipline, c'était vraiment le silence, moi, je ne peux pas dire que j'ai été disciple complètement mais en tous les cas, à un moment, je me suis rendu compte que cette personne a fait partie des gens qui m'ont renvoyé vers mes racines, et au bout de quelques contacts, je ne sais pas, j'allais la voir tous les six mois ou tous les ans, et bien j'ai senti comme un appel par rapport à ce qui était vraiment ma culture religieuse d'origine, mes racines chrétiennes ». 
Ayant renoué avec le catholicisme en 1991-92, Marius n'en poursuit pas moins ses pérégrinations au sein la nébuleuse mystique ésotérique. Progressivement, son engagement dans l'Église s'affirme. En 1995, il fréquente la Maison de Tobbie, maison tenue par un dominicain et qui s'inspire du travail de Grave Durckëim et de la spiritualité chrétienne orientale. Il multiplie les retraites et pèlerinages (il fait plusieurs retraites dans les foyers de charité de Marthe Robin ; il se rendra à Taizé, lieu de pèlerinage œcuménique ; il ira à Tibériade, association catholique s'occupant de personnes touchées par le VIH-Sida,...) pour finalement se fidéliser complètement à sa paroisse et devenir un pratiquant exclusif. Ainsi, en 2001, il se rend régulièrement à l'Église, au moins une fois par semaine, il accepte de faire partie du conseil paroissial, et surtout, son rapport à l'institution ecclésiale a changé.

«Plus ça va, dit-il, plus il faut que ma vie soit d'abord ancrée dans la fidélité au Christ, dans la connaissance de Dieu, jour après jour, petit à petit, par la parole, par les sacrements, les enseignements, par les relations, et que tout le reste me sera donné par surcroît, tout le reste arrive par rebond mais ça, vraiment, je l'expérimente ».

Parallèlement à sa démarche spirituelle, Marius cherche à trouver une voie thérapeutique qui lui convienne. Son refus de prendre toute forme de médication, notamment l'AZT, a certainement été influencé par la fréquentation du groupe SIDA (Source Intérieure de Développement Acquis), groupe fondé par Mark Griffiths, à une époque où il n'existait pas de traitement efficace contre le VIH-Sida.

«Dans ce cercle de partage (SIDA), raconte Marius, (...) y'avait une idéologie qui était un peu dominante, qui était très hygiéniste c'est à dire zéro médicament, on se guérit par des prises de conscience, de la nourriture saine, du grand air, de la combativité et Dieu en prime évidemment ».

Adhérent à ce type de croyance, et notamment au fait que la «guérison » s'obtient par un travail sur le «terrain », Marius continue néanmoins à faire des examens biologiques qui lui permettent de savoir où il en est vis-à-vis du virus. Progressivement, ses défenses immunitaires vont baisser. Physiquement, il s'est senti fortement affaibli et a tenté d'y remédier par différentes thérapies parallèles. Le recours à un régime qu'il qualifie «d'hygiéniste » lui semblait être un moyen sûr. « Le virus, explique Marius, n'est vraiment là que pour pousser à la faute et souligner les déficiences du terrain ». De fait, il suit un régime macrobiotique (végétarien) fait de jeûnes. Avec le recul, il estime que ce type de régime doit être adapté en fonction des personnes. Lui, il a eu beaucoup de mal à s'y habituer car, dit-il, «à l'époque, j'avais un grand appétit, j'étais très bouffeur donc j'ai eu beaucoup de mal à me discipliner ».

Après les grandes grèves de 1995 qui vont le fatiguer, il va rester une année entière en congé maladie. Il tente à nouveau de se mettre au régime macrobiotique et pratique des jeûnes. Au bout d'une année, il se rend compte qu'il n'obtient pas les résultats escomptés ; il reste très affaibli et a le sentiment de vivre comme une personne du troisième âge alors qu'il a une quarantaine d'années. Par ailleurs, au cours de l'année 1996, plusieurs de ses connaissances lui 
font part des effets bénéfiques des multithérapies. Ayant longtemps évolué dans un milieu pour qui «médication »= «empoisonnement organisé », Marius est encore sceptique.

À la même période, il a des contacts plus réguliers avec ses parents et décide de leur annoncer sa séropositivité (avril 1997), par courrier, après dix années de silence et de secret. Leur réaction le touche car il vont être attentifs à sa santé. Quelques mois plus tard, Marius décide de suivre une multithérapie. Il envisage ces différentes étapes comme un retour à la normalité.

Le chemin parcouru par Marius ne peut cependant être compris si l'on ne s'attarde pas quelques instants à sa relation avec son père. Il estime que l'absence de contact avec son père, durant son enfance - celui-ci travaillait beaucoup et s'investissait peu dans le foyer familial (famille nombreuse) - et le surinvestissement de la relation à sa mère, ont fait de lui un homosexuel («le schéma un peu classique de l'homosexuel », dit-il). Cette situation explique, selon Marius, la situation conflictuelle qu'il a longtemps eue avec son père.

«J'ai été très en conflit avec mes parents explique t-il, notamment avec mon père, quelque chose d'assez terrible, je veux dire, y'avait quand même un mépris de mes parents et de mon père ». Cette situation va évoluer au gré de son engagement spirituel. «Le fait, dit-il, que j'ai eu une vraie démarche de conversion au christianisme et je trouve que plus je suis dans cette démarche et plus, je ne sais pas pourquoi, je l'ai mieux compris (son père), ça m'a rapproché de lui, et du coup, je me suis mis à lui parler » et de poursuivre en ces termes, « je ne lui en veux plus, maintenant je l'aime bien ».

Le parcours de Marius rend compte des différentes imbrications entre séropositivité, identité sexuelle, famille, médecine et religion. L'annonce de la séropositivité le conduit à un retour progressif au catholicisme, religion héritée, puis à une réconciliation avec ses parents et la médecine officielle. Autrement dit, Marius est parvenu à trouver un équilibre de vie en retrouvant ses racines religieuses. L'identité sexuelle de Marius reste toutefois un domaine sensible dans le sens où il dit vouloir " guérir » sa relation aux femmes (il garde toujours un souvenir douloureux de son mariage).

\section{Réfréner des « tentations »}

Olivier, la quarantaine, va renouer avec sa religion d'origine à la suite d'une déception amoureuse. Son retour au catholicisme se fait progressivement; élevé dans un milieu qu'il décrit comme croyant mais pas pratiquant, il se détache assez jeune de sa religion, vers l'âge de neuf ans, quand il part avec son père en province. Son retour à la spiritualité passe d'abord par des voies hétérodoxes où, avec son ami, ils expérimentent l'ésotérisme.

Olivier apprend sa séropositivité à l'hôpital. Il passe par une phase difficile où il doit à la fois repenser son avenir professionnel (il ne peut rester vendeur car c'est un métier qui le fatigue) et faire face à la rupture avec son ami. C'est une retraite dans l'un des foyers de charité de Marthe Robin qui le ramène dans le giron catholique : 
« ce centre-là, explique Olivier, est spécialisé pour des gens, laïcs ou religieux, qui ont un problème ou un doute au cours de leur parcours spirituel, ils ont besoin de se ressourcer comme on fait quand on va à la source de n'importe quoi, on reprend de l'énergie, et cette démarche-là, je savais que c'était en inadéquation avec ma vie sexuelle, avec mon homosexualité, y'avait un truc qui n'allait pas et il fallait que je règle le problème de la culpabilité ».

La rencontre d'un «père spirituel» le convainc de poursuivre son engagement spirituel. Celui-ci lui donne la vision d'un Dieu aimant et le déculpabilise par rapport à son homosexualité.

De cet homme, Olivier raconte qu'il lui a totalement « enlevé de la tête cette culpabilité par rapport à mes mœurs, (...) Je n'ai plus du tout eu peur de Dieu, du Dieu qui punit, le Dieu de mon enfance, et j'ai eu un Dieu beaucoup plus copain, beaucoup plus proche des hommes, beaucoup plus accessible, au travers de ma relation et de mes rapports avec ce prêtre qui m'a dit 'mais Dieu t'aime tel que tu es maintenant, il ne te demandera pas encore une fois des choses humainement impossibles, si l'homosexualité à un sens, je l'ignore, je ne peux pas te répondre à cette question, en revanche, ce que tu en fais, ça peut être une belle chose, c'est à dire vivre ton partenariat avec ton ami dans le respect, la confiance, de ne pas faire n'importe quoi de ton corps, de ne pas t'évader, te disperser, de ne pas oublier que tu as une âme' ».

À partir de là, Olivier décide de s'investir dans sa paroisse, en participant à la chorale, et d'avoir un rôle apostolique auprès de son frère qui a des tendances suicidaires. Pour autant, Olivier s'interroge toujours sur sa capacité à réfréner ses désirs. Ainsi, à propos d'un rêve où il voit des Christ en érection, il raconte qu'il était

« en plein combat, un combat interne entre ma culpabilité d'homosexuel et mon attirance spirituelle, je n'ai pas besoin de voir un psy pour comprendre, dans mon rêve y'avait et du sexe et du spirituel, le Christ qui bande c'est quand même un mélange de ça, c'était évident que c'était le symbole de ma dualité interne, mélange de spirituel et de sexe, c'est le malin qui voyait que je pouvais avoir du plaisir de cette façon, c'est très pervers, mais je suis persuadé que c'était le diable qui donnait une connotation spirituelle au plaisir et qui donnait une connotation sexuelle au spirituel, pour que je m'embrouille les cartes là-dedans, pour me paumer ». Olivier s'interroge sur les attentes du malin : «Qu'est-ce qu'il attend ? C'est mon âme, et quand je vois des gens qui sont dans des saunas, dans des boites qui se paument, je ne fréquente plus les endroits, les saunas de temps en temps oui, quand je dis que je fais de temps en temps une entorse, c'est ce à quoi je faisais allusion tout à l'heure, je prie de temps en temps pour ceux qui ne savent pas ce qu'ils font, comme l'a dit le Christ sur la croix, ils sont là, ils ont du sexe, du plaisir, du désir mais ils sont d'une solitude inouïe et je me considère comme faisant partie d'eux puisque j'y vais aussi, mais moi j'ai la chance de croire en Dieu et d'avoir pu développer une réflexion par rapport à ça ». Quelques temps plus tard, il 
ajoute, « le mauvais, il cherche à nous paumer parce que l'homme perd ses racines, ses repères ».

En quête de repères, Olivier trouve dans le catholicisme et surtout dans sa relation privilégiée avec son « père spirituel » les éléments lui permettant de trouver un équilibre de vie, notamment en se sentant responsable de lui et des autres (cf. son frère).

\section{La continuité religieuse}

Le cas de Florentin, la soixantaine, se différencie des deux précédents dans le sens où ce n'est pas l'annonce de la contamination au VIH-Sida qui l'a conduit à la religion. En fait, Florentin n'a jamais vraiment établi de rupture avec sa religion d'origine, le catholicisme mais, s'il croit c'est sans pratiquer (au sens classique du terme : se rendre à un office religieux).

Né en Italie en 1937, Florentin émigre en France avec sa famille à l'âge de 10-11 ans. Il fréquente le patronage et a, pendant quelques temps, l'intention de devenir prêtre. Son attirance pour les jeunes femmes vont le dissuader de s'engager dans cette voie.

Professionnellement, Florentin s'engage dans le Music-Hall. Les spectacles dans lesquels il chante et danse plaisent; il va se produire essentiellement au Moyen et Proche-Orient. Son mentor, homosexuel, le séduit; leur relation va durer douze ans, et ce alors que Florentin continue à avoir des relations sexuelles avec des femmes. Dans ses mémoires, Florentin évoque les nombreuses relations sexuelles (homo- et hétéro-) qu'il a eues au cours de ces voyages.

Au début des années 1970, il cesse le music-hall et se lance dans une carrière d'acteur ; il joue dans des films érotiques et pornographiques. C'est au retour d'un voyage, en 1985, qu'il décide de faire un test HIV ; celui-ci s'avère positif. Il arrêtera de travailler sept ans plus tard, en 1992.

Rien n'a jamais entamé le rapport de Florentin à la religion. Sa religiosité se manifeste par des signes épars qu'il faut rassembler pour lui donner une consistance. Il ne pratique pas mais peut aller allumer un cierge à la chapelle Sainte-Rita (sainte des causes perdues) - à Paris -, ou regarder la messe à la télévision, le dimanche matin. De même, il se rend plus ou moins régulièrement à un pèlerinage célébrant la Vierge Marie qui a lieu dans sa ville natale. En 2000, il a été à Lourdes. Par ailleurs, il ne s'endort pas avant d'avoir fait le signe de croix et récité une prière.

L'autre forme de religiosité présente chez Florentin tient à sa volonté de faire la « charité », notamment en aidant les personnes de son entourage. Il aide un neveu à se sortir de la drogue ; il rend régulièrement visite à un ami touché par un cancer de la gorge ; il s'engage quelque temps dans des associations de lutte contre le sida; il finit un repas au restaurant avec une femme qui avait besoin de parler, ... Le rapport entretenu par Florentin à la religion témoigne d'un désir de trouver une voie de salut à travers des «bonnes œuvres » (cf. aider son prochain) ; ce rapport à la religion, plutôt traditionnel, peut s'expliquer par l'âge de Florentin (plus de soixante ans). 


\section{Rapport paradoxal à l'institution ecclésiale}

De manière plus générale, pour les homo- bi-sexuels qui ont renoué avec leur héritage religieux, en l'occurrence le catholicisme, on constate que la question de l'identité sexuelle joue un rôle notoire dans leur histoire. Les écrits de M. Pollak ont déjà souligné la difficulté pour les homosexuels de devoir construire leur identité au sein d'une société où le modèle sexuel dominant est l'hétérosexualité. Cela peut conduire à un fort sentiment de culpabilité mais aussi à la haine de $\operatorname{soi}^{80}$. Et, ajoute cet auteur, «l'entrée » dans l'homosexualité peut conduire à une séparation avec la famille.

Dans le cadre de la présente étude, l'identité sexuelle est au cœur de l'engagement religieux. Paradoxalement, c'est en se tournant vers une religion qui condamne leurs pratiques sexuelles (mais pas les individus) qu'ils vont trouver un certain équilibre de vie. Il faut indiquer qu'un certain nombre d'entre eux ont envisagé de devenir prêtre ou moine, manière de mettre un terme à leur sexualité. En fait, s'ils ont décidé d'assumer leur sexualité au sein de l'église catholique, c'est qu'ils vont lui donner une configuration différente. On peut ainsi constater que, pour différentes raisons, ils ont tendance à réfréner leur pratique sexuelle.

François, la cinquantaine, a des pratiques sadomasochistes. Pour éviter les risques de transmission, il dit préférer vivre sa sexualité sur le mode fantasmagorique. Quant à Hubert, ayant quitté sa compagne avec qui il a vécu cinq ans et sachant qu'il est toujours attiré par les hommes, il disait, au moment de l'entretien, vouloir prendre du recul par rapport à tout ça.

Jérôme, la trentaine, vit avec son ami sans avoir de relation sexuelle avec lui. Pour lui, il y a un avant et un après sa conversion au catholicisme.

« Comparé à la vie que j'avais auparavant, où le seul sens qui avait pour moi véritablement de la valeur, était disons le sexe, et bien là, il y avait autre chose, et le sexe qui était quelque chose qui dirigeait ma vie et qui me poussait à faire tout le temps un circuit et à organiser ma vie tout autour de ça, et donc à perdre beaucoup de temps et finalement à ne pas construire grand chose, puisque finalement c'était du sexe peut-être avec ce que j'appelais de l'amour, mais au bout du compte, c'était assez superficiel comme amour, là soudain, j'avais vraiment l'impression, en me levant le matin, de vivre, je ne sais pas, que les choses étaient belles ». De ses rapports avec l'Église, il dit la chose suivante : «pour moi, au départ, la quête spirituelle m'a permis d'avoir une hygiène de vie que je n'avais pas auparavant, donc ça m'a appris une certaine rigueur, des valeurs, et des valeurs du corps, de moi-même aussi, donc ça m'a permis de revaloriser le corps et l'humain (...) la quête de spiritualité m'a permis de me remettre debout, c'est une image mais en même temps c'est au sens propre et figuré, de prendre conscience carrément que mon corps n'est pas une voiture, n'est pas un objet, qu'on prend, qu'on jette, qu'on maltraite, qu'on drogue n'importe comment, en fait, la spiritualité c'est quelque chose qui va donner un sens, qui va re-sacraliser la vie, qui va resacraliser le corps et les rapports qu'on peut avoir avec notre prochain ».

80 - M. Pollak, Une identité blessée. Étude de sociologie et d'histoire, Métailié, Paris, 1993, p. 187. 
Olivier, lui, semble trouver un arrangement avec Dieu pour pouvoir concilier vie sexuelle et spiritualité.

«J'évite, dit-il, de faire trop souvent des conneries (au niveau sexuel), mais quand je ne peux plus, je ne pense pas que Dieu nous en veuille de craquer, là où il nous en veut c'est quand on ne lutte pas, quand y'a pas de lutte, qu'on cède immédiatement à la tentation et là je crois que le pardon est beaucoup plus difficile à obtenir, mais si on a lutté avant, si on connaît le prix de nos conneries, si on en a compris le sens, je pense qu'on est plus accessible au pardon de Dieu ».

Les uns et les autres ne renient pas leur identité sexuelle. Ils continuent à se dire homo ou bi-sexuels et acceptent, à ce titre, d'être marginalisés au sein de l'institution ecclésiale. Cette marginalisation est supportable/acceptable parce qu'elle s'inscrit dans un processus de normalisation (renouer des rapports familiaux, respecter son corps, réfréner ses «pulsions »,...).

\section{Modes mineur et majeur de la spiritualité}

Deux autres portraits vont être brossés de personnes qui n'ont pas connu de rupture avec leur religion d'origine mais dont l'une vit sa spiritualité sur un mode mineur, et l'autre sur un mode majeur.

Hervé se situe dans le premier cas de figure. Au début de l'entretien, il était difficile de se rendre compte de l'impact ou de la place de la spiritualité dans son quotidien. Rencontré dans le cadre d'un Appartement de Coordination Thérapeutique (ACT), j'ai pensé, au départ, qu'il avait répondu à l'enquête par curiosité ou tout simplement pour passer le temps en discutant.

Le parcours de Hervé est marqué par la toxicomanie. Au cours des années 1980, alors qu'il est en cure de désintoxication, il suit les conseils de son amie en faisant un test HIV qui s'avère positif. Il est étonné de ne ressentir aucun symptôme. Quelques temps plus tard, il reprend de la drogue pour à nouveau arrêter. Il se met en ménage avec une femme qui décèdera, cinq ans plus tard, d'une hépatite.

Hervé se remet en ménage avec une autre femme qui se fera avorter à deux reprises. Cela le rend «fou » et, explique t-il, c'est à la suite de ça qu'il recommence ses « conneries ». Il ira en prison à diverses reprises et reprend de la drogue. Il va vivre un temps en maison de repos et là, une assistante sociale lui trouve un ACT. Au moment de l'entretien, il dit avoir arrêté la drogue depuis trois ans.

Pour traiter le VIH, il suit une multithérapie qui l'amène à prendre treize cachets par jour ; sa vie semble rythmée par la prise des médicaments (cf. supra).

Issu d'une famille arménienne, Hervé a été élevé par sa grand-mère orthodoxe qui a des pratiques religieuses populaires; elle lit dans le marc de café et interprète les rêves. Elle est croyante mais ne pratique pas. La religiosité de Hervé ne se manifeste pas au premier abord. En 
fait, au fil de l'entretien, elle est apparue de différentes manières. Il fait tout d'abord état d'une expérience «physique » qu'il a eu, semble-t-il, dans un groupe évangélique, alors qu'il était en cure de désintoxication. Le groupe pratique l'imposition des mains sur les malades. À ce moment-là, dit-il,

«c'est comme si, c'est une façon de parler, c'est comme si j'étais possédé, disons que le virus, c'est comme s'il allait sortir, et en fait c'est tout le mauvais qui sort, et c'est bizarre parce que y'a que quand on priait que ça me faisait ça ».

En dépit du caractère marquant de cette expérience, Hervé n'a plus de contact avec ce groupe religieux. Le regard qu'il porte sur le monde est néanmoins emprunt de religiosité dans la mesure où il envisage les calamités et autres catastrophes naturelles comme des signes annonçant l'apocalypse.

« Dans l'apocalypse, dit-il, au départ y'a le calme et puis la tempête, après ce sont les animaux qui mourront, après ce sera les eaux et après les hommes, regardez, on va droit dessus, la tempête, y'a deux ans (1999), on en a eu une, l'eau, y'a en a souvent maintenant, les animaux, regardez en Angleterre combien y'en a qui sont morts (épidémie de fièvre aphteuse), les hommes déjà avec le sida et le cancer et les maladies cardio-vasculaires, ça aussi y'en a des morts avec ça, bientôt ça va être l'apocalypse ».

Hervé estime avoir bénéficié de la protection de Dieu au cours de sa vie. Ce constat peut sembler optimiste tant son histoire est marquée par des évènements tragiques : décès de sa mère alors qu'il a cinq ans ; vers l'âge de 6-7 ans, il est renversé par une voiture et traîné sur trente mètres, l'un de ses cousins meurt du sida, ... En fait, pour Hervé, la protection divine ne signifie pas un rempart contre les malheurs mais un maintien en vie. Ainsi, le fait de ne pas avoir développé de maladie opportuniste est pour lui une forme de protection divine, c'est « grâce à Dieu », dit-il.

Quant à ses pratiques religieuses, elles se manifestent essentiellement par la prière. Il prie dans la journée, le soir avant de se coucher, ... mais il n'a aucun contact avec des organisations religieuses.

À la différence de Hervé, Barthélémy vit sa spiritualité sur un mode majeur. Élevé dans un milieu catholique, il s'est fortement investi dans la religion. L'annonce de la séropositivité, en 1987, va bouleverser l'image qu'il se faisait de l'église catholique. Son discours est celui d'un homme blessé, meurtri par des paroles ou gestes de chrétiens.

Quand il quitte la province pour venir sur Paris, Barthélémy a l'intention de devenir prêtre ; il est dans une démarche de discernement.

«C'est venu, dit-il, surtout par rapport à ce désir par rapport à l'Église, je faisais plein de choses, j'animais les chants, j'avais envie de faire plein de trucs et j'aime les Églises moi, j'ai ce don, j'aime l'Église ». 
Il fait part de sa séropositivité auprès des personnes qui l'entourent et se rend compte que cela va lui fermer les portes de la prêtrise.

«C'était en 1987, dit-il, moi, j'étais dans une démarche de prêtrise, c'est à dire que je faisais un discernement et puis ça s'est bloqué à cause de ça (séropositivité), j'ai été honnête en plus avec la hiérarchie (ecclésiale), ce que je n'aurais peut-être pas du, mais alors là, j'ai appris qu'il ne faut pas forcément dire à tout le monde, on peut dire les choses dans des cadres particuliers et avec des réserves ».

Barthélémy continue néanmoins à évoluer dans le milieu catholique, soit dans un cadre associatif (cf. des associations catholiques de lutte contre le sida : Tibériade et Basiliade), soit dans un cadre professionnel. Il en garde un souvenir désagréable où il a le sentiment d'être un «bouc émissaire ».

"C'est un peu ça que j'ai vécu depuis 14 ans, les gens se déchargent sur vous, la tradition du bouc émissaire, c'est une tradition judaïque où le peuple hébreux, le jour du grand pardon (...) ils mettaient un bouc sur l'autel, dans le temple de Jérusalem, et ils imposaient les mains et ils déchargeaient sur ce bouc tous les péchés du peuple hébreux et les péchés individuels des personnes, donc toutes les années y'a le Yom Kippour, le jour du grand pardon et le bouc émissaire c'est donc la personne sur qui on, en l'occurrence aujourd'hui, c'est la personne sur qui on décharge tout, et on envoie cette personne au désert, le bouc après on l'envoie au désert, dans un lieu où il n'y a pas de vie, et c'est un peu ça, malheureusement, ce que j'ai vécu ».

Ayant travaillé quelques temps dans une entreprise catholique, il se fait «coincer » dans les toilettes par le comptable qui lui demande des comptes sur sa situation; pourquoi, à quarante ans, il n'est toujours pas marié, lui demande t-il ? De la même façon, il raconte comment, dans certains milieux catholiques, l'histoire de la personne est divulguée sans son consentement. Il constate que l'on parle de lui, de sa séropositivité. Certaines personnes connaissent son histoire avant même qu'il ne les ait rencontrées; il a alors le sentiment qu'on lui vole son histoire. $\mathrm{Ou}$ encore, il fait état d'un repas au cours duquel des catholiques disaient qu'il n'y a pas de séropositifs au sein de leur communauté.

À cette époque, aux alentours de 1987, il raconte la chose suivante : « je n'avais personne à qui en parler, et donc le milieu où je vivais qui était un milieu chrétien, ce que j'entendais comme commentaires ce n'était que des commentaires complètement réacs ».

Barthélémy vit ces moments difficilement car pèsent sur lui la culpabilité et l'exclusion.

«Le plus dur à combattre, dit-il, c'est la notion de faute, si vous avez le sida c'est de votre faute de toute façon donc c'est la notion de culpabilité, vous 
êtes coupable, et les gens vous traitent comme quelqu'un de coupable donc vous n'êtes plus invité, moi, j'ai vraiment vécu une exclusion totale »

Deux aspects doivent ici être soulignés. En premier lieu, il faut indiquer que la plupart des lieux dont parle Barthélémy appartiennent à la tendance traditionaliste de l'Église catholique. Les évènements qu'il relate traduisent la difficulté de vivre sa séropositivité dans certains milieux, notamment par rapport à une maladie marquée par la culpabilité. Contaminé par voie sexuelle, Barthélémy n'a pas voulu dire si c'était par rapports hétéro- ou homosexuels. En second lieu, il ne m'appartient pas de juger les faits relatés par Barthélémy. Il fait part de son vécu et, s'il met en cause certaines personnes, ces faits doivent être envisagés comme tels ; d'autres individus auraient pu tenir un discours différent.

En dépit des difficultés rencontrées par Barthélémy, à aucun moment il n'a songé à quitter l’Église, et pour cause, il vit une relation avec le Christ qui dépasse les dissensions humaines.

«Le Seigneur, raconte Barthélémy, ne m’a pas abandonné, j’ai eu beaucoup de joie spirituelle, je me suis senti beaucoup protégé par Dieu, d'une certaine manière, le Seigneur lui réparait un peu ce que les êtres humains avaient déglingué ».

Par ailleurs, Barthélémy envisage certains signes comme étant la manifestation de son état de grâce. Ainsi, le jour où on lui annonce sa séropositivité, c'est le jour de la Pentecôte, et, au loin, il entend les soeurs de la rue du Bac (Paris) chanter une prière mariale. De là, il se sent accompagné par le Seigneur. La rencontre d'un couple de catholiques, qui l'aident beaucoup dans sa démarche spirituelle, le convainc de relativiser son jugement sur l'église, surtout qu'il apprécie beaucoup la liturgie catholique (prière communautaire, sacrement, notamment le sacrement de réconciliation - confession - où Dieu pardonne l'offense et restaure le corps). Quant aux retraites qu'il effectue régulièrement dans des monastères, elles lui permettent de maintenir une relation intime avec Dieu.

\section{2 . La dimension « positive » de la maladie}

Pour la plupart des personnes de ce groupe, il y a un rejet d'être identifié comme séropositif ou sidéen. Reconstruire leur identité passe par l'affirmation d'un soi non identifié à la maladie. Ce rejet permet notamment d'expliquer leur faible engagement dans des associations de lutte contre le sida où, ils ont le sentiment d'être reconnus d'abord et avant tout à partir de leur pathologie.

François, la cinquantaine, catholique, a ainsi décidé, dès l'annonce de sa séropositivité, en 1992, de dénigrer le VIH, de ne pas lui accorder de place dans son quotidien ; il arrête de faire les examens biologiques préconisés par son médecin. Selon lui, «si on traitait la maladie par le mépris, si on faisait comme si elle n'était pas là et on pensait à autre chose, si on ne se laissait pas bouffer moralement, on arriverait plus tôt à s'en sortir ». Et de considérer que ceux qui en sont mort, «c'est ceux qui n'avaient pas beaucoup de raison de vivre ». Il précise qu'il ne souhaite pas être comme certains qui se complaisent dans la maladie et qui en font leur fond de commerce. De la même façon, pour Nordine, la quarantaine, musulman, toute personne touchée par le virus HIV 
doit cesser de se définir comme séropositive ; elle doit d'abord et avant tout se dire quel(le) est une personne.

La contamination au $\mathrm{VIH}$, paradoxalement, est souvent envisagée de manière positive, et ce au regard du passé ; elle permet de changer de vie, de prendre conscience d'un certain nombre de choses, d'évoluer, de grandir, ... tout en prenant des formes différentes selon les individus.

Ainsi, pour Nordine, «la maladie, en tradition spirituelle musulmane, je parle d'une tradition ancienne, qui est honnête, c'est de dire, probablement, toutes ces maladies nous arrivent pour qu'on apprenne à se connaître mieux (...) Cela oblige à ce que chacun fasse une remise en question, et se dise, je dormais tranquillement, enfin, j'étais tranquillement calfeutré dans mes idées, mes points de vue, mes opinions et, probablement, y'a quelque chose, là, qui me fait réfléchir un peu ».

Quant à Hubert, la quarantaine, catholique, il envisage sa contamination au VIH à partir du dilemme qu'il vivait à cette époque : avoir des relations sexuelles avec des hommes sans éprouver de sentiments pour eux, et ne pas réussir à en avoir avec des femmes. Pour lui, il n'est pas séropositif par hasard :

« si je vais au bout de ce raisonnement-là, explique t-il, ça veut dire que d'une certaine façon, même si c'est extrêmement provoquant ce que je dis-là, c'est que j'ai choisi ou une certaine partie inconsciente de moi, à un moment donné, dans ma vie, a désiré ça, en tous les cas, à un moment donné, j’ai choisi de me mettre dans des conditions qui ont fait que ça a pu paraître dans ma vie, la séropositivité (...) Ca voulait dire ne pas être dans une relation d'estime avec moi-même, le fait de me débattre très fort contre mon sentiment amoureux, mon attirance pour les hommes, de me juger par rapport à ça ». Plus tard, il ajoute, « je crois que la séropositivité, elle est intervenue dans ma vie pour que je me développe (...) Le paradoxe, c'est justement comment, des thérapeutes connaissent très bien ça, c'est comment je me mets en danger de mort pour en fait vivre, c'est à dire que la partie malade en vous est la partie la plus saine, être malade, ce n'est jamais qu'un moyen pour arriver à résoudre un problème psychologique, psychoaffectif, tout ce que tu veux, un problème intérieur ou inconsciemment tu te dis, la seule façon de résoudre ce problème c'est de tomber malade, et si je ne tombais pas malade, là, je me foutrais en l'air ».

Pour Olivier, la contamination au VIH lui a permis de changer de vie, d'envisager les évènements sous un autre angle.

La maladie (sida) disait-il « a un sens, pour d'autres c'est un drame total, pour moi c'est une chance, je n'aurais pas pu m'émanciper et avoir la vie que j'aie, que Dieu m'a donnée, si je n'avais pas eu la notion de la mort à côté, cette épée de Damoclès que j'ai tous les matins en me levant qui s'appelle HIV (...) je ne serais ce que je suis aujourd'hui, si je n'avais pas le sida (...) J'aurais continué à être infidèle, j'aurais pas regardé les pauvres de la même façon, je 
serais resté dans mon milieu protégé, de politiquement bien pensant, que je trouve totalement stérile aujourd'hui, j'aurais été plutôt attiré par les choses matérielles, je n'aurais pas compris les choix de ma mère, je n'aurais pas compris sa passion qui a fait qu'on s'est séparé d'elle pendant longtemps, je n'aurais pas du tout eu le regard que j'ai sur mon frère aujourd'hui, il m'aurait fait chier, je l'aurais vu comme un poids plutôt que comme quelqu'un qui est là, ça a remis en valeur la fraternité ». Fortement influencé par le discours de Jean-Paul II, Olivier insiste également sur l'utilité de la souffrance : "l'utilité de la souffrance, disait-il, c'est se mettre au même niveau que les autres, ça renvoie à sa propre condition d'humain, vous êtes les autres, les autres c'est vous, vous n'êtes ni au-dessus, ni en-dessous, par rapport à la souffrance, c'est vrai, on est tous au même niveau par rapport à la souffrance, c'est une utilité, l'une des utilités de la souffrance c'est de nous ramener dans une égalité vis-àvis des autres ».

La dimension positive de la séropositivité n'est pas envisagée par ce seul groupe ; on la retrouvera particulièrement prononcée auprès des personnes proches du New Age. Cet aspect doit être envisagé, au-delà d'un discours doloriste (aspect salvateur de la souffrance) comme une forme de reconstruction identitaire. Il est un moyen de s'approprier la maladie, de dépasser les contraintes qu'elle impose, et de pouvoir vivre avec.

\section{3 . Des pratiques thérapeutiques conformes au modèle dominant}

Les rapports que ces personnes entretiennent avec l'institution médicale sont relativement attestataires dans le sens où la plupart d'entre elles suivent les prescriptions de leurs médecins mais surtout, elles mettent rarement en cause leur rapport à l'autorité médicale. Le fait que peu d'entre elles fréquentent des groupes charismatiques, groupes accordant une place importante à la "guérison $»^{81}$, abonde dans en ce sens. Divers cas de figure vont permettre d'envisager ces rapports à l'institution médicale.

Florentin estime que s'il est resté asymptomatique depuis l'annonce de sa séropositivité (1985), c'est parce qu'il a toujours respecté scrupuleusement les prescriptions de ses médecins. Jusqu'au début des années 1990, il est suivi régulièrement par un praticien hospitalier. À cette époque, ses défenses immunitaires baissent; il va être mis sous AZT (premier médicament ayant montré une efficacité sur le VIH). Puis, il fera partie d'un protocole d'essai thérapeutique, et même s'il fait partie du groupe témoin (placebo), il a le sentiment que le traitement lui fait du bien. Au cours de l'année 1996, il bénéficiera des premières multithérapies.

Confiant dans la médecine, Florentin est resté fidèle à son médecin de famille, ce qui lui a valu quelques déboires. Ainsi, il raconte

«Mon médecin se trompe des fois, il me donne un médicament qui ne convient pas, vous savez avec la trithérapie, tout médecin peut se tromper, on n'est pas au courant de tout non plus, si on fait une grippe par exemple, y'a

\footnotetext{
81 - M. Cohen, «Les charismatiques et la santé. Offres religieuses de salut ou nouvelles médecines parallèles ?»; Gestions religieuses de la santé, sous la direction de F. Lautman et J. Maître, L'harmattan, Paris, p. 61-87.
} 
des médicaments qui ne sont pas compatibles avec la trithérapie avec les autres médicaments que je prends ». «Maintenant, poursuit-il, je fais plus attention, à chaque fois que j'ai quelque chose, avant de prendre mon médicament, si mon médecin (généraliste) me prescrit un médicament, je téléphone à mon médecin hospitalier (et je demande) si je peux prendre le médicament, si je ne vais pas avoir trop d'effets secondaires (rire) ».

Autre cas de figure, relativement proche de Florentin, celui de Barthélémy. Celui-ci envisage son rapport à l'institution médicale sous l'angle du respect et, d'une certaine façon, de la « soumission » à l'autorité.

«Curieusement, dit-il, j'ai rencontré des gens qui ont refusé le traitement (multithérapie), personnellement, je n'ai jamais compris pourquoi, parce que pour moi, le médicament c'est un devoir de le prendre (...) Ca m'avait presque choqué que mon médecin me laisse libre d'en prendre ou de ne pas en prendre, pour moi c'était une évidence que si je pouvais me soigner, je devais me soigner ». Pour mieux justifier sa position, Barthélémy se réfère aux autorités ecclésiales et à la Bible. Lors d'un rassemblement religieux, il raconte que « le prêtre avait dit, quand on est malade, il faut se soigner (...) En plus, poursuit-il, je suis tombé sur des textes bibliques, notamment dans l'Ancien Testament, où on dit que au travers des médecins, c'est Dieu qui te soigne $»$.

Jérôme, catholique, âgé d'une trentaine d'années, est beaucoup plus critique à l'égard de l'institution médicale. Il estime que l'hôpital n'est pas assez adapté au malade, que le corps médical n'est pas suffisamment attentif à l'homme dans sa dimension globale voire spirituelle, que la recherche est gouvernée par l'argent («c'est le capital maintenant qui gère la recherche »), ... Et de préciser, « la médecine actuelle, telle qu'elle est pratiquée en Occident, est une médecine qui, en dernier lieu, finalement, met en avant l'humain, et encore moins le spirituel, encore moins l'âme (...) Nous avons une médecine qui est, à mon sens, trop attachée à des chiffres, elle est trop mathématisée (...) Il y a un fossé entre le corps médical et l'homme actuellement et si aujourd'hui je dois rendre grâce d'être toujours là, ce n'est pas vraiment grâce aux médecins ».

Le rapport entretenu par ces personnes à l'institution médicale rejoint les analyses faites par l'anthropologue S. Fainzang ${ }^{82}$. À partir d'une étude de terrain, elle constate que la variable religieuse (culturelle) est susceptible d'influencer le comportement médical des individus. Les catholiques et les musulmans, ayant davantage un rapport de «soumission » à l'autorité religieuse reproduiraient, d'une certaine façon, ce rapport dans d'autres domaines de la vie sociale. Ainsi, concernant leur rapport au médecin, ils n'envisagent pas de mettre en cause sa parole $^{83}$.

\footnotetext{
82 - S. Fainzang, Médicaments et société. La patient, le médecin et l'ordonnance, PUF, coll. Ethnologies, Controverses, Paris, 2001, 156 p.

83 - Pour autant, ce rapport à l'autorité ne se traduit pas forcément dans l'observance thérapeutique cf. les musulmans ont tendance à arrêter leur traitement une fois les symptômes disparus et les catholiques ont tendance à se cacher quand ils ne suivent pas leur traitement.
} 
Pour les catholiques et musulmans rencontrés, l'efficacité thérapeutique passe par un respect des prescriptions médicales et ils envisagent rarement leur religion comme un moyen d'obtenir une guérison physique. Lorsque le terme "guérison » est employé, il désigne une voie de salut à suivre ou une réconciliation avec soi-même.

Barthélémy explique la distinction qu'il fait entre la guérison spectaculaire/miraculeuse et la guérison comme voie de salut.

« Un couple d'amis, dit-il, m'aide, ils croient à la guérison, c'est très important pour moi, aussi, tous ces gens qui ont cru à la guérison, que la guérison était possible, parce que dans le désir de guérison, pas simplement le vôtre, y'a le désir de salut, d'éternité etc., d'un chemin ensemble, plus loin que la mort, et quand les autres désirent ça pour vous, c'est formidable ... Mais, y'a beaucoup de manipulation là-dessous, y'en a beaucoup qui en font leur fond de commerce (...) Il y a des gens qui interprètent, ils attendent le phénomène exceptionnel qui n'est pas du tout un acte de foi d'ailleurs, qui est plutôt, je crois en Dieu et il va faire des merveilles (...) On ne peut pas reprocher non plus, aux gens, de vouloir la guérison des gens, vous savez c'est très ambiguë parce que aller reconnaître ce qui est prise de pouvoir et ce qui est le vrai désir du bien de l'autre, c'est parfois très compliqué (...) parce que si justement il n'y a pas de guérison, on peut s'imaginer ce qui se passe, philosophiquement parlant, ça veut dire que Dieu n'a pas guéri donc là on entre dans des culpabilités autres, ça peut être pervers de vouloir à tout prix que l'autre guérisse, non, on peut dire que la volonté de Dieu soit faite sur cette personne et puis voila, après c'est à Dieu qu'appartient le choix de guérir ou de ne pas guérir»

Quant à Marius, s’il envisage la guérison comme un moyen de faire le « lien avec la vie éternelle » ou comme un mieux-être physique (il a demandé à trois reprises le sacrement des malades quand il était dans des états de faiblesse avancés), il dit :

«moi, ma guérison, c'est de vivre réconcilié avec moi-même, c'est vraiment arriver à m'aimer tel que je suis, malgré ce que j'ai raté ». "Cette évolution de l'être profond, ajoute-t-il, est peut-être plus importante que la guérison physique, immédiate ».

En s'inscrivant dans une démarche spirituelle, certaines personnes ont pu avoir le sentiment d'être protégé par une puissance divine. Ainsi, pour Hubert, catholique, les choses sont claires ; s'il a pu passer quatre années à vivre sans système immunitaire (zéro CD4) c'est grâce à Dieu mais aussi grâce aux médicaments (AZT essentiellement).

«Aujourd'hui, dit-il, ce que je mesure c'est la chance que j'ai de vivre, c'est vrai que je me rends compte, justement, de ces quatre années où je pouvais mourir dans les trois mois qui suivaient, chaque mois j'avais un bilan, ça va, ouais, ça a l'air d'aller, peut-être que le mois suivant, je suis encore-là, mais dans six mois je ne suis peut-être plus-là, et ça pendant quatre ans, avec ces 
questions-là, après, a posteriori, quand tu mesures ça, tu te dis bon je pense que effectivement, je suis vraiment protégé, les protections, je ne sais pas si elles sont divines, ou si c'est un ange gardien ou si c'est quelque chose de cet ordre-là, je crois qu'il y a, à l'intérieur de moi, aussi une partie qui est bienveillante et qui veille extrêmement bien sur moi, alors c'est clair que si je n'avais pas pris ces traitements, si je n'avais pas pris ces médicaments, peutêtre que je ne serais pas là aujourd'hui, il ne s'agit pas pour moi de dire il suffit d'aller à l'Église pour guérir du sida, ce n'est pas ça mais ce que je pense qu'il y a une combinaison des deux ».

À travers les propos de Jérôme, on constate que les rapports entretenus avec l'institution ecclésiale peuvent être reproduits au niveau de l'institution médicale. Jérôme est la seule personne a avoir tenu un discours critique à l'égard de l'hôpital et, en même temps, c'est celle qui a pris le plus de distance avec l'institution ecclésiale. Pour lui, certaines pratiques religieuses peuvent avoir une efficacité thérapeutique mais surtout, il les considère comme plus efficaces que les traitements médicaux.

À l'hôpital, «je mettais toute ma confiance dans le seigneur, au point de m'abandonner complètement à lui, et à répéter des prières que Saint Jean attribue à Jésus au moment de l'agonie, et comme je crois que la foi peut déplacer les montagnes, c'est normal qu'au bout du compte, les prières peuvent être écoutées, et que soudain, là, personne ne s'y attendait, soudain y'a un retournement de situation (...) Pour moi, poursuit-il c'était mon âme qui pouvait faire quelque chose pour mon corps et non pas l'inverse ». Plus tard, il explique, « je dis toujours que je n'ai qu'un seul médecin, pour moi-même, c'est Jésus, le Christ, c'est mon premier médecin, c'est mon seul médecin, c'est lui qui gère, c'est lui qui contrôle tout pour moi, tous les autres médecins aussi fabuleux qu'ils puissent être, aussi agréables, gentils, pertinents puissent-ils être, pour moi, ils ne sont jamais aussi rigoureux, ils ne seront jamais autant attentifs comme peut l'être Jésus, et en plus, ils ne seront jamais aussi présents que peut l'être Jésus, donc, pour moi, Jésus c'est pratique, je tourne les yeux vers lui, je sens son regard, donc je sens sa présence, elle me calme, elle m'apaise, mon médecin, si je dois l'appeler maintenant, je vais sûrement devoir prendre rendez-vous pour le voir, et puis ensuite, peut-être que je vais l'agacer par une question qui va être moins importante pour lui face au problème urgent qu'il doit traiter. Jésus, c'est bien, c'est pratique, pour lui vous êtes toujours important, à ses yeux, vous êtes toujours prioritaire, il n’y a pas de compétition, y'a pas de couleur ou d'état d'âme ».

Au-delà de la guérison physique, certaines personnes manifestent un rapport émotionnel à la religion. Ainsi, lorsque Olivier visite une église bretonne, il raconte qu'il est resté une demiheure à genoux,

« et je voyais le corps de Jésus avec plein de lumière qui sortait, et je sentais une chaleur étrange, une joie immense en moi et en même temps, j'avais un 
regard sur la souffrance des hommes, je sentais en moi ce que, je crois, Jésus sentait quand il voyait des gens malheureux ».

L'image du Christ souffrant a été, pour un certain nombre de catholiques, une aide précieuse. Ainsi, au moment où Jérôme vit d'intenses souffrances, il dit «qu'à travers la souffrance du Christ, j'avais un repère, j'avais quelque chose à me référer, pour donner un sens à ma souffrance et pour la dépasser ».

De la même façon, Hubert raconte qu'au cours des moments où il n'avait plus de système immunitaire, le fait de se référer aux souffrances du Christ l'aidait.

« Si j'admets, dit-il, que je crois en l'existence du Christ, est-ce que je crois que cet homme-là a pleinement vécu toute la palette des sentiments, est-ce que au moment où moi, je suis mal (VIH), à chialer parce que demain je vais peutêtre être mort et que j'ai des chiasses et que je prends des médicaments et que ça me déprime et tout ça, et je me dis, à ce moment-là, dans ma merde où je suis, lui, il l'a connue aussi, exactement la même, la même et peut-être encore pire, certainement pire, tout ça il l'a exploré de fond en comble et bien je sais que moi, dans ces moments-là, de me dire ça, ça m'aidait, de me dire à ce moment-là, je ne suis pas seul ».

\section{Conclusion}

Le retour des homosexuels vers leur religion d'origine traduit une recherche de sens vis-àvis de leur identité, notamment de leur identité sexuelle. L'usage du terme « conversion », par certains d'entre eux, signifie qu'ils ont opéré un choix parmi des possibles. Renouer avec leurs racines religieuses, c'est vouloir trouver une structure dans laquelle il est possible d'inscrire leur histoire, de penser leur avenir, d'envisager leur salut et de donner un sens à leur sexualité voire à leur séropositivité. L'acceptation de leur marginalisation au sein de l'institution ecclésiale tient à l'entreprise de normalisation effectuée par ailleurs. Autrement dit, l'identité se construit autour d'une dialectique entre marginalisation et normalisation. 


\section{II . La religion comme lien culturel}

La population de ce groupe se caractérise par trois aspects. En premier lieu, il s'agit d'une population qui, pour la plupart, a récemment immigré en France. Les motifs de l'immigration sont d'ordre économique, sanitaire et plus rarement politique ; la plupart de ceux qui vont obtenir des papiers officiels pour résider et/ou travailler en France, le seront au titre de leur séropositivité au HIV. En effet, la politique migratoire de la France fait de la maladie un élément légitime de droit du sol et, une circulaire de juin 1997, prévoit la régularisation de certains immigrés en situation illégale, lorsque leur vie serait mise en danger par un retour au pays; depuis 1998, ils bénéficient d'un droit à un titre de séjour en cas de maladie grave ${ }^{84}$. Cette situation peut s'avérer problématique dans la mesure où l'identité de la personne est réduite à celle de malade. Les migrants rencontrés dans le cadre de cette étude sont originaires d'Afrique et plus précisément de l'Afrique sub-saharienne.

En second lieu, cette population est, de manière générale, fortement précarisée $e^{85}$. Dans le cadre de la présente étude, on est face à une population venue en France pour des raisons économique ou sanitaire, qui vit généralement des aides sociales mises en place pour les précaires, notamment des Appartements de Coordination Thérapeutique (ACT) ${ }^{86}$. Ces structures ont pour vocation d'apporter un suivi médical, social et psychologique et d'être provisoire, le temps de trouver un logement plus approprié. Au moment de la réalisation de l'entretien, sept d'entre elles (sur onze) en faisaient partie. Les autres étaient soit dans une situation encore plus précaire (foyer d'hébergement), soit elles étaient parvenues à sortir de ce réseau de soutien (deux sur onze). En ce sens, on peut reprendre les propos de Cl. Herzlich et de Ph. Adams «...il faut admettre, écrivent ces auteurs, que le sida porte la marque des inégalités sociales, des hiérarchies et des dominations les plus traditionnelles (...) Malgré ce qu'on a dit de son 'exceptionnalité', le sida n'est jamais hors des rapports sociaux habituels $»^{87}$.

Enfin, dernière caractéristique, les personnes composant ce groupe ont gardé la religion qu'elles avaient dans leur pays d'origine. Neuf sont chrétiennes (trois catholiques et six

84 - D. Bonnet, « Au-delà du gène et de la culture », Hommes et migrations, Santé, Le traitement de la différence, $\mathrm{n}^{\circ}$ 1225, mai-juin 2000, p. 36.

85 - «Les immigrés et les étrangers, écrit D. Fassin, se trouvent bien plus souvent que le reste de la population dans des conditions matérielles défavorables, aussi bien en termes d'emploi et de ressources que de logement. La pauvreté et la précarité ne leur sont pas propres, mais ils sont beaucoup plus nombreux à en faire l'expérience », D. Fassin, "L'indicible et l'impensé : la 'question immigrée' dans les politiques du sida », Sciences Sociales et Santé, vol. 17, $\mathrm{n}^{\circ} 4$, décembre 1999, p. 22-23. Dans un autre article, cet auteur cite les chiffres suivants : les étrangers sont presque deux fois plus souvent des ouvriers que les Français et la mobilité inter-générationelle est trois fois plus faible ; le taux de chômage des étrangers est le double de celui des Français, et même le triple pour ce qui est des personnes originaires de pays extérieurs à l'Union Européenne ; un étranger sur trois originaire d'Afrique subsaharienne, du Maghreb ou de Turquie, vit dans un habitat dégradé, alors que cette situation ne concerne qu'un Français sur quatorze, D. Fassin, «Santé : des inégalités sociales sans droit de cité », Mouvements, n 4, mai-juin-juillet 1999, p. 51.

On retrouve cette précarité au niveau du VIH/Sida.

${ }^{86}$ - Les ACT ont été mis en place en 1994 par la Direction Générale de la Santé. L'objectif était d'éviter de regrouper un trop grand nombre des malades du sida afin de ne pas encourager la ségrégation des personnes souvent déjà marginalisées, A. Monlouis-Félicité, «Au plus proche de la vie familiale », Informations sociales. Sida: les nouvelles donnes, $\mathrm{n}^{\circ} 71,1998, \mathrm{p} .49$.

87 - Cl. Herzlich, Ph. Adams, "Urgence sanitaire et liens sociaux : l'exceptionnalité du sida», Cahiers internationaux de sociologie, vol. CII, 1997, p. 26. 
protestantes) et deux musulmanes. Certaines se rendent plus ou moins régulièrement dans un lieu de culte tandis que d'autres préfèrent pratiquer à leur domicile. On a préféré envisager leur rapport à la religion/spiritualité sous l'angle « culturel » plutôt « qu'ethnique ${ }^{88}$.

Après une présentation de certains parcours typiques, on s'intéressera au sens de la maladie et aux rapports à l'institution médicale.

\section{1 . Parcours spirituels}

\section{Des catholiques peu engagés}

Bien que rassemblant des personnes ayant des parcours relativement distincts les uns des autres, les catholiques se caractérisent pas un faible engagement religieux auprès de leur paroisse. Il faut néanmoins souligner que la double appartenance religieuse (catholique et protestante) ${ }^{89}$ de deux d'entre elles a pu être un facteur de dissolution du sentiment religieux. À leur arrivée en France, ces deux personnes ont fait le choix de se rendre dans des églises catholiques, c'est la raison pour laquelle on les a inscrites dans ce groupe.

On commencera par décrire le parcours de Lucien, âgé d'une quarantaine d'années. Originaire du Cameroun, il arrive en France en 1997 pour subir diverses interventions chirurgicales (cardiaque et respiratoire). C'est au cours de l'une de ces interventions qu'on découvre qu'il est porteur du VIH. Il pense avoir été contaminé par voie sexuelle, mais il ne sait pas quand. De fait, cette annonce lui provoque un choc.

Hébergé par de la famille, Lucien en est plus ou moins congédié quand son séjour en France se prolonge. Il va vivre un temps sans avoir de domicile, dormant dans des aéroports. Par le biais de l'hôpital, il est mis en contact avec une assistante sociale qui se charge de constituer un dossier pour qu'il puisse bénéficier d'un Appartement de Coordination Thérapeutique (ACT). Après l'avoir sorti de la rue, son assistante sociale entreprendra également des démarches pour qu'il puisse avoir une carte de séjour et bénéficier de l'Allocation Adulte Handicapé (AAH). Au moment de l'entretien, Lucien était en possession de papiers et percevait l'AAH. De fait, les liens entre Lucien et son assistante sociale sont très forts ; il l'envisage comme une « mère ».

« Je crois, dit-il de son assistante sociale, qu'elle est un peu de cette qualité de femme qu'on peut qualifier d'exceptionnelle de part sa manière de travailler et par son côté humain parce qu'elle associe un savoir faire et un autre côté qui consiste à vraiment aider les gens, elle a été un peu pour nous, nous qui

\footnotetext{
88 - En prenant en compte la dimension culturelle on souhaite élargir la notion de religion. «L'appartenance à l'un ou l'autre de ces groupes (religieux), écrit S. Fainzang, n'est pas envisagée comme l'adhésion à un système de croyances, mais comme participation à des valeurs et à une culture dont il s'agit de cerner comment elle imprègne des pratiques quotidiennes extérieures au champ des pratiques religieuses » (op. cit., p. 12). En l'occurrence, on envisagera la religiosité/spiritualité des migrants comme une composante de leur culture et/ou comme une façon de réifier leur rapport à leur culture d'origine.

Il n'est plus seulement question d'un rapport aux croyances, pratiques, communauté de croyants, ..

89 - Les deux sont issues de familles protestantes mais alors que la première se marie avec un catholique et adopte la religion de son mari, la seconde fait ses études dans un pensionnat catholique et, en France, se rend essentiellement dans des églises catholiques.
} 
sommes dans l'association, elle a été un peu une mère, parce que, à tout moment, de jour ou de nuit, elle a toujours été là pour nous apporter son secours, son aide, ses grandes qualités de gestion, parce que chez les gens, elle sait écouter, elle sait prendre les décisions en conséquence, c'est une femme exceptionnelle, c'est grâce à elle que je suis arrivé à cette stabilité dont je dispose aujourd'hui, stabilité financière, je me dis qu'elle m'a prise en charge, je n'avais pas le moindre sou, je ne recevais rien, aujourd'hui je bénéficie d'une $\mathrm{AAH}$, ce qui fait que je peux déjà, je suis presque indépendant ». Lucien est néanmoins conscient qu'il se laisse un peu porter par son assistante sociale car il n'a jamais entrepris, de lui-même, de contacter des associations de lutte contre le sida. À propos de l'une d'entre elles, il disait, elle en «a quand même parlé mais généralement c'est elle qui prenait les rendez-vous et tout, donc je me suis peut-être habitué à cette facilité ».

Lucien doit faire face au chômage. Cadre dans la gestion des ressources humaines, au Cameroun, il ne peut faire valoir son expérience ou ses diplômes en France. De fait, il doit orienter ses recherches d'emploi dans d'autres domaines, notamment des professions peu qualifiées. Aujourd'hui, il accepte d'être déclassé et recherche un emploi dans n'importe quel domaine.

«je suis maintenant obligé de chercher un emploi dans n'importe quel domaine, et c'est pas facile », explique-t-il.

Par ailleurs, Lucien est divorcé et père de sept enfants dont deux en bas âge. Lors de son départ en France, son frère aîné a pris en charge ses deux derniers enfants. Malheureusement, un accident a conduit son frère en prison et laissé ses enfants livrés à eux-mêmes. Cet incident interroge d'autant plus Lucien qu'il en a appris la nouvelle au retour d'un pèlerinage à Lourdes. Son objectif est de les faire venir en France pour qu'ils puissent bénéficier d'une «bonne » éducation.

Élevé dans un milieu catholique, Lucien a été baptisé et a fait sa communion. À l'âge de l'adolescence, plusieurs « affaires » viennent ébranler son engagement religieux. L'affairisme, les intrications avec le monde politique, le favoritisme envers les nantis, ... sont les principaux griefs qu'il a envers l'église catholique.

« Je vais à l'église, dit-il, mais je sortais petit à petit de la position de chrétien pour ne devenir que croyant. Moi je crois en Dieu, point, et à une certaine philosophie de l'église catholique. Quand on vous parle des commandements, je me dis que c'est tout à fait normal, je peux les suivre, on vous dit, ne péchez pas, rachetez vos parents, ne tuez pas, je me dis, ça c'est une bonne logique, là, je suis avec eux, là, je suis partant, mais quant à une certaine philosophie, qui tourne beaucoup plus autour de l'argent parfois de la politique, je m'écarte ». 
De fait, Lucien souhaite garder ses distances avec l'institution catholique sans pour autant renoncer à une certaine pratique. Ainsi, en France, il se rend occasionnellement au culte dominical, dans des paroisses de la banlieue parisienne pour, dit-il,

« tirer le meilleur, pas pour gober tout ce qu'on dit là-bas, oui, pour tirer le meilleur, parce qu'il peut arriver qu'au cours d'une messe le prêtre vous donne des conseils vraiment appropriés, lui qui maîtrise mieux la Bible, parce que je vous ai dit tout à l'heure que je ne rejette pas entièrement la Bible, qu'il vous dise que telle chose n'est pas bonne à faire, et à partir de cet exemple, c'est mieux de suivre cette voie, c'est un peu dans ce sens-là, quand je vais à l'église, j'écoute ce qui est bon pour moi, le reste tant pis, si ça ne me plaît pas, je ne prends pas ça en considération ».

Il préfère ne pas communier ou se confesser et, plutôt que de changer de confession, il s'en remet, seul, à Dieu.

«Ce que les autres peuvent transmettre à Dieu (les prêtres), explique-t-il, je peux le faire moi-même, je peux moi-même parler à Dieu à travers mes prières, exprimer ce que je ressens, mes craintes, mes souffrances, peut-être exprimer mes fautes, exprimer mes fautes à travers, une manière de m'adresser à Dieu directement ». Il préfère s'adresser à quelqu'un qui a « les mains propres». Et, comme il estime que ce n'est pas le cas des prêtres, «je me dis, que je peux m'adresser directement à Dieu, je crois en Dieu, je suis son fils, et, à ce titre, je peux lui parler parce qu'on dit qu'il est mon père, au même titre que tout le monde, pourquoi je ne parlerais pas directement à Dieu, pourquoi est-ce qu'il faut que je passe par certaines voies pour m'adresser à Dieu qui est mon Père, qui m'a créé, je préfère donc faire mes prières, parler à Dieu à ma façon, mais puiser dans une certaine philosophie parce qu'on ne se suffit pas, j'ai une Bible dans laquelle je tire ce qui, à mon avis, est important, je m'adresse à Dieu de cette manière ».

L'important, aux yeux de Lucien, est la relation qu'il entretient avec Dieu, sans médiation ecclésiale. D'une certaine façon, cette relation est la seule chose qui lui reste ; au chômage, cherchant un emploi sous qualifié par rapport à ses compétences, ayant laissé ses enfants au pays dont deux enfants en bas-âge, ... Lucien est dépossédé de tout (rôle de père, statut de travailleur, ...), sauf de cette relation privilégiée qu'il entretient avec Dieu.

L'histoire de Viviane, la cinquantaine, originaire du Congo-Kinshasa (République Démocratique du Congo) est particulièrement complexe dans le sens où, dans son récit, il n'est pas toujours évident de faire la part des choses. En 1992, deux de ses filles, vivant en France, lui payent un billet d'avion pour qu'elle vienne faire traiter un zona. L'hôpital décèlera une séropositivité au VIH mais elles refusent, dans un premier temps, de le dire à leur mère. Celle-ci vivra chez l'une de ses filles, d'abord en province, puis dans la banlieue parisienne. Là, elle suit des cours d'alphabétisation auprès de sœurs catholiques. 
Quelques années plus tard, en 2001, Viviane va être hospitalisée mais sa fille ne souhaite pas qu'elle revienne vivre chez elle. Une assistante sociale prend en charge son dossier et lui trouve une place dans un Appartement de Coordination Thérapeutique. Viviane explique le rejet de sa fille par sa séropositivité au VIH et la honte qu'elle suscite. Son assistante sociale me dit qu'il s'agit plutôt d'une sombre histoire d'inceste entre Viviane et l'un de ses beaux-fils. Quoiqu'il en soit, Viviane souffre de cette situation qu'elle considère comme un abandon. Elle vit également difficilement cette coupure de huit ans avec ses enfants restés en RDC. Partie en 1992, son benjamin avait douze ans ; aujourd'hui, dit-elle, c'est un adulte âgé de vingt ans.

Étant fortement affectée physiquement (diabète, fièvre, tension), Viviane peut difficilement envisager de travailler. Elle participe à certaines activités d'une association et sort de temps en temps avec une amie, sur Paris, sa mobilité étant toutefois réduite parce qu'analphabète et sans ressource. Son assistante sociale a engagé une procédure pour qu'elle puisse bénéficier de l'Allocation Adulte Handicapé mais, elle n'a pas encore abouti. Viviane est consciente des dangers de rester constamment dans son appartement (ACT) qu'elle partage avec deux autres locataires :

« je ne peux pas, dit-elle, rester tout le temps à regarder la télé, parce que cette maladie quand tu restes comme ça, ça va pas, non il faut que je bouge ».

L'absence de revenu pose à Viviane quelques problèmes et ce tant vis-à-vis d'elle-même que de sa famille, restée au pays. Elle explique que

« au pays on croit que, comme je suis ici, je suis milliardaire mais rien $\mathrm{du}$ tout, moi quand je suis venue ici, je vais chez mes filles mais je ne vois pas l'argent, je ne peux pas demander parce que j'ai honte, au pays je ne demandais rien, moi-même j'ai travaillé, j'avais de l'argent mais ici je n'ai rien, il faut que je demande à mes enfants, ça fait mal à la tête ».

Née dans un milieu protestant, Viviane a été mariée, à l'âge de quatorze ans, avec un séminariste qui pratiquait la polygamie. Elle divorcera et s'occupera de ses neuf enfants. Elle dit ne pas avoir de préférence pour le protestantisme ou le catholicisme («c'est la Bible qui compte » explique t-elle) mais, en France, elle fréquente surtout des églises catholiques. Elle se rendra également à Lourdes, dans le cadre d'un pèlerinage. Ayant quitté le Congo-Kinshasa depuis huit ans, la religion est l'occasion de maintenir des liens avec sa famille restée au pays.

Ainsi, elle raconte que sa fille lui a «envoyé une cassette de l'église, si je l'écoute, je suis bien, je suis bien, elle me l'a envoyée pour écouter la parole du Seigneur ». Un autre de ses enfants l'appelle pour lui dire de prier.

De ces deux portraits (Lucien et Viviane), il ressort une faible pratique religieuse et un engagement relativement modéré au sein de l'institution ecclésiale. Cette situation tient, dans un cas, au ressentiment, et dans l'autre, à une culture religieuse mixte (catholique et protestante). Pour autant, en immigrant en France, ces personnes ont continué, dans une certaine mesure, à maintenir des rapports avec le catholicisme. Cela peut être envisagé comme un moyen de 
maintenir d'une part un lien avec le pays d'origine, et d'autre part une continuité (religieuse) là où il y a eu rupture (immigration).

\section{Une identité protestante affirmée}

Sur les six personnes engagées dans le protestantisme, on peut constater que leur religiosité est davantage affirmée, ne serait-ce qu'en terme de pratique religieuse. Quatre portraits vont permettre de rendre compte des différentes situations observées pour ces personnes.

Arrivé en France en 1999, Clément était venu pour une période d'un mois. Au cours de ce séjour, il est traité pour des poussées de fièvre. Il demande à faire le test HIV qui s'avère positif. De fait, il est hospitalisé et là, le médecin découvre une tumeur au cerveau, provoquant une paralysie faciale et des crises d'épilepsie. Il ne mange plus et maigrit énormément.

Traité par les multithérapies, Clément se sent mieux physiquement mais reste dans une grande précarité. Il est hébergé dans des foyers ou des hôtels durant deux ans. Son dossier aboutit dans une association gérant des Appartements de Coordination Thérapeutiques (ACT) et sera accepté.

Ayant laissé au pays, la Côte d'Ivoire, sa femme et ses sept enfants, Clément aimerait pouvoir travailler pour leur envoyer de l'argent. Là, il doit faire face au même problème que Lucien, celui d'un déclassement professionnel. Ayant une formation dans la comptabilité et les assurances, on lui a proposé, en France, de suivre une formation sur deux ans, de comptable, rémunérée deux mille francs par mois. Il a refusé cette offre car il pense ne pas pouvoir subvenir à ses besoins une fois parti de l'ACT mais aussi parce que cela signifiait retourner à l'école.

N'ayant aucun revenu, Clément a introduit une demande d'Allocation Adulte Handicapé ; en attendant, il vit des quatre cents francs que lui alloue l'association dans laquelle il se trouve.

«Pour le moment, dit-il, je n'ai aucune ressource, je vis des tickets service qu'on nous donne ici, je n'ai pas de ressource, c'est dur, très dur, ici, même si j'ai besoin de dix francs, il faut que j'aille demander, il faut que je parcours tout Paris pour voir si je peux trouver cent francs pour appeler ma femme, tout ça, je reste en contact avec elle pour voir si avec les enfants ça se passe bien, tout ça c'est un peu dur ».

La situation de Clément est particulièrement délicate en ce qui concerne sa femme. Lorsque j'aborde avec lui la question de sa contamination au VIH, Clément est assez évasif. Il évoque une possible transmission par voie sanguine : une aiguille non stérile utilisée lors d'examens médicaux.

«Souvent, dit-il, au pays, vous êtes malade, dans une clinique vous avez mal à la tête, on vous fait une injection, on vous fait une piqûre et on ne sait pas si ça a servi à plusieurs personnes et on peut être infecté comme ça ». 
Puis, au cours de l'entretien, sans être complètement explicite, il évoque l'éventualité d'un adultère.

«Moi, disait-il, je ne sais pas où j'ai eu le virus mais à ce que je sache, peutêtre que c'est par infidélité, peut-être parce que j'avais ma femme et puis j'avais eu une amie quelque part et je ne sais pas si c'est avec elle parce que je lui ai demandé de faire le test, pour voir exactement où le mal se situe, mais à mon niveau ce n'est plus nécessaire pour moi ».

Clément est pris dans un étau ; sa femme pense qu'il est en France pour traiter une tumeur au cerveau et il n'ose pas lui parler de sa séropositivité.

«Je ne peux pas l'informer, disait-il, en étant ici parce que je ne sais pas ce que ça va provoquer parce que c'est dur quand tu as ce genre de maladie, les gens ne te fréquentent pas (...) Si je lui dis, je ne sais pas comment elle va le prendre, peut-être qu'elle va abandonner les enfants à la maison, ou bien les gens vont la rejeter ». Et en même temps, il souhaite l'informer pour qu'elle fasse le test HIV. «Si elle est contaminée, c'est mon épouse et je dois la soigner comme on me l'a fait », ajoute t-il.

Clément décrit ses parents comme étant animistes. Lui, il s'engage religieusement au cours des années 1980. À cette époque, il perd son emploi et est alcoolique. Une personne de son entourage lui parle de Dieu et du baptisme. Il se convertit et décide d'abandonner boisson et tabac. Arrivé en France, il prend contact avec une «filiale » de son église ivoirienne qui se trouve en banlieue parisienne. Il n'a pas évoqué sa séropositivité au HIV auprès de l'ensemble des personnes de son église. Seuls, le pasteur de l'église et quelques amis, «frères » de l'église, sont au courant car, dit-il, il faut avoir du « discernement » pour évoquer cette question (certaines personnes retournant au pays pourraient informer sa femme). Ce silence autour de sa séropositivité lui permet aussi de ne pas être connu ou reconnu comme «malade » mais comme immigrant à part entière.

Malgré un trajet long et coûteux, Clément se rend régulièrement aux services religieux, une à deux fois par semaine. Là, il retrouve des «frères » et «sœurs » originaires de son pays pour qui fraternité et solidarité riment ensemble. Ces voyages lui permettent de briser l'isolement social dans lequel il se trouve car les quelques contacts qu'il a avec les locataires de sa résidence ne remplissent pas ses journées.

L'entretien de Blandine et Honoré, un couple congolais a été réalisé en commun. Ils se sont mariés (mariage coutumier), en 1991, en République Démocratique du Congo (RDC), pays dont ils sont originaires. Un an plus tard, Honoré part en France et fait une demande d'asile politique ; il va immédiatement être emprisonné. En prison, il commence à ressentir certains symptômes; on lui propose de faire le test HIV qui s'avère positif. Transféré dans un centre pénitencier ayant un hôpital, Honoré vit des instants graves, proches de la mort. Il est mis sous perfusion, puis tombe dans le coma. Là, il vit une expérience qui le rapproche de Dieu. 
« là où j'étais, raconte t-il, dans la cellule où j'étais, donc dans l'attente de la mort, si vous voulez, j'ai senti une chaleur immense et une voie intérieure qui me disait de retirer la perfusion, et j'ai crié, j'ai crié, au nom de Jésus, sors d'ici, moi qui étais épuisé, j'ai eu un petit souffle où je disais Jésus, l'Esprit disait ce n'est pas assez puissant, j'ai dit Jésus plus fort, ce n'est pas assez puissant après j'ai crié d'une telle façon que toute la prison a entendu, j'ai arraché la perfusion, j'étais debout devant la porte, les gardes sont arrivés, ils m'ont vu, ils m'ont attrapé, ils m'ont remis sur le lit attaché, ils m'ont remis la perfusion mais quand le docteur est arrivé le matin, il était fâché, il avait la réaction qu'il fallait, c'était la première fois que j'ai appelé pour demander à manger, je commençais à parler, on m'a lavé, j'ai pris une douche, et j'ai repris, petit à petit, je suis revenu à la vie »

En sortant de prison, Honoré se rend dans un temple protestant où il est bien accueilli. Il y reste quelques temps avant de rejoindre la région parisienne. Là, c'est sur les conseils d'une femme, rencontrée dans le métro, qu'il se joindra aux Assemblées de Dieu, église dont il fait toujours partie aujourd'hui.

Durant cette période, la situation de Honoré est plus ou moins stable : une assistante sociale lui a trouvé une place dans un foyer mais il aimerait pouvoir en partir. Plus tard, elle lui proposera un Appartement de Coordination Thérapeutique dans lequel il vit toujours au moment de l'entretien.

Après plusieurs années de silence, Honoré reprend contact avec sa femme, restée au pays. Il tente plusieurs pistes pour la faire venir, sans succès. Désespéré, il met Dieu au défi :

« je ne remettrais plus un pied dans ta maison, sans ma femme, et j'ai arrêté, et c'est quatre mois après, au mois de février que c'est arrivé ».

Blandine arrive donc en France en février 2000. Elle découvre son mari amaigri et en mauvaise santé ; il lui parle alors de sa séropositivité. De son côté, elle lui raconte qu'elle aussi elle ne se sentait pas bien ces dernières années. Elle avait de la fièvre et des problèmes de sinusite. Les antibiotiques l'aidaient à passer ces crises mais un jour, la fièvre a été plus importante et elle a été hospitalisée. Là, on lui fait le test HIV qui s'est avéré positif.

Peu après son arrivée en France, Blandine va être hospitalisée ; on lui détecte un lymphome derrière la gorge. Après huit mois de traitement intensif, elle retrouve l'usage de la parole, reprend du poids, ses cheveux repoussent, et se sent beaucoup mieux. Dans l'attente d'une régularisation de sa situation (elle a également déposé une demande d'asile politique), Blandine est plus ou moins condamnée à l'immobilisme car elle ne peut travailler.

«Ici (en France), raconte Blandine, on ne sait plus quoi faire, on se tourne les pouces, on attend, mais sinon, j'aimerais faire quelque chose, apprendre surtout l'informatique, j'ai quelques notions mais j'aimerais approfondir ce que j'ai comme connaissances en informatique, et travailler, c'est ennuyant de 
rester comme ça, sans rien faire, surtout qu'à Kinshasa, j'étais tout le temps en mouvement, je sortais le matin, j'allais faire les courses, ... ».

Issue d'un foyer catholique, Blandine se convertira au pentecôtisme dans le courant des années 1990. À son arrivée en France, elle ira dans l'église que fréquente son mari, Honoré, les Assemblées de Dieu. Elle ne perçoit pas vraiment de différence entre l'église où elle était, en RDC, et celle qu'elle fréquente en France.

Pour autant, le choix des Assemblées de Dieu, un groupe moins marqué par la dimension « ethnique » (public mixte, composé de Noirs et de Blancs) et émotionnelle (peu d'effusion émotionnelle), traduit une inscription différente au sein de la société française. L'objectif est de privilégier autant les liens avec des «frères » et «sœurs » du pays mais de nouer qu'avec des Français. Le temps passé en France (Honoré est là depuis neuf ans), et les projets d'avenir (la venue de Blandine signifie que le couple compte rester un certain temps en France) traduisent un autre rapport à la société française, plus proche du modèle d'intégration républicain.

Rose, la quarantaine, arrive en France au cours de l'année 2000. Hébergée par une cousine, elle tombe malade. Elle est hospitalisée durant six mois pour un fibrome à l'estomac ; là, on lui annonce sa séropositivité au VIH. L'assistante sociale de l'hôpital lui trouve un Appartement de Coordination Thérapeutique, et a engagé les démarches pour qu'elle puisse obtenir des papiers lui permettant de travailler.

Originaire de Côte d'ivoire, Rose quitte son pays après la faillite de l'entreprise dans laquelle elle travaillait comme ouvrière. Les indemnités de licenciement lui permettent de se payer un billet pour l'Italie. Elle y travaille quelque temps pour ensuite rejoindre la France. Divorcée, elle a laissé quatre enfants au pays et tente, dès qu'elle le peut, de leur envoyer de l'argent.

Au moment où elle est hospitalisée, une femme, Blandine (la femme de Honoré), qui deviendra par la suite son amie, lui parle de la parole de Dieu. Rose renoue avec la spiritualité ; elle confesse ses péchés et prie intensément. Elle apprend qu'une « filiale » de l'église ivoirienne où elle a été baptisée, existe dans la région parisienne, en Seine Saint-Denis (93). Elle décide de s'y rendre et s'y investit fortement ; elle participe au culte tous les dimanches, elle assiste aux autres réunions données au domicile des frères et sœurs de son église, elle fait partie du groupe d'organisation de l'église, elle fait du prosélytisme, ...

«Sinon, dit-elle, y'a des gens que je croise dans les rues, dans le métro, que j'évangélise, j'arrive à parler de Dieu, souvent ces personnes viennent (dans son église), et quand elles viennent, elles restent, ils voient que vraiment Dieu est vivant, Dieu est là, et quand ils écoutent la parole de Dieu, ils restent ».

Sa vie est rythmée par la prière.

« Je me lève souvent à cinq heures, ou bien quand je suis trop fatiguée, je me lève à six heures, je prie, je prie, au moins trente à quarante minutes, et puis comme je ne travaille pas en ce moment, je me recouche, jusqu'à neuf heures, 
là je prends mon déjeuner, je prends mes cachets et puis à treize heures, je prie un peu, à seize heures je prie, le soir encore avant de me coucher je prie, en tous les cas, à longueur de journée, je ne fais que prier, je lis, je prie, je lis, je prie, voilà, quand je suis avec des amis, comme j'ai des amis chrétiens, on ne fait que parler de Dieu ».

Les frères et sœurs de son église sont devenus sa « nouvelle » famille.

«Ici (en France), malheureusement, je n'ai pas de famille, je suis seule, parce que je suis venue seule, toute ma famille est en Côte d'Ivoire, mais j'ai des amis de l'Église, des sœurs en Christ qui sont vraiment devenues ma famille parce que souvent je passe tout mon week-end chez des amis, des sœurs en Christ, et le dimanche, ensemble, on va au culte et c'est comme ça, par exemple, là où j'ai dormi hier, c'était une sœur de l'église, on a veillé, on a prié jusqu'au matin et nous nous sommes séparées, et mois je suis rentrée chez moi, c'est un peu comme ma famille, mais ma vraie famille n'est pas ici »

La solidarité entre coreligionnaires va jusqu'au don d'argent.

«Dans l'église où je suis, explique-t-elle, à la fin du mois, les gens me font des dons, de gauche à droite, parce qu'ils savent que je ne travaille pas et des gens me font des dons, ce n'est pas parce que je leur demande, mais ça leur fait plaisir de me donner quelque chose, je peux me retrouver comme ça, à la fin du mois avec mille francs, plus ce que l'association me donne, quand je mets ensemble ça me fait quelque chose, donc ça, c'est la grâce de Dieu ».

Rose a un rapport très pragmatique à la religion dans le sens où elle envisage son engagement religieux au regard des «avantages/bénéfices» que cela lui procure, personnellement.

«Moi, dit-elle, en l'espace de deux ans, j'ai déjà eu un récépissé, bientôt j'aurais mes papiers, y'a des gens qui sont hospitalisés, qui ne savent même pas comment faire mais aujourd'hui, avec la grâce de Dieu j'ai une maison dans laquelle je dors, je ne paye même pas cinq francs, je mange, je suis nourrie, j'ai tout ce que je veux, avec le peu qu'on me donne à l'association, j'arrive à économiser, à envoyer un peu d'argent à mes enfants, tout ça c'est la grâce de Dieu ».

L'engagement religieux de Rose est à la mesure de sa situation, en France ; démunie de tout, elle s'est investie, corps et âme, dans un groupe où des « frères » et « sœurs » l'entourent et l'aident. Cette «nouvelle » famille lui permet de supporter une situation pour le moins difficile ; celle de devoir refaire sa vie dans un pays étranger et laisser ses enfants en Côte d'Ivoire. Quelques temps plus tard, son amie Blandine m'a dit que Rose avait trouvé un travail comme aide à domicile mais qu'elle avait du subir la perte de l'un de fils (accident de voiture), resté en Côte d'Ivoire. 
Des différents portraits protestants dressés, deux aspects ressortent : une fidélité au culte d'origine, et un engagement religieux plus important par rapport aux catholiques. En France, l'identité protestante est souvent fortement affirmée, manière de se distinguer d'un catholicisme prédominant. Dans le présent cas de figure, il ne semble pas que l'engagement des personnes soit lié à cette dimension minoritaire. Il s'agit plutôt de trouver un lieu d'accueil au sein duquel les uns et les autres sont reconnus autrement que comme malade et de maintenir un lien symbolique avec le pays d'origine voire avec ceux qu'ils y ont laissés.

\section{Une pratique de l'islam peu communautaire}

Aïcha, jeune femme d'une trentaine d'années, me reçoit dans son Appartement de Coordination Thérapeutique avec Aminata, sa fille âgée de quelques mois. Originaire du Mali, Aïcha a été élevée dans une famille musulmane où son père dirigeait une école coranique. Mariée à l'âge de seize ans, elle part vivre auprès de son mari en Côte d'Ivoire. Là, elle travaille pour son compte en vendant des repas qu'elle prépare elle-même. Son mari décède après quelques années de mariage ; elle décide de retourner auprès de sa famille, au Mali.

L'une de ses sœurs, vivant en France, lui demande de venir la rejoindre. Aïcha hésite car elle souhaite se stabiliser. Elle se décide à partir en 1999. Elle trouve un travail dans la restauration et se marie religieusement (elle n'avait pas encore de papiers officiels pour se marier civilement) avec son compagnon dont elle attend un enfant. Un jour, alors qu'elle était au travail, l'hôpital l'appelle et lui demande de venir en urgence. Là, on lui apprend qu'elle est séropositive. Aïcha ne comprend pas : son compagnon est séronégatif et elle n'a jamais eu d'autres relations sexuelles qu'avec lui et son défunt mari (elle présuppose que c'est son mari décédé qui a du la contaminer). Elle raconte son histoire de la manière suivante :

«J'étais avec mon mari, il est décédé, j'ai fait trois ans, quatre ans, je ne me suis pas mariée, j'étais au Mali, après je suis venue ici (en France, il y a deux ans), j'ai jamais couché avec quelqu'un, pour nous, c'est un péché de coucher avec un homme comme ça, sans mariage, et sans qu'il ne demande la main à tes parents, eux, ils acceptent, et là, tu commences à être mariée, on va faire la cérémonie du mariage religieux, là, c'est ton mari, même si on n'a pas fait le mariage civil, c'est ton mari donc tu peux coucher avec, mais avant, tu commets un grand péché et tu seras punie, tu seras punie, le fait que tu as fait ça, moi, je n'ai jamais fait ça ».

À l'annonce de sa séropositivité, son compagnon la délaisse. Seule avec son enfant, elle va bénéficier de l'aide d'une assistante sociale. Elle lui trouve une place dans un ACT après son accouchement. Elle lui trouve également une formation pour devenir aide à domicile et une place en crèche pour sa fille. L'objectif étant qu'elle puisse devenir indépendante et quitter l'ACT. Les rapports qu'elles entretiennent entre elles sont fait de compréhension mutuelle.

Aïcha n'a jamais délaissé la religion : elle fait ses cinq prières par jour mais se trouve dans l'incapacité de se rendre à la mosquée, trop éloignée de son domicile. Pour autant, quand elle pouvait y aller, elle ne parlait pas de sa séropositivité. 
« Je n’ai jamais parlé de ça, discuter de ça, chez nous, les maladies comme ça, on ne parle jamais ou on dit peut-être, maintenant, tout le monde va avoir peur de toi ».

Lors de sa grossesse, elle n'a eu de cesse de prier pour que sa fille ne soit pas contaminée au HIV. Elle a du attendre quelques mois avant d'en avoir la certitude (cf. à la naissance, tous les enfants nés de mères séropositives, portent les anticorps de leur mère ; ce n'est qu'au bout de quelques mois qu'il est possible de savoir s'ils ont été ou non contaminés). Le fait que sa fille soit séronégative lui donne une certaine fierté.

Comme elle le dit, « je suis parfaitement contente que ça va, ça va bien, même si je meurs aujourd'hui, je meurs la tête haute, tout va bien, avant qu'on a fait le test, avant que je n'aie les résultats, avant, je ne dormais pas, mais quand j'ai eu les résultats et qu'on m'a dit qu'elle n'avait rien, j'étais soulagée, ça m’a vraiment fait plaisir ».

Et, concernant sa vie conjugale, elle semble avoir pris le dessus :

«Mon mari m’a laissé tomber, c'est le destin dit-elle (...) je vais trouver un autre mari, qui va être meilleur pour moi ».

Aïcha, à l'instar des personnes du groupe «catholique », va peu dans les lieux de culte : cela ne traduit pas une distance à la religion mais l'impossibilité de mener de front plusieurs activités : formation professionnelle et éducation d'un enfant. L'isolement de sa communauté d'origine est « compensé » par les relations professionnelles et sociales qu'elle peut avoir par ailleurs.

Quant à Selman, la quarantaine, il est arrivé en France en 1993, pour trouver du travail. Originaire du Sénégal, il a exercé de nombreux métiers, s'expatriant en Côte d'Ivoire, au Cameroun, au Togo, au Gabon, ... En France, il sera hébergé chez son frère durant deux ans, mais il ne peut pas travailler car il n'a pas les papiers nécessaires.

En 1995, il est hospitalisé pour des problèmes de dos ; les examens révèlent une tuberculose et l'entrée dans la phase sida. Une assistante sociale lui trouve un logement en Appartement de Coordination Thérapeutique et engage des démarches pour l'obtention d'une carte de séjour. Après une formation de deux mois comme agent d'entretien, Selman signe un contrat de travail à mi-temps pour un an.

Élevé dans un foyer musulman, Selman ira dans une école coranique à l'âge de sept ans. En France, il continue à pratiquer mais trouve certaines difficultés à se rendre dans une mosquée. Le quartier dans lequel il vit n'a pas de lieu de culte à proximité, de fait, il ne peut s'y rendre régulièrement.

«Maintenant que je suis arrivé (ACT), dit-il, il n'y a pas de mosquée, c'est de temps en temps que je passe, le vendredi, si je n'ai pas de travail, tous les 
vendredis que je n'ai pas de travail, je prends le métro et je vais Gennevilliers, je fais le musulman et je fais les mosquées avec les musulmans mais je fais la prière tous les jours, 5 fois, tous les jours je le fais 5 fois mais le vendredi, comme c'est un grand jour de prière pour les musulmans, si je n'ai pas de travail, je suis obligé d'aller chercher une mosquée, deux fois je suis allé à Barbès ou bien la mosquée de Paris, ou bien à Gennevilliers ».

Selman ne sait pas comment il a été contaminé et il garde un silence absolu autour de sa séropositivité. Son frère, qui vit en France, n'est pas au courant ainsi que sa femme, restée au Sénégal, avec ses trois filles.

«Dieu avec mon médecin, et avec moi, le reste je ne demande à personne quelle est leur situation, je ne parle à personne de mon secret (HIV), je ne demande pas son secret, je ne parle pas de mon secret, moi c'est comme ça ». Il en est de même de l'imam de la mosquée : «moi si je vais là-bas (mosquée), je n'ai pas de coopération avec un imam, moi ce qui m'intéresse seulement c'est pour faire la prière (...) je ne vais pas là-bas pour chercher autre chose ou pour demander autre chose (...) je ne connais pas les autres, je ne demande pas et je ne parle pas, parce que ton secret, vous avez le secret qui est avec vous, moi je ne peux pas, je ne connais pas, c'est Dieu seulement avec vous qui connaît votre secret $\gg$.

\section{2 . Sens de la maladie : modèles exo- et endogène}

Pour chaque groupe religieux présenté ci-dessus, il existe un modèle étiologique différent ou plutôt dominant dont on va dégager les principales caractéristiques.

\section{Des modèles étiologiques coextensifs}

Au sein du groupe catholique, on retiendra le témoignage de Lucien. Pour mémoire, on peut rappeler que Lucien, la quarantaine, originaire du Cameroun est venu en France pour être traité de problèmes cardiaque et respiratoire ; le VIH a été décelé lors de l'une de ces interventions chirurgicales.

Lucien adhère à plusieurs registres explicatifs, concernant sa contamination au VIH. Ayant fait des études supérieures (niveau licence), il dit souscrire totalement au discours scientifique sur les modes de contamination au VIH.

«Pour nous qui avons fait quelques études, dit-il, on se dit que c'est une maladie normale c'est à dire qu'elle peut arriver à tout un chacun par transmission ». "Le côté scientifique, c'est 'est-ce que c'est une maladie que j'ai contracté de manière tout à fait normale comme on contracte la tuberculose à travers je ne sais pas quoi' ?». 
À ce premier modèle explicatif, Lucien en ajoute un second qu'il qualifie de « traditionnel ».

Le deuxième aspect, dit-il, «se situe au niveau de nos moeurs, des coutumes, voilà un peu comment les choses se présentent (...) on se dit, de manière traditionnelle, que c'est peut-être une malédiction ou des choses de ce genre, ça, c'est le côté typiquement africain ». "Le côté traditionnel, ajoute Lucien, c'est quand vous attrapez une maladie incurable, on se dit, c'est une malédiction qui part peut-être des parents, qui part peut-être des ancêtres, c'est un peu ça, c'est comme ça chez nous, par moments on parle de sorcellerie, voilà ; ça c'est le côté traditionnel ». Et de s'interroger, « est-ce que c'est un sort qui m'a été lancé ? »

Lucien établit un lien entre cette dimension traditionnelle et son « identité africaine ».

«Tout au fond de nous, dit-il, nous restons des africains, attachés à notre tradition et nous voyons aussi ce côté traditionnel comme je vous l'ai expliqué, par des sorts qu'on vous a lancés, par des malédictions, par des trucs maléfiques, on ne peut pas totalement écarter les deux, sinon, je ne mangerais pas la pâte d'arachide au manioc tout en étant à Paris, c'est pour ça que y'a le Château Rouge (quartier de Paris ayant une forte population africaine), qu'on retrouve tous nos produits parce que de temps en temps, on replonge, et si nous nous retrouvons au restaurant, je vais manier la cuillère avec dextérité, comme un occidental, je vais manger je ne sais pas quoi, le fromage et tout, mais quand je me retrouve dans mon milieu, je mange le coucous à la main avec les sauces de chez moi, ça suppose que je ne peux pas totalement rejeter le monde dans lequel j'ai vécu, où je suis né, et je ne peux pas non plus rejeter le monde dans lequel je vis aujourd'hui et les deux cultures, je sais faire certaines alliances, une certaine symbiose ».

À la fin de l'entretien, Lucien se fait plus explicite sur le lien entre sa contamination au VIH et la sorcellerie. Un sort lui aurait été envoyé d'Afrique, et ce en dépit de ses problèmes de santé.

«Ils (les sorciers) sentaient que je m'en sortais (en France), explique-t-il, si on peut voir le problème sous cet angle-là, en venant en France, tout le monde sait que y'a rarement des cas qui ne trouvent pas de solution, ils se disaient, si on tient compte de ce côté-là, et je me dis, ils ont dit, voilà, il va en France, il sera guéri, il faut qu'on associe autre chose, qui soit plus grave (VIH) et à laquelle il ne pourra pas s'en sortir, ça, c'est le côté traditionnel ».

L'accumulation de malheurs (dans le cas de Lucien : divorce, perte d'emploi, problèmes de santé, contamination au VIH, emprisonnement de son frère,...) peut en soi justifier le recours à un modèle étiologique exogène (sorcellerie). " Le seuil de l'angoisse sociale une fois franchi, écrit l'ethnologue A. Zempléni, certaines 'maladies' - graves, aiguës, atypiques, chroniques, répétitives... - sont expliquées, légitimées et disculpées de la même manière que les autres 
infortunes qui affectent les corps, les biens et la vie sociale des individus (...) Tous ces évènements (malheurs) peuvent renvoyer les uns aux autres comme autant d'effets de la même chaîne causale ou comme autant de coup portés à l'intégrité du même corps (...) Et si tous ces évènements néfastes sont connexes et enchaînables, c'est qu'ils sont interprétables au moyen des mêmes schèmes étiologiques tels que par exemple la sorcellerie $»^{90}$. Dans le cas de Lucien, le recours à la sorcellerie lui permet à la fois de donner un sens à cette série de malheurs, de perpétuer un lien symbolique avec son pays d'origine (le sort a été envoyé d'Afrique), et de se déculpabiliser vis-à-vis de «fautes » éventuelles.

À ces deux modèle explicatifs (scientifique et traditionnel), Lucien en évoque un autre, de manière implicite.

« Par rapport à ma religion (catholicisme), dit-il, la seule chose qui me vient en tête, aujourd'hui, c'est de me poser la question, celle de savoir, est-ce que je n'ai pas été très respectueux de la logique divine, de ce que Dieu prescrit, est-ce que je suis sorti de cette voie pour pouvoir mériter cette maladie-là, c'est un peu la question que je me fais, est-ce que j'ai désobéi à Dieu au point où c'est pour moi une sorte de sanction divine, qui tombe sur ma tête, c'est dans ce sens que je réfléchis au niveau de la religion, auquel cas, je me dis, la seule façon serait de chercher à me rapprocher davantage de Dieu, pas de bénéficier totalement de son pardon parce qu'on dit que cette maladie, elle est incurable, peut-être de bénéficier d'un pardon pour l'avenir, pour la fin de mes jours, pour que je puisse reposer en paix le jour où ça viendra, c'est un peu de cette manière que je vois les choses » (...) Pour cela, « je me dis de la même façon que d'avoir le pardon de Dieu c'est d'abord faire une rétrospective de ma vie, une rétrospective qui pourrait me permettre de voir ce que j'ai fait, quelles ont été mes erreurs, mes fautes, à partir d'où j'ai perdu le fil même tracé par Dieu et quelles ont été, durant toute ma petite vie, les plus grosses fautes que j'ai pu commettre pouvant m'amener à subir cette sanction, c'est ça, c'est à partir de cette recherche que je peux peut-être demander à Dieu sa miséricorde » (...) C'est un travail que je suis en train de faire parce que y'a pas longtemps je suis allé dans le Sud de la France, dans un lieu de culte de la religion catholique (Lourdes), on y est allé pendant plusieurs jours, on a la possibilité de pouvoir s'exprimer, de se sentir un petit peu plus proche de Dieu, j'y suis allé, j'ai fait trois jours, j'ai passé des jours à prier, à faire mon mea culpa, donc c'est un peu ça, c'est de cette manière que j'essaye de voir le problème d'analyser le problème ».

À la différence du modèle étiologique exogène (sorcellerie, vih), le modèle endogène donne le sentiment d'avoir prise sur l'événement car à la «faute » commise existe le « rachat », et ainsi, il permet d'envisager une voie de salut possible.

\footnotetext{
90 - A. Zempléni, «La 'maladie' et ses 'causes'. Introduction », L'ethnographie. Causes, origines et agents de la maladie chez les peuples sans écritures, n 96-97, 1985-2 et 3, p. 17.
} 
Ces deux modèles étiologiques (endogène et exogène), a priori antagonistes, s'inscrivent dans une logique de seuils. Le passage d'un modèle explicatif à un autre peut ainsi s'expliquer en fonction du degré de « tolérance » face à l'accumulation de malheurs.

\section{Des modèles étiologiques hiérarchisés}

Les explications avancées par certains protestants, à la contamination au VIH, accordent une place importante à la notion du mal/malin.

Clément fréquente un groupe, une filiale de son église baptiste ivoirienne. Au cours de l'entretien, il aura parfois recours à la Bible, qu'il tient proche de lui. La manière dont il se représente Dieu est particulièrement ambivalente. D'un côté, il affirme que «rien n'arrive à l'homme si Dieu n'a pas prévu, tout ce qui arrive à l'homme c'est dans le plan de Dieu ». Et d'un autre côté, il explique aussi que «Dieu n'a pas programmé que l'homme soit malade, Dieu a programmé que nous nous portions bien ». De fait, il envisage la maladie comme l'œuvre du diable : «la maladie vient du malin, et la bible dit que le malin c'est Satan donc la maladie ça vient du mal et ce qui est mal c'est le malin c'est à dire que c'est le diable en quelque sorte qui a programmé ça pour détruire l'humanité ». Et d'ajouter, «Dieu veut seulement voir si nous sommes croyants en lui, si nous avons cette foi, bon dès fois on est tenté, par exemple, je trouve quelque chose et y'a mon coeur qui me dit de prendre alors que c'est interdit alors si je prends, je désobéis, je n'ai pas la force, donc je n'ai pas obéi à la parole, c'est pour cette raison qu'il faut croire parce que la foi et la croyance vont ensemble or croire veut dire obéir quand tu crois à quelque chose c'est pour obéir à celui qui donne des ordres, et si tu désobéis tu vas avoir des problèmes, donc moi je ne sais pas où j'ai eu le virus mais peut-être que c'est par infidélité ». Clément poursuit en ces termes, "il faut savoir comment demander pardon à Dieu si c'est un péché que j'ai commis, pour avoir la grâce de Dieu ».

Rose, également ivoirienne, est membre d'une église pentecôtiste. Son discours sur la maladie se fait plus précis au fil de l'entretien. Au départ, il est même proche de celui de Clément. Selon elle, Dieu ne peut avoir créé le mal, il s'agit de l'œuvre de Satan.

«Dieu, dit-elle, il nous aime tellement qu'il n'a jamais voulu le mal pour nous mais à cause de ce que nous sommes, de l'incrédulité pour nous-mêmes, on marche en dehors de la parole de Dieu alors quand tu es en dehors de la parole de Dieu, tu oeuvres pour le Satan et là, le Satan, il est libre, il peut mettre la main sur toi à tout moment, quand il veut, mais quand tu marches selon la parole de Dieu, tu as l'Esprit Saint, tu es protégé de tout ». Elle poursuit en distinguant les croyants des mécréants. «Quand tu n’es pas en Jésus-Christ de Nazareth, dit-elle, tu ne peux pas le savoir, tu es guidé par un esprit maléfique et tu ne le sais pas, c'est quand tu viens en Jésus et qu'on te prêche la parole de Dieu, et que tu te rappelles un peu de ta vie, tu vois ta vie, et tu te rends compte que vraiment tu es possédé par un esprit maléfique ».

Plus tard, Rose évoque vaguement la sorcellerie mais son propos est encore généraliste : 
« vous les Blancs, vous avez une chance de ne pas connaître la sorcellerie, je sais que vous connaissez la sorcellerie mais ici, ça ne se pratique pas, mais chez nous, en Afrique, les gens ont fait de ça une affaire, un camp, les gens quand ils sont dans la sorcellerie, quand vous avez un membre de votre famille qui fait partie de la sorcellerie, je ne vous dis pas madame, on vous barre tous les chemins de la réussite totale, dans les études, le mariage, même pour enfanter, on vous bloque tout $»(\ldots)$

pour devenir plus précis...

« le vih, ça c'est une maladie, je ne sais pas d'où ça vient, les gens appellent ça la maladie du siècle (...) chez nous, les gens qui sont sorciers peuvent utiliser ça, ils peuvent vous jeter ce sort (...) mystiquement, les gens utilisent, ils peuvent vous rendre fous, ils peuvent vous donner le cancer, ils peuvent vous donner le sida ».

et enfin être personnalisé : Rose considère que sa contamination au VIH est un sort que lui aurait lancé sa mère.

«Elle (sa mère) pratique la sorcellerie, elle connaît la sorcellerie, oui, puisque elle était en moi, c'est un peu mystique, je ne sais pas comment vous expliquer, son esprit de sorcellerie m'avait envoûté donc je faisais des choses par rapport à elle, son plaisir, moi, je ne pouvais plus guider ma vie, c'est à dire que je faisais des choses, selon elle, sa volonté. Et elle, sa volonté c'était quoi ? C'était de me nuire, et moi je faisais des choses selon elle, sa volonté ».

Le regard porté par Rose sur son histoire repose sur cet acte d'envoûtement dont elle situe l'origine à son mariage, quand elle avait quatorze ans.

« Ma mère n'était pas contente parce que je me suis mariée, j'ai eu un homme qui devait s'occuper de moi et de mes enfants et dans le monde mystique, elle a fait que nous nous sommes séparés (...) Ma mère, qui est dans la confrérie de la sorcellerie, et je ne savais pas au départ, c'est quand j'ai donné ma vie à Jésus (conversion au pentecôtisme), que c'est sorti de la prophétie, le prophète (de son église) a prophétisé, il a vu que c'était ma mère qui était à la base de mon échec de mariage et ça fait dix ans que j'ai quitté mon mari, il s'est remarié, je ne peux plus repartir avec lui (...) Je l'ai connu, on était encore tous à l'école, après il a travaillé, moi aussi j'ai travaillé de mon côté mais ça n'a pas marché, il m'a fait quatre enfants mais nous nous sommes séparés, et c'est maintenant que je me rends compte que ce n'était pas de notre volonté lui et moi mais c'était préparé quelque part, dans le monde mystique et comme à ce moment-là je ne connaissais pas Jésus, et ça a marché, et là, elle (sa mère) a gagné, elle a eu la victoire sur moi, je suis partie, mon mari m'a chassée ». 
Ce type de schéma permet de tout expliquer, notamment l'échec scolaire de ses deux plus grands enfants qui passent le BAC pour la troisième fois. Face à l'échec, explique Rose, «vous êtes la risée de tout le monde ».

Au sein des groupes pentecôtistes, les croyances ne sont pas relativisées ou formulées sur le mode du « pourquoi pas ». Elles s'inscrivent dans un système global de sens et sont envisagées comme « la » réalité. Dans la mesure où Rose croit qu'elle a été contaminée «mystiquement», elle estime qu'elle n'est pas « réellement » porteuse du virus HIV. Elle en veut pour preuve d'une part, le fait qu'elle a eu, juste avant l'annonce de sa séropositivité, une relation avec un homme qui, depuis, est resté séronégatif, et d'autre part, le fait que sa charge virale soit «indétectable ». Reste à savoir si ce type de croyance reste dans le domaine du discours ou s'il se traduit par des pratiques spécifiques.

À la différence de Lucien, où l'explication par la sorcellerie est coextensive au discours scientifique, Rose semble hiérarchiser les deux modèles explicatifs : celui du groupe religieux venant supplanter le discours médical.

\section{Un modèle étiologique fataliste}

La caractéristique commune à Selman et Aïcha, tous deux musulmans, est d'inscrire leur séropositivité dans l'ordre des choses ou plutôt celles voulues par Dieu. À la différence des groupes précédents, ils considèrent que Dieu est à l'origine de toute chose et notamment des maladies. Pour Aïcha, il n'y a pas de doute :

«C'est Dieu qui fait toutes les maladies, ça dépend de Dieu, c'est le destin, depuis le jour où tu es né, avant que tu ne viennes dans ce monde, ton destin il est déjà tracé, ton destin est tracé, ça, tu peux être sûr de ça, tu vas passer par là, moi, c'est ce que j'ai mis dans ma tête, c'est le destin, c'est ton Dieu qui l'a voulu, tu es malade ou tu n'es pas malade, si ton Dieu le veut, tu vas partir, ça, il n'y a pas de doute » (...) Ce n'est pas que je cours de gauche à droite que j'ai eu cette maladie-là, c'est le destin, c'est la vie ».

Des différentes interprétations avancées par les interviewés, un élément commun apparaît : celui d'une vision exogène du mal. Outre le sens qu'elle peut apporter aux individus, cette vision est aussi une manière de les disculper d'éventuelles « fautes » qu'ils auraient commises et ainsi de leur accorder une nouvelle identité. 


\section{3 . Des pratiques thérapeutiques diversifiées}

Deux logiques président les pratiques religio-thérapeutiques du groupe en question ; la première est complémentaire tandis que la seconde est plutôt alternative.

Les rapports entretenus par les catholiques et les musulmans avec l'institution médicale sont, on l'a vu, relativement conformes aux attentes du corps médical. On le signalait précédemment, au sein des religions catholique et musulmane, il existe un rapport de « soumission » à l'autorité (médicale et/ou religieuse). En dépit de traitements lourds au niveau des effets secondaires, les personnes appartenant à ces religions ont tendance à suivre les recommandations de leurs médecins.

Ainsi, Viviane (catholique) ne remet pas en cause son inscription dans un protocole d'essai thérapeutique, même si elle sait que cela aura des effets secondaires importants. "Y'a un médicament qui est sorti, dit-elle, et mon médecin m'a dit, on va essayer, j'ai signé les papiers et moi j'ai dit au docteur, si ça donne des malaises, il vaut mieux gérer ça à l'hôpital plutôt qu'à la maison ».

Ces rapports n'empêchent pas certaines considérations médico-religieuses. Par exemple, pour Aïcha, musulmane, il est nécessaire de croire en Dieu pour pouvoir bénéficier de l'efficacité des médicaments. «Dieu, dit-elle, fait que c'est le médicament qui va te guérir, mais si tu ne crois pas, je ne sais pas ».

Thérèse, catholique, est l'une des rares personnes à avoir fait état de rapports conflictuels avec le corps médical. La première fois, c'était à propos d'un médecin qui voulait la renvoyer au Cameroun parce qu'elle était asymptomatique. Elle a dû s'obstiner pour pouvoir rester en France. La seconde fois, cela concernait un différend entre médecins ; l'un voulait la traiter pour son hépatite $\mathrm{C}$ alors qu'un autre le lui déconseillait. À nouveau, elle a dû insister pour pouvoir bénéficier des soins nécessaires.

Thérèse ne conçoit pas d'être soignée sans s'informer et de se soumettre au pouvoir médical. Pour cela elle suit les ateliers et conférences d'une association de lutte contre le sida. Cette volonté d'indépendance et d'autonomie est également présente dans ses autres démarches ; elle a quitté un ACT pour vivre, seule, dans un studio, elle a trouvé un travail, ...

Pour les catholiques et musulmans, le sens de la « guérison » prend des formes différentes. Ainsi, chez Viviane plusieurs signes témoignent de sa «guérison » : elle est encore en vie alors que d'autres en sont morts, et elle va mieux physiquement, et tout cela, «grâce au Seigneur ».

Quant à Aïcha, si elle a eu recours aux lavements d'eau teintée de lettres du Coran, lavements au cours desquels elle récite des sourates et demande à Dieu de la guérir, elle n'envisage pas cette pratique comme exclusive ; elle s'accompagne du traitement médicamenteux prescrit pas son médecin. 
Quant aux rapports des protestants à l'institution médicale, ils oscillent entre attestation et protestation. Ainsi, l'attitude de Roger, presbytérien, âgé d'une soixantaine d'années est très proche de celle de Florentin, catholique, se trouvant dans la même tranche d'âge :

« Je suis âgé, explique Roger, et je suis né avec la conscience de ce qu'est le bien, je suis responsable de ma santé, quand je suis malade je respecte scrupuleusement les recommandations (...) Je ne souffre pas pour la bonne raison que j'essaie de respecter ce qu'on me dit et mon organisme s'adapte au régime du traitement pris ».

Le fait qu'il soit venu en France expressément pour bénéficier des multithérapies, inexistantes au Cameroun, permet de comprendre ce rapport au traitement médical. Cette explication doit cependant être relativisée au regard des pratiques des personnes qui fréquentent des groupes pentecôtistes.

Clément, lui, est dans un entre-deux : d'un côté, il a de très bons rapports avec son médecin qui passe le voir régulièrement et avec qui il discute longuement, et d'un autre côté, il affirme être guéri, sans toutefois donner le sentiment d'être convaincu de cette guérison. Deux aspects de la guérison sont présents dans son discours. En premier lieu, et de la même façon que Viviane, il attribue sa guérison au fait qu'il a pu bénéficier de traitements et qu'il va mieux physiquement. Il faut rappeler qu'à son arrivée en France, les médecins lui ont diagnostiqué une tumeur au cerveau.

«Moi, dit-il, je sais que dans mon cas, je serai guéri parce que y'a peut-être des gens qui sont dans la même situation que moi et qu'en ce moment, ils n'ont pas le privilège d'être soignés, y'a des gens à Paris qui sont malades, qui ont le virus du sida mais qui ne se font pas soigner et qui sont morts ». Plus tard, il ajoute, «vous parlez avec moi, est-ce que celui qui souffre peut parler, je suis guéri, y'a des gens qui sont dans le même état que moi, montez au premier, vous allez voir, ils ne peuvent pas marcher, ils sont sur des béquilles, moi je marche, je vais en ville, je vais chercher du travail, c'est que je suis guéri ».

Le second aspect de la guérison est à attribuer à un acte de foi. Pour obtenir une guérison «miraculeuse », tel que cela est mentionné dans la Bible, un acte de foi est exigé du fidèle. Clément y croit mais il sait qu'il n'est pas (encore) dans ce cas de figure ou plutôt, il sait qu'il doit affirmer être guéri pour qu'un miracle se produise ; c'est la raison pour laquelle son discours est si alambiqué.

«Moi, explique t-il, pour le moment, je ne suis pas encore guéri, pour moi, je confirme, je sais que c'est par la foi donc je sais que je suis guéri (...) si tu dis que tu n'es pas guéri, tu ne seras jamais guéri, y'a des gens, qui disent j'ai mal à la tête, tu seras toujours malade, il faut dire, je suis guéri, parce que je vous ai montré tout à l'heure, dans le livre des Hébreux, que la foi c'est la ferme assurance des choses qu'on ne voit pas et la démonstration de celles qu'on espère donc ceci étant, moi j'ai la foi que Jésus m'a guéri, quelle maladie 
Jésus ne peut pas guérir, c'est lui qui nous a créés ». Et d'ajouter, «pour ma part, Dieu, il a un plan pour moi, peut-être qu'il va me guérir demain, mais ce que je sais, c'est que je suis déjà guéri ».

Avec Rose, on se trouve dans un registre beaucoup plus protestataire. En ce sens, la référence au groupe d'appartenance éclaire sur le type de rapport que l'individu entretient avec la société globale. Ainsi, alors que Clément est dans un groupe baptiste africain, Rose fréquente également un groupe africain mais pentecôtiste. Appartenant au protestantisme « historique », le baptisme est moins dans une logique protestataire que le pentecôtisme, notamment celui de la troisième vague ${ }^{91}$; on va le voir à travers les croyances et pratiques de Rose. L'appartenance à un milieu social plus populaire (Rose était ouvrière en Côte d'ivoire et aide à domicile en France) permet aussi de comprendre un rapport plus émotionnel à la religiositéé .

Après un séjour de six mois à l'hôpital où elle a été traitée pour un fibrome, elle rencontre une « filiale » du groupe religieux dans lequel elle était en Côte d'Ivoire. Un jour alors qu'elle se rend à une croisade, le leader de cette église prophétise :

«il disait que en ce moment précis, parmi tous ceux qui étaient dans la salle, y'avait des personnes qui étaient séropositives et que le Seigneur leur donne aujourd'hui une grâce, qu'il les guérissent ».

Quelques temps plus tard, au cours d'une assemblée, la femme du prophète a une vision : elle voit Rose attachée dans un cercueil. Cette vision signifie qu'un acte de sorcellerie a été commis et elle décide de la délivrer de ce sort. Rose raconte la suite de la séance :

«Elle (la femme du prophète) est venue, elle m'a appelée et m'a imposé les mains, je suis tombée, l'Esprit de mort avait pris la place, et elle a prié, prié, prié, prié, et quand je suis revenue un peu, elle m'a dit maintenant on est dans la délivrance et quand je suis partie pour la délivrance, les gens ont prié pour moi, prié pour moi, et l'Esprit de mort m'a quitté ».

\footnotetext{
91 - Traditionnellement, le pentecôtisme s'est développé à travers le monde au cours de trois phases : la première vague remonte au début du $\mathrm{XX}^{\mathrm{e}}$ siècle, à la naissance du mouvement ; la seconde apparaît au cours des années 1950 , et la troisième au cours des années 1970. Cette dernière vague se caractérise, selon F. Laplantine, par un prosélytisme très fort, intégrant un «audiovisuel religieux national » largement inspiré de la pratique des télévangélistes nord-américains. Ces mouvements n'entretiennent plus aucune relation avec le protestantisme historique européen et nord-américain. Ils s'affirment comme internationaux, mondiaux universels. «Ils procèdent à l'inversion du courant missionnaire qui va aujourd'hui des pays d'Amérique latine vers les États-Unis ainsi que vers l'Europe, l'Afrique et 1'Asie », F. Laplantine, « Maladie, guérison et religion dans les mouvements pentecôtistes latino-américains contemporains », Anthropologie et Sociétés, 1999, vol. 23, n² 2, p. 104.

92 - Cet argument doit être relativisé au regard des analyses faites des groupes privilégiant la dimension émotionnelle. Pour D. Hervieu-Léger, ces groupes véhiculent une dimension protestataire « contre l'encadrement bureaucratique de l'expérience croyante personnelle. Ce sursaut du sujet contre l'organisation, poursuit cet auteur, correspond bien aux tendances culturelles de la modernité avancée, centrée sur le droit de l'individu à la subjectivité, y compris en matière religieuse. Il n'y a pas lieu de s'étonner, dans ces conditions, de ce que ces communautés émotionnelles attirent, de façon privilégiée, des éléments des classes moyens intellectuelles et techniciennes, dont on sait qu'elles sont les plus sensibles à la thématique tout à fait moderne de l'accomplissement personnel et du droit au bonheur », D. Hervieu-Léger, «Renouveaux émotionnels contemporains. Fin de la sécularisation ou fin de la religion ? », De l'émotion en religion. Renouveaux et traditions, D. Hervieu-Léger, F. Champion (éds), 1990, Paris, Centurion, p. 244.
} 
Au cours de cette délivrance, la femme du prophète signifie que la propre mère de Rose serait à l'origine de cet acte de sorcellerie.

Rose explique, « quand je suis partie à la délivrance, quand on m'avait imposé les mains, pour chasser les démons qui étaient en moi, son esprit (celui de la mère de Rose) a parlé en moi, elle s'est dénoncée (comme sorcière), c'est là que les gens l'ont chassée, Esprit impurs sors d'elle, sors d'elle, sors, sors, son corps ne t'appartient pas, c'est le temple de Dieu, allez sors, et on a invoqué le sang du Saint Esprit, on a évoqué le feu du Saint Esprit et c'est comme ça qu'elle est partie, aujourd'hui je me sens libre ».

Victime d'un acte de sorcellerie, Rose se voit délivrée de ce sort par la femme du prophète. Cette délivrance s'effectue au cours d'une cérémonie particulièrement intense sur le plan émotionnel où des gens sont pris de convulsions et tombent à terre. Elle signifie que Rose est délivrée de tous ses maux et notamment du VIH. Celle-ci ira effectuer des tests auprès d'un hôpital qui constatera d'une part que ses défenses immunitaires sont revenues à un seuil «normal» mais surtout que sa charge virale est devenue indétectable. Ces résultats, Rose les interprète de la façon suivante :

«Dieu m'a fait une grâce, la grâce qu'il m'a faite c'est que le test est indétectable et il n'y a plus de virus dans le sang circulant, vous ne croyez pas que c'est une grâce de Dieu ? Y'a des gens qui meurent nuit et jour pour cette maladie, et moi à cause de ma croyance, aujourd'hui, je suis délivrée de ça, j'ai rendu témoignage de ça dans mon église, et moi, je leur ai dit que je crois que Dieu peut me guérir, et il m'a dit déjà guérie, je crois qu'il m’a guérie, pas qu'il peut me guérir, mais qu'il m'a guérie ».

Pour Rose, cette guérison témoigne de la toute puissance de Dieu.

«C'est vrai, dit-elle, que les médecins soignent, ils font tout, mais à Dieu seul la décision, c'est Dieu qui donne ça, il a toujours le dernier mot, c'est quand il veut, ça marche, s'il ne veut pas, c'est sa volonté qui compte quoi, donc tout de suite j'ai placé ma foi en Dieu ».

Le comportement de Rose est cependant ambiguë car d'un côté elle affirme qu'elle ne mettra pas de préservatif lors de relations sexuelles avec son futur mari, et de l'autre elle continue à prendre ses médicaments. Dans le premier cas de figure, elle tenait les propos suivants :

«moi, j'ai la foi, je sais que je suis guérie, et le jour où je croiserai l'homme de ma vie, je sais que je n'ai pas besoin de préservatif parce que je sais que je ne peux pas le contaminer parce que je suis guérie ».

Quant au fait de prendre son traitement médicamenteux, elle précise qu'il s'agit d'un choix momentané, pouvant évoluer au gré des prophéties divines : 
«En ce moment, explique t-elle, je continue à les prendre parce que le médecin m'a dit de continuer mes traitements, et moi je sais que comme mon Dieu est un Dieu fidèle, et que de part son Esprit Saint, il nous parle, il parle à sa servante, à ses serviteurs dans l'Église, je sais qu'un jour la prophétie va sortir du Seigneur, ma fille arrête de prendre les médicaments, et là, je vais arrêter de prendre les médicaments, parce que ça vient de Dieu, moi, je ne fais rien maintenant en dehors de la parole de Dieu, tout ce que je fais maintenant, il faut que ça vienne de Dieu, sinon je ne le fais pas ».

Rose n'hésite pas à jeûner quand son église le demande et à interrompre son traitement médical durant cette période.

«Quand on a un problème dans l'Église, dit-elle, toute l'Église jeûne, donc je jeûne, ça peut durer trois jours, ça peut durer dix jours, je jeûne, et là je ne prends pas mes médicaments, parce que quand tu jeûnes, tu n'as pas le droit de prendre quelque chose et là je ne prends pas mes médicaments mais quand je finis mon jeûne, je continue mon traitement ».

L'attitude de Rose est partagée entre deux impératifs : fidélité et soumission à une autorité (divine et/ou ecclésiale), et respect des clauses tacites du contrat qu'elle a avec l'association qui l'héberge. Le groupe auquel appartient Rose relève apparemment du type secte ${ }^{93}$; en ce sens, il exige de ses fidèles la reconnaissance d'une autorité absolue qui se traduit souvent par une rupture avec le «monde ». Par ailleurs, au sein de ces groupes, il y a une absolutisation de l'expérience du sensible où la guérison annonce l'imminence du retour du Christ, l'imminence du temps où Satan sera définitivement vaincu ${ }^{94}$.

Dans l'absolu, la « guérison » de Rose impliquerait l'arrêt des traitements médicamenteux. Son appartenance à l'association qui gère l'Appartement de Coordination Thérapeutique dans lequel elle vit, l'empêche, quelque part, de s'engager totalement dans cette voie. En effet, dans le cadre des ACT, les personnes sont suivies par des médecins, psychologues, et assistantes sociales, lesquels insistent sur la nécessité de suivre les traitements prescrits par le praticien hospitalier, et ce tant pour des raisons sanitaires qu'idéologiques (cf. un nombre important d'étrangers entre dans la phase sida car ils n'ont pas suivi un traitement médicamenteux). Par ailleurs, Rose sait qu'elle ne peut atteindre les objectifs qu'elle s'est donnée (avoir un titre de séjour lui permettant de travailler, faire venir ses enfants en France, ...) sans compromis avec la société globale.

Le cas de Rose est relativement isolé parmi les personnes que l'on a interviewées. Et pourtant, il est la quintessence de ce que d'autres vivent sur un mode plus euphémisé : une réappropriation symbolique des corps. Corps physique : volonté de ne pas se «soumettre » au

\footnotetext{
93 - Selon J.-P. Willaime, Les trois caractéristiques du groupe religieux, de type secte, sont les suivantes :

1) rupture plus ou moins radicale par rapport au monde environnant ;

2) reconnaissance et soumission à une autorité religieuse absolue ;

3) le groupe religieux est considéré comme une association volontaire de personnes religieusement qualifiées. Cf. J.-

P. Willaime, «Les définitions sociologiques de la secte », in F. Messner (éd.), Les sectes et le droit, 1999, Paris, P.U.F., 21-46.

94 - F. Laplantine, «Maladie, guérison et religion dans les mouvements pentecôtistes latino-américains contemporains », Anthropologie et Sociétés, 1999, vol. 23, n² 2, p. 101-115.
} 
corps médical. Au corps allongé et immobile des séjours hospitaliers s'oppose le corps frénétique et en mouvement des cérémonies religieuses pentecôtistes. Corps social : à l'isolement social et familial dans lequel vivait Rose à son arrivée en France a fait place une communauté de frères et sœurs, chaleureuse, solidaire et unie.

\section{Conclusion}

L'engagement spirituel des personnes originaires d'Afrique subsaharienne peut être interprété, pour certains d'entre eux, comme une forme de réappropriation symbolique de leur histoire. Pour la plupart démunis de tout, à leur arrivée en France, ex-pays colonisateur, ils ont dû passer par différents services sociaux. Au regard des propos tenus par certains usagers d'associations, le travailleur social peut être envisagé, à l'instar de J. Bodart, comme un " néoclerc »dont les préoccupations (sens de la vie, de la relation, du vécu, ... de ses « clients») l'amènent à une quête d'un " sacré humain » ${ }^{95}$. Il faut toutefois mesurer les incidences d'une telle quête ; elle peut être vécue comme une entreprise de «dépossession » pour ceux qui sont de l'autre côté de la barrière. La religiosité serait alors un moyen de retrouver une dignité voire une reconnaissance sociale. Ce besoin de reconnaissance est d'autant plus criant que ce personnes savent que leur retour au pays est plus qu'improbable.

Les croyances et pratiques proposées par certains groupes religieux, notamment des groupes évangéliques protestants, peuvent également être envisagées comme une forme de réappropriation symbolique du corps, libérant des contraintes imposées par le corps médical.

L'engagement spirituel permet de sortir d'un certain isolement social, notamment pour ceux qui sont sans travail et vivent en Appartement de Coordination Thérapeutique, et de maintenir un lien symbolique avec le pays d'origine voire avec ceux qu'ils ont laissé sur place (cf. des liens de parenté peuvent ainsi être maintenus). Conserver la même religiosité que celle du pays d'origine donne un sentiment de continuité et de familiarité, sentiment d'autant plus important à préserver que le retour au pays ne peut pas être envisagé (cf. les moyens médicamenteux y font défaut).

95 - J. Bodart, «Modernité et néo-clercs. À partir de l'image de soi du travailleur social », Social Compass, 1982, vol. XXIX, n 4, p. 283-295. 


\section{III . Les ruptures religieuses}

$\mathrm{Au}$ sein du troisième groupe, la plupart des personnes se trouve dans une situation de « rupture » religieuse, en faisant le choix d'une spiritualité différente de leur héritage religieux. L'annonce de la contamination au VIH-Sida est souvent à l'origine de cette quête spirituelle. On reprendra le plan suivi pour les deux groupes précédents : après avoir présenté le parcours spirituel de certaines personnes, on s'intéressera au sens de la maladie puis aux pratiques religiothérapeutiques.

\section{1 . Les parcours spirituels}

Au sein de ce groupe, on peut dégager trois ensembles : le premier envisage le thème de la maladie initiatique, le second de la sécularisation de la spiritualité, et le troisième de l'engagement « total ».

\section{La maladie initiatique}

Dans certains groupes sociaux, l'expérience de la maladie est envisagée comme une initiation au monde supra-empirique ; cette expérience confère à ceux qui l'ont vécue des pouvoirs dont ils peuvent se servir pour en soulager d'autres. La maladie devient initiatique dans le sens où elle légitime l'accès à des pouvoirs thérapeutiques. Fréquemment observée en Afrique $^{96}$, l'initiation thérapeutique est également observable dans d'autres cas de figure. Ainsi, dans le cadre de la présente étude, il a été possible de rencontrer des personnes qui voulaient devenir psychothérapeutes, et ce suite à leur expérience du VIH. On présentera trois portraits sur les cinq personnes qui se trouvent dans cette situation.

Julien est la seule personne de l'étude à ne pas avoir de religion d'origine ; son père était athée. L'annonce de la contamination au VIH intervient en 1988. Sa première réaction est de se tourner vers les thérapies parallèles ; il consulte différents thérapeutes dont un radiesthésiste et prend le parti de ne pas prendre de traitement médicamenteux. Il continue toutefois à faire des examens biologiques.

Au milieu des années 1990, différents évènements vont bouleverser sa vie. En premier lieu, son entreprise déménage dans le Sud de la France. Là-bas, il se retrouve face à un médecin hospitalier dont il n'apprécie guère les méthodes de travail.

« Je suis tombé sur la caricature du médecin, dit-il, comme si c'était fait exprès (...) Il me donnait à peine un quart d'heure de temps, et encore, il fallait enlever les coups de fil et en plus de ça, il a cherché à m'entuber parce que je lui avais dit que je ne voulais pas d'AZT parce que j'avais lu les rapports sur les contre-indications et l'efficacité plus que douteuse du

\footnotetext{
96 - Ainsi, J. Trincaz souligne le fait que les thérapeutes mancagnes de Casamance (Sénégal) reçoivent le B-Pena (pouvoir divinatoire et pouvoir thérapeutique) par révélation, au cours d'une maladie : «l'élu qui est choisi pour être le réceptacle du B-Pena en reçoit généralement la révélation par la maladie », J. Trincaz, « Le pouvoir thérapeutique des Ba-Pena (Casamance). Initiation et pouvoir libérateur », Psychopathologie africaine, 1975, vol. XI, n 3, p. 325.
} 
traitement, et il m'en a prescrit en me disant qu'il me prescrivait un autre médicament, et en fait c'est la même chose, c'est le nom de la molécule et l'autre c'est le nom commercial, enfin, je suis vraiment tombé sur le mec qui ne pouvait que me renvoyer vers une médecine autre ».

Dans le Sud de la France, il fait la rencontre d'une femme médecin qui le conforte dans son choix de se soigner par les médecines parallèles.

«On m'a mis en contact, raconte-t-il, avec une femme médecin qui a une soixantaine d'années et qui a travaillé avec le dalaï-lama, qui a vécu cinq ans en Inde et qui a eu un traitement complètement différent que je n'avais jamais entendu (...) Cette femme m'a dit, votre premier médecin ce n'est pas moi, c'est vous et ensuite elle m'a dit ayez foi dans la vie qui est en vous, donc dans le mot foi il y avait le mot vie, ça a bien résonné et les consultations duraient vachement longtemps (...) Y'avait cette écoute dont j'avais vraiment besoin, qui était un peu maternant, là, je me sentais exister et je ne prenais pas de traitement, et elle me disait on va voir, on va refaire des analyses, on va essayer d'autres choses donc là, je me sentais en confiance (...) Je pense que elle, ce qui la souciait, c'était vraiment de travailler sur ce capital confiance que j'avais dans la vie, dans ma capacité de m'en sortir, de changer mon système de référence, d'arrêter de me dire qu'être séropo ça voulait dire terminer ta vie avec un traitement ou de toute façon, à terme, à l'époque c'était entre quatre planches ».

Cette femme lui recommande des retraites dans un centre bouddhiste (tibétain); il va y faire un bref séjour qu'il apprécie car les pratiques (méditation) sont simples et épurées mais aussi parce qu'il y règne une certaine tolérance; le pluralisme des croyances est accepté. Il a cependant un rapport très pragmatique à la spiritualité ; il s'approprie des pratiques et/ou techniques utilisées sans pour autant s'investir dans un groupe particulier.

En 1996, Julien va suivre les stages de Niro Assistent ${ }^{97}$, une femme qui dit s'être « séronégativée ». Il retient de cette expérience la notion de «changement de paradigme »; il s'agit de prendre une position différente face à la vie, de l'envisager autrement qu'un combat. D'un point de vue thérapeutique, cela signifie que le VIH n'est pas un virus à combattre mais un hôte à recevoir. Pour parvenir à ce type de conception, Julien doit pouvoir dépasser la crainte/peur de la mort. Il y parvient au cours d'un séjour dans un centre bouddhiste :

«j'étais épuisé, dit-il, j'étais à bout, je n'en pouvais plus, c'était bien que ça se passe là-haut (dans le centre), quand je suis arrivé j'ai cherché à faire de la médiation dans la nature, pour me recharger et puis en fait rien ne réussissait,

\footnotetext{
97 - Niro Assistent est une américaine qui dit s'être « séronégativée ». Découverte séropositive en 1985, cette femme s'est créée un «programme de guérison» où elle «transforme ses émotions en force et en acceptation d'elle même »; un an plus tard, elle dit être devenue séronégative. Dans son ouvrage, Comment je me suis guérie du sida, elle s'inspire principalement des techniques de Osho Rajneesh. Leader d'un groupe religieux, Osho Rajneech enseignait et pratiquait la méditation. Il fonde, au début des années 1980, une communauté de fidèles, aux EtatsUnis. En 1985, il est arrêté et expulsé après avoir été condamné à dix ans de prison. Il décède cinq ans plus tard, en 1990.
} 
c'était toujours le même vide, la même envie de se laisser aller, je n'avais plus d'énergie et je me suis dit le seul truc à faire c'est de rentrer et tu t'allonges, donc je retourne dans ma chambre et là j'ai vraiment la surprise, je me suis vraiment laissé aller, et ça a duré 3-4 heures, je me suis dis la seule chose que tu as à vivre c'est ça, Niro disait toujours d'accueillir ce qui venait, donc je me suis dis accueille ça, et en fait je me suis rendu compte que j'étais en train d'accueillir, quand je dis j'accueille, j'étais convaincu que c'était ça quoi, que j'étais en train de mourir, et donc cette espèce de relaxation, de méditation, de lacher-prise complet a duré 3-4 heures, évidemment après je me suis dis il n'y a pas de raison que je meurs, mais quand je me suis réveillé et que je suis revenu à la vie et je me suis rendu compte que là, ce que j'avais dépassé c'était ma peur de la mort, tu vois c'était vraiment initiatique parce que j'avais vraiment accepté ce truc de «OK, je meurs, je l'accepte, je meurs » et réellement tout mon corps a dit « oui, je meurs », et donc ça c'était vraiment une étape essentielle dans mon parcours ».

Quelques temps plus tard, en 1997, Julien décide de quitter son entreprise ; il bénéficie d'un congé qui lui permet d'entreprendre une formation de naturopathe. Il ne poursuivra pas dans cette voie qu'il estime trop technique. Il poursuit néanmoins ses investigations dans le champ des médecines parallèles et de la spiritualité : chi qong, méditation, macrobiotique, produits Beljanski $^{98}, \ldots$

Après avoir dépassé sa peur de la mort, Julien parvient à ne plus craindre la maladie en vivant, à nouveau, une expérience corporelle. Lors d'un séjour en Bretagne, après avoir fait un jeûne, il se sent revivre.

«Tous les médecins que je voyais à l'hôpital à l'époque, parce que j'en voyais encore à ce moment-là, ils me disaient que j'étais fou d'avoir fait une expérience de jeûne et que les expériences n'ont jamais montré qu'on n'a jamais vu personne aller mieux avec ça, j'avais remarqué que quand je faisais des jeûnes, ma charge virale descendait, ma charge virale revenait à zéro, les T4 ça ne changeait rien mais en tous les cas ma charge virale descend et là ça a vraiment été une deuxième prise de conscience, après le dépassement de ma peur de la mort, là, ça a été vraiment le dépassement de la peur de la maladie parce que là, je me suis dis écoute il y la vérité des médecins, si tu les écoutes, tu n'es pas dans quelque chose de juste puisque eux te prédisent que tu vas tomber malade ne serait-ce qu'en faisant un jeûne, là, ils ont eu tort, tu vois, donc je me suis dit, sois tu choisis de les écouter, d'écouter la vérité scientifique qui est extérieure à toi, ou alors tu choisis d'écouter ton expérience et tu ne sais pas où elle va te mener, c'est vrai que je ne sais toujours pas à l'heure d'aujourd'hui ».

\footnotetext{
98 - Le biologiste Mirko Beljanski a mis au point différents médicaments permettant de traiter le VIH/Sida et le cancer mais qui sont très controversés au sein de la communauté scientifique. Ainsi, écrivent B. Paillard et A. Guérin, le Pao pereira, l'un des médicaments de Beljanski, ne deviendrait efficace en tant qu'antiviral que lorsqu'il est administré à fortes doses c'est à dire à des doses toxiques, B. Paillard, A. Guérin, Médecines parallèles et sida, Paris, rapport ANRS, 1999, p. 150.
} 
Julien est conscient d'un risque de déni de la maladie. Pour l'éviter, il continue à faire des examens biologiques et se fait suivre par un psychiatre. De ce dernier, il disait :

«Lui, il est très cartésien et il me dit, tu n'as pas fini de perdre tes illusions, tu cherches le boulot idéal, l'endroit idéal, le truc idéal, et il me dit ça n'existe pas, enfin bon, mais je sais pas dans quelle mesure il me dit ça pour me pousser dans mes retranchements, me mettre en face du danger que représente cette démarche, en tous les cas ça me fait vachement avancer parce que chaque fois que je sors de là je suis un peu déconstruit et ce fait de déconstruire, par contre ça me renforce, parce que si après je connais le message, c'est qu'il y a quelque chose de solide derrière ».

Étant dans une recherche constante, de soi et de son rapport au monde, la reconversion professionnelle de Julien n'est pas encore faite. Il anime des ateliers d'expression théâtrale et de réflexion dans une association de lutte contre le sida; il intervient également dans des conférences axées sur le bien-être, ... Par ailleurs, au moment de l'entretien, il était dans l'attente d'une réponse pour pouvoir suivre une formation d'art thérapeute.

Diane est la seule femme a vouloir devenir psychothérapeute. Agée d'une trentaine d'années, elle est élevée dans une famille catholique. À l'adolescence, elle prend ses distances avec la religion. Son retour à la spiritualité commence aux débuts des années 1990, après le décès de son ami.

Diane se sait séropositive depuis 1989, lorsque son ami, avec qui elle vivait depuis une dizaine d'années, déclare le Sida. En 1993, elle est hospitalisée pour une dépression, suite au décès de son ami. Là, une infirmière lui parle de spiritualité et la met en contact avec des voyants. Réticente au départ, Diane est ensuite convaincue que ces voyants ont des « dons ». Ils vont lui permettre de faire le deuil de son ami.

Ces voyants, dit-elle, «me rassuraient sur le fait que je savais que mon ami, là où il était, était heureux, en fait c'était ça, je n'arrivais pas à faire le deuil parce que je le pleurais, et je pensais qu'il était hyper malheureux et eux, ils m’ont montré qu'il était bien là où il était » (...) «On dit toujours, poursuit Diane, qu'il ne faut pas pleurer les morts parce qu'on les retient sur terre, que leur âme n'arrive pas à évoluer, que plus on pleure quelqu'un moins il évolue, et ça ce n'est pas pour eux, en fait, il faut penser que eux sont bien, là où ils sont, et il faut être heureux pour eux ».

Diane parvient à faire le deuil de son ami au cours d'expériences inédites où elle « communique » avec les morts.

«Moi, dit-elle, j’ai communiqué avec lui (son ami), chose en quoi je ne croyais pas du tout avant (...) deux-trois fois j'ai communiqué avec lui et là j'ai dit ok, c'est bon, et puis j'ai fait un voyage astral, je me suis vue sortir de mon corps, mon arrière grand-mère, qui est décédée, est venue me chercher, 
j'en ai des frissons, elle m'a prise par la main et j'ai traversé la terre, moi je disais, à la vitesse de la lumière, mais en fait, c'est la vitesse de la pensée, je me suis vue partir de là, à mon balcon, c'était en pleine nuit, j'ai donc traversé toute la terre, et je suis arrivée dans un endroit lumineux et j'ai vu mon copain qui était là, debout, il était rayonnant, c'était une lumière en fait, et il souriait, et il me regardait d'un air de dire, tu vois je suis heureux ».

Étant parvenue à faire le deuil de son ami, Diane va également dépasser sa peur de la mort à travers ce qui est convenu d'appeler, dans le milieu du New Age, une expérience proche de la mort (Near Death Experience).

«Une fois, raconte-t-elle, je suis tombée dans le coma, et vous savez, les gens qui tombent dans le coma, ils parlent tout le temps d'une grande lumière, un grand couloir avec une grande lumière au bout, et effectivement je l'ai vue, et vous êtes attirée par cette lumière, vous avez envie d'y aller, et vous vous sentez bien, et donc je suis allée vers cette lumière et j'étais bien, j'ai jamais été aussi bien de ma vie, et en fait, ce sont les pompiers qui m'ont ranimée et je me suis réveillée, ils me faisaient un massage cardiaque, ils me faisaient vachement mal, je leur ai dit, attendez, pourquoi vous ne m'avez pas laissé partir, j'étais bien là-bas, j'ai vu la lumière, c'était beau, je me sentais bien, et donc là, j'ai conclu que c'était ça la mort, en fait que la mort n'était qu'un passage, et qu'on allait vers cette lumière où on se sent bien, où tous les gens sont plein d'amour, et c'est beau, je vous assure, vous vous sentez bien, c'est incroyable ».

Diane estime que sa démarche spirituelle lui a permis de sortir de la drogue. Toxicomane depuis l'âge de dix-sept ans, elle a plusieurs fois tenté d'arrêter mais sans succès.

«J'ai réussi à arrêter, explique-t-elle, parce que je crois en Dieu, et parce que je crois en une force énergétique qui nous guide, et j'ai arrêté du jour au lendemain alors que ça faisait seize ans que je me droguais ».

Progressivement, Diane s'investit dans ce milieu et quand, en 1995, elle entre dans la phase Sida, elle décide de recourir aux médecines parallèles pour se soigner. L'Énergie Universelle, technique proche du reïki, censée équilibrer et harmoniser les énergies qui circulent dans le corps, lui apporte, selon ses propos, un réel mieux-être ; elle poursuit dans cette voie en multipliant les stages dans le milieu du New Age : ostéopathie, acupuncture, homéopathie, radiesthésie, chromothérapie, reïki, chi-qong, tarologie, astrologie, .... Elle gère aussi les effets secondaires de sa trithérapie par la radiesthésie. Pour Diane, cette démarche a vraiment été salvatrice car c'est à partir de là, dit-elle, que sa charge virale est devenue indétectable.

«En fait, moi, j’ai déclaré le sida mais je suis redevenue asymptomatique, et je suis sûre que c'est par cette démarche des médecines parallèles ».

En arrêt maladie depuis 1993, Diane va bénéficier, à partir de 1996, d'une pension invalidité. Cela lui permet de suivre différents stages de médecines parallèles et de se constituer 
un réseau informel de connaissances. Elle met en pratique les techniques acquises au cours de ces stages mais elle en maîtrise mal tous les aspects car elle a tendance à prendre sur elle le mal des autres. En faisant des séances de reïki, dit-elle,

« je sentais la douleur des autres et elle ne partait pas, donc je faisais un soin aux autres mais moi, après, j'étais mal, et donc là, on vous apprend à vous protéger, de sentir les énergies des autres mais de ne pas les ressentir en vous, de ne pas les garder, chose que je ne savais pas faire, donc moi je trouve ça génial, et puis bon quand je transmets des énergies, je sens tout mon corps, je sens plein d'énergie dans mes mains, partout dans mon corps, j'aime bien cette sensation, je trouve ça génial ».

Elle apprend progressivement à maîtriser la technique et se met à la disposition de sa famille, de ses amis et d'autres connaissances pour leur faire bénéficier de ses « dons »(elle ressent la présence des esprits, âmes ou autres par des frissons).

« Je fais ça à mon entourage, ma famille, l'été, quand je vais les voir, je suis réquisitionnée de tous les côtés, oui je veux une séance de reïki, mais souvent ce sont des personnes qui n'étaient pas du tout au courant, qui ne connaissaient pas, et finalement elles trouvent ça génial, c'est vrai qu'après, vous êtes apaisé, vous n'êtes plus stressé, les énergies circulent bien dans votre corps, et non c'est vraiment très bien ».

Diane dissocie deux types de pratique, celles pour lesquelles elle ne peut pas se faire payer (transmission d'énergie) car il s'agit d'un don qu'elle ne peut monnayer, et celles où elle peut être rémunérée (massage de relaxation) car il s'agit de pratiques purement techniques ne faisant pas intervenir d'énergie divine.

Actuellement, Diane suit une formation pour obtenir un professorat de chi-qong. Son objectif est d'ouvrir un cabinet de psychothérapeute et de mettre en pratique l'ensemble des techniques et connaissances qu'elle a apprises ces dernières années.

Le dernier cas de figure sera illustré par Xavier. Âgé d'une quarantaine d'année, il a été contaminé au VIH par voie intraveineuse. Toxicomane durant treize ans, il décide d'arrêter en suivant le programme des Narcotiques Anonymes. Il découvre sa séropositivité alors qu'il a trois mois d'abstinence. Il décide néanmoins de poursuivre ce programme et s'y investit sans compter. Durant plusieurs années, il se rend quotidiennement aux réunions organisées par ce groupe. Il va être le parrain de plusieurs centaines de filleuls ${ }^{99}$. Au milieu des années 1990, il décide de se retirer de l'organisation du mouvement mais continue à assister aux réunions car son témoignage (quinze ans d'abstinence) est important pour les nouveaux venus. Il envisage sa présence au sein de ces groupes de la manière suivante :

\footnotetext{
99 - «Chaque nouveau est invité à prendre un parrain dans la 'fraternité' Narcotiques Anonymes, ce parrain ayant plus de temps d'abstinence », M. Jauffret, «L'auto-support des usagers de drogues en France », Toxibase, 1997, $4^{\mathrm{e}}$ trimestre, p. 18.
} 
Il s'agit « de redonner aux autres, parce qu'on m'a sauvé la vie quelque part, gratuitement ».

Le programme de Narcotiques Anonymes, fait de douze étapes, contient une dimension spirituelle dans le sens où l'individu reconnaît l'existence d'une puissance supérieure et s'en remet plus ou moins à elle. Chacun est libre de concevoir cette puissance supérieure comme il l'entend. Pour Xavier, issu d'un milieu catholique, cette puissance prendra le nom de Dieu. Il raconte la manière dont il est parvenu à se sevrer de la drogue :

« J'étais complètement barré spirituellement c'est à dire que je voyais Dieu partout, quand j'ai arrêté de me droguer, je voyais Dieu partout, je priais énormément ». Puis, d'expliquer, «moi, j'ai eu la chance de ne plus avoir eu envie de consommer, je n'ai plus jamais eu d'obsession à consommer de la drogue et pour moi, ça, c'est vraiment Dieu ou une puissance supérieure, c'est vraiment une volonté plus forte que la mienne qui m'a enlevé ça, parce que moi, ma volonté, en tant que toxicomane c'est de consommer, et moi j'adore la drogue, et toujours aujourd'hui, je trouve ça très très bon, je n'ai aucun dégoût de la drogue bien au contraire, mais je sais que pour moi ça ne fonctionne plus ».

Cet « éveil » spirituel ne se traduit pas par un retour à sa religion d'origine.

«Je n'aime pas tellement la religion (catholique) qu'il y a autour en fait, je trouve qu'elle est extrêmement restrictive, culpabilisante, enfin tous les reproches qu'on peut faire à l'église, je peux les faire aussi, et je ne me suis pas senti à l'aise dans le cadre de l'Église ».

Par contre, il sera tenté par le bouddhisme (il fait une retraite spirituelle) et l'hindouisme mais il ne s'engagera dans aucune de ces religions. En fait, il préfère ne pas s'inscrire dans un cadre religieux (organisationnel) précis ; il pratique quotidiennement la prière de méditation et se satisfait de cette situation.

Xavier s'est aussi engagé dans le milieu associatif. Ainsi, il fait partie d'une association qui se donne pour objectif d'affirmer la masculinité de l'homme et qui considère que la difficulté de vivre, de certains hommes, tient en partie au fait qu'ils ne trouvent plus leur place au sein d'une société en perpétuelle mutation. À travers des rites d'initiation et des stages, organisés par Xavier, certains parviennent à reconstruire une identité masculine blessée.

D’un point de vue médical, les premiers contacts établis par Xavier avec des médecins sont, pour lui, insupportables. Un premier lui annonce, on est en 1986, qu'il a une espérance de vie de cinq ans ; un autre le «menace » plus ou moins en lui disant que s'il ne prend pas d'AZT, il risque de mourir.

Finalement, « je me suis dit, moi, je vais bien, donc si aujourd'hui je vais bien, je n'ai pas de raison de me dire que je vais mourir et donc j'ai décidé de vivre ça vingt-quatre heures à la fois, parce qu'il y a des outils à NA qui est de 
vivre un jour à la fois (...) J'ai été voir quelques médecins au départ, et j'ai fait des tests, des machins et en fait, j'ai essayé de suivre mon intuition, on n'avait pas beaucoup de données et la seule chose que je voyais c'est qu'à chaque fois que je voyais des médecins, c'est que je ressortais et j'avais peur, c'est à dire qu'ils me mettaient une pression qui était assez dure, très vite, ils ont voulu me donner de l'AZT que j'ai refusé parce que j'avais beaucoup de gens autour de moi qui prenaient de l'AZT et qui avaient des séquelles énormes et puis j'en ai vu beaucoup mourir aussi, j'ai quand même perdu dixsept amis du sida, en une dizaine d'années ».

Partant du constat que le modèle allopathique ne peut pas grand chose pour lui, Xavier se tourne vers les médecines parallèles. Il essaye un peu tout ce qui se fait dans le domaine : digipuncture, étiopathie, ostéopathie, homéopathie, ... Certaines expériences l'ont convaincu, d'autres moins ; il dit avoir dépensé une fortune pour bénéficier de ces soins. Toujours dans une logique alternative à l'institution médicale, il décide, avec sa femme séronégative, d'avoir un enfant, et ce en dépit des risques encourus.

«On est allé voir divers médecins, dit-il, on a eu divers conseils et puis finalement on a abouti de le faire comme tout le monde, je dirai, c'est à dire qu'on faisait l'amour à des moments bien précis où elle était fécondable, on calculait la courbe des températures et donc on a fait un enfant, qui a cinq ans maintenant et qui est magnifique, qui est très bien, et ma femme n'a jamais eu de problèmes (...) On a eu cette grâce et puis c'était un risque à courir mais c'est vrai qu'à l'époque on avait tellement confiance dans ce qu'on faisait que ce n'était pas un risque quelque part, y'avait un risque potentiel mais on était vraiment conscients et confiants de ce qu'on faisait donc je pense que c'est pour ça que ça s'est si bien passé ».

En 1999, après l'opération d'une hernie, Xavier sort de l'hôpital mais ne se sent pas bien ; il a des maux de tête et est pris de vomissements. Les médecins qu'il consulte lui donnent divers traitements sans qu'il soit soulagé. Finalement, il décide de se rendre à l'hôpital où on lui diagnostique une méningite à cryptocoques. Il devient sourd, aveugle et paralysé. À la suite de ça, il fait un cytomégalovirus. Durant deux mois, il est entre la vie et la mort avec deux malheureux T4 et perd une trentaine de kilos. Cet épisode l'a beaucoup interrogé :

«ça m'a appris beaucoup de choses, la première chose importante c'est que j'étais vraiment face à ma mort, alors moi si vous voulez, historiquement, ne serait-ce que les quinze dernières années j'ai été énormément confronté à la mort (...) j'ai perdu dix-sept personnes autour de moi, donc c'est quelque chose qui m'a interrogé parce que quand on voit mourir les gens, on les accompagne dans la mort, parce que moi je les ai vraiment accompagnés, pas tous, mais y'en a beaucoup que j'ai accompagnés jusqu'au bout, ça m'a évidemment interrogé sur ma propre mort. (...) Là, tout d'un coup j'étais de l'autre côté de la barrière c'est à dire que c'était moi qui était confronté à la mort et là, c'était en direct parce que je voyais bien que je mourrais, je le voyais sur mon corps, je voyais mon corps qui partait, et en fait, sincèrement, 
je n'ai pas eu peur de mourir, c'était très étonnant, je pense que j'avais, entre guillemets, nettoyé ma maison c'est à dire que justement en faisant ces amendes honorables (l'un des principes de Narcotiques Anonymes est de faire la paix avec soi-même et son entourage), j'avais nettoyé le passé, je ne partais pas en me disant, merde, j'ai plein de trucs derrière moi pas résolus, c'est l'enfer (...) ». Xavier prend alors conscience de son envie et de sa volonté de vivre : « je me suis rendu compte, dit-il, que j'avais vraiment envie de vivre et du coup, je me suis accroché à la vie, je me suis vraiment battu, et c'était dur parce que je souffrais énormément, j'étais sous morphine en permanence, ce qui était un paradoxe pour moi qui venait d'un passé de toxicomane, il fallait que je retourne à ça, là, de manière permanente, et malgré cette souffrance, j'avais envie de vivre ». Les nombreuses visites qu'il reçoit, de ses filleuls et amis, de sa famille lui apportent un soutien incommensurable. "Surtout, ajoute-t-il, ce qui a vraiment été extraordinaire, pour moi, c'est que pendant ces quatre mois, j'ai été extrêmement entouré c'est à dire que j'avais des gens en permanence dans ma chambre ».

À la suite de cette expérience Xavier se décide à suivre un traitement antirétroviral. Il s'interroge aussi sur l'opportunité de devenir psychothérapeute. Le thérapeute qui le suit depuis plusieurs années le lui conseille. Finalement, Xavier s'engagera dans cette voie mais un seul jour par semaine ; le reste de la semaine, il continue à exercer son autre métier.

La redéfinition de l'identité professionnelle peut être envisagée à partir de la dépossession du capital socio-économique. Ainsi, Diane envisage une démarche de psychothérapeute après avoir été licenciée de son entreprise. D. Friedman avait déjà observé ce cas de figure à propos de certains « guérisseurs » ${ }^{100}$. Cette explication n'est cependant pas recevable pour tous.

Dans les trois cas de figure présentés, on peut déceler un schéma typique : il s'agit de personnes qui ont vécu une expérience éprouvante du VIH, entrant parfois dans la phase Sida. Ayant frôlé la mort, ces personnes se sentent dépositaires d'un savoir qu'elles veulent transmettre. Cette expérience va leur conférer certains pouvoirs thérapeutiques. La légitimité de ces pouvoirs tient au fait qu'en vivant une maladie grave elles ont accès au monde supraempirique voire à la manipulation de forces supraempiriques. Ne pas suivre de traitement médicamenteux (deux personnes sur cinq) peut augmenter leur légitimité dans la mesure où elles se placent en dehors du système de soins classiques.

Enfin, on notera que les positions adoptées par certaines personnes, notamment le refus de suivre la voie médicamenteuse ou de s'estimer guéri du VIH, sont, sous certains aspects, relativement proches de celles des pentecôtistes. Dans les deux cas de figure, on est face à une protestation qui, selon les individus, prend un sens différent. On ajoutera, avec J. Benoist à propos des médecines douces, « on adopte une thérapie comme on se convertit. L'engagement dépasse l'épisode que l'on entend soigner; il faut suivre des règles et adopter une vision de soi-même, du monde et des conduites à suivre qui n'est pas seulement une hygiène mais bien une morale ${ }^{101}$.

\footnotetext{
100 - D. Friedman, Les guérisseurs. Splendeurs et misères du don, Métaillé, Paris, 1981, 260 p.

101 - J. Benoist, «Les médecines douces », Passions ordinaires. Du match de football au concours de dictée, Ch. Bromberger (éd.), Bayard, Paris, 1998, p. 536.
} 


\section{Sécularisation de la spiritualité?}

Les différentes personnes (six) qui constituent ce sous-groupe se caractérisent par la recherche de pratiques thérapeutiques alternatives, et par la sacralisation de certaines valeurs (soi, la vie, ...), processus que l'on peut envisager comme une forme de sécularisation de la spiritualité.

\section{La spiritualité : un travail intérieur}

On commencera par évoquer le cas de Solange, la quarantaine. Élevée dans une famille catholique, Solange a eu un parcours relativement engagé d'un point de vue religieux : elle sera baptisée, suivra des cours de catéchisme, ira à la messe, participera aux activités d'un mouvement de scouts, s'inscrira à l'aumônerie de son lycée, .... Elle prend quelques distances avec le catholicisme après le lycée.

Au début des années 1980, elle vit avec un homme qui est toxicomane. Quand elle l'a su touché par le VIH, elle a fait le test qui s'est avéré positif. Peu de temps après, elle décide de le quitter et de refaire sa vie. Son objectif était de ne pas sombrer dans la victimisation (ne pas devenir une victime du sida), d'avoir des projets et de continuer à avoir une vie «normale ». Elle va énormément s'investir dans une petite société d'édition dont elle est la gérante. Au cours de l'année 2000, elle fera faillite. Au moment de l'entretien, Solange était toujours à la recherche d'un emploi.

Dès le départ, Solange a refusé de se traiter médicalement pour le VIH. Ce choix tient avant tout à l'éducation que lui ont donnée ses parents qui étaient, selon elle, "plutôt médecines douces ».

Quand son médecin lui a proposé de prendre de l'AZT, « il fallait se réveiller toutes les deux heures pour prendre le médicament, mais moi, avec mon approche de l'automédication, moi, je me refusais de me réveiller toutes les deux heures parce que j'estime que c'est la nuit qu'on se ressource et c'était rentrer, plonger encore plus vite vers la mort si je me réveillais toutes les deux heures pour prendre un cachet, (...) Finalement, dit-elle, je m'en suis passée pendant quinze ans ».

Elle se fera suivre par une acupunctrice qui, à l'aide d'aimants, gère ses reins congestionnés et son foie irrité. Elle s'inspire également des livres du docteur Bernie S. Siegel qui préconise une approche holiste de la maladie. Elle a aussi recours à la phytothérapie. Peu favorable à la médecine allopathique, Solange s'y résoudra quand même, au cours de l'année 2000, lorsque ses défenses immunitaires baisseront fortement. Elle tient cependant à préciser :

« même maintenant, je prends le minimum de médicaments et puis quand j'ai décidé de me traiter, j'ai fait tout un travail à l'intérieur, je me suis fait aider par d'autres lectures pour préparer ma tête à la gestion de ces molécules ». 
Dans le cas de Solange, il est difficile de parler d'un retour à la spiritualité dans la mesure où elle l'envisage comme une réflexion par rapport à la vie.

Pour elle, la spiritualité «c'est un travail intérieur, j'ai toujours du recul par rapport aux choses, j'ai toujours ce travail d'auto-analyse, de quête, de développement».

Elle se sent proche de toutes les religions et attirée par les autres cultures. Ainsi, elle a fait un voyage en Amérique du Nord pour rencontrer les Indiens Navajos. De la même façon, elle consulte auprès du service d'ethnopsychiatrie de Tobie Nathan.

\section{La spiritualité : une conscience de soi}

Michelo, la quarantaine, est aussi issu d'une famille catholique. Il a passé une partie de sa scolarité dans un internat catholique où il faisait partie d'une chorale. Cette expérience lui a beaucoup plu car il a beaucoup voyagé mais elle prend fin dès la pré-adolescence car sa voix a mué. Déçu, il doit retourner sur les bancs d'une école traditionnelle. Il explique que c'est à partir de là qu'il a commencé à consommer des drogues.

Michelo a appris sa séropositivité en 1991. Quelques temps après cette annonce, il s'engage auprès des Narcotiques Anonymes pour tenter de se désintoxiquer. Cette démarche est relativement difficile car assez rapidement, il doit gérer différents problèmes physiques liés au VIH (infections, anémie, neuropathie, ...) ; durant trois ans, il va rester avec zéro T4. À cette occasion, il se rend compte de sa fragilité ou plutôt de l'état de dépendance dans lequel il se trouve. Lorsqu'en 1995, il évoque ses symptômes à son médecin (maux de tête, de gorge et douleurs dans les oreilles), celui-ci va rester sourd à ses problèmes. Michelo va devoir passer l'hiver à l'hôpital et n'en sortira que pour se rendre dans une maison de repos. À partir de là, il décide d'apprendre à s'auto-perfuser car, dit-il,

«j'ai pris conscience que l'erreur était humaine et que pour moi ça pouvait avoir des conséquences assez graves (...) J'ai demandé au système de soins qui était mis en place autour de moi, de m'aider à être autonome pour être plus vigilant par rapport aux erreurs que pourraient faire l'être humain qui prenait en charge mes soins. Et puis quelques mois après, j'ai voulu partir en vacances, alors j'ai continué dans cette autonomie et j'ai appris à me perfuser tout seul».

Michelo renoue avec la spiritualité en fréquentant les Narcotiques Anonymes. L'éducation religieuse qu'il a reçu refait surface mais il cherche à la dépasser.

«Très rapidement, dit-il, j'ai compris que les mots n'étaient que des mots et qu'il serait bien de passer au-delà des mots, comme Dieu ou comme, des trucs qui pouvaient a priori me poser des appréhensions, très rapidement, j'ai pris ce qu'il y avait à prendre et je me suis dit que les mots n'étaient que des mots et que c'était bien de les dépasser ». 
Il fréquentera plusieurs religions (protestantisme, bouddhisme et hindouisme) pour finalement se rendre compte qu'il préfère ne pas s'attacher à un groupe en particulier. Il conçoit la spiritualité avant tout comme une recherche intérieure.

« J'ai tendance à penser, dit-il, que la spiritualité c'est être conscient de qui on est, d'être présent à soi, et d'être présent à ceux qui vous entourent, c'est un peu ma perception personnelle de la chose ».

Intéressé par les médecines parallèles, il sera soigné par un acupuncteur et suivra des cours de tai chi et de chi qong. Une fois sa formation reçue, il donnera lui-même des cours dans le cadre d'une association de lutte contre le sida.

Des différents stages qu'il a effectué, Michelo a conservé les techniques qui lui apportent un bien-être physique et psychique.

«Je fais de l'assise tous les matins, j'en fais un petit peu le soir, et puis le matin je fais de la pratique énergétique d'assise, un peu de ce que moi j'appelle de la méditation, me recueillir dans le vide, sans penser, et puis après, je me fais un petit auto-massage et puis après je me fais un petit exercice de chi qong, (...) ça me permet d'être vraiment à l'écoute de moi ».

\section{Spiritualité versus Matérialisme}

Florent, la trentaine, séropositif depuis douze ans, s'est tourné vers le bouddhisme tibétain peu de temps après l'annonce de sa séropositivité. Il est un pratiquant irrégulier car il s'investit beaucoup au niveau professionnel mais aussi parce que son entourage immédiat ne sent pas concerné par la religion. Conscient que cette irrégularité ne lui est pas forcément bénéfique, en terme de « rétribution spirituelle » (une pratique faible mais quotidienne permet de se libérer plus facilement de ses incarnations, explique t-il), Florent préfère envisager les choses sous l'angle du bien-être procuré dans l'instant présent.

Sur l'ensemble des recherches spirituelles qu'il a entreprises, il a préféré le bouddhisme, car, dit-il, on lui a proposé des choses concrètes, notamment la méditation. Ainsi, il regrette que le catholicisme, sa religion d'enfance, dissocie tellement le corps de l'esprit. Selon lui, la pratique de la méditation lui permet de prendre du recul par rapport aux évènements et lui procure un mieuxêtre physique.

« Il y a quand même, dit-il à propos du bouddhisme, un bénéfice évident, un recul par rapport à une approche uniquement matérialiste de l'existence et ça fait déjà beaucoup parce que ça permet de relativiser pas mal quand on est séropositif, je crois, consciemment ou pas, on se sent avec une épée de Damoclès sur la tête même aujourd'hui avec des traitements efficaces et cette connexion permet de relativiser, d'être sans doute plus fort, une sorte de puissance comme ça à laquelle on est relié qui permet de se sentir mieux, ». 
Le recours à la médecine tibétaine a été l'occasion, pour lui, de découvrir un autre rapport entre santé et religion, deux domaines interdépendants. Il ne peut cependant pas dire si ce traitement lui a été bénéfique dans la mesure où il ne l'a pas renouvelé.

À partir de ces trois portraits, il ressort une dimension spécifique de la spiritualité qui se réalise en dehors de toute médiation ecclésiale ou avec un rapport distancié. Le terme "énergie » est en soi significatif de leurs représentations du monde supraempirique ; il s'agit d'une capacité intrinsèque à l'individu, pouvant être stimulée par des techniques spécifiques (taï chi ou chi qong). Dès lors, on peut se demander si l'on n'est pas face à une sacralisation de l'individu et inversement à une sécularisation de la spiritualité ou à ce que certains sociologues ont appelé une « sortie de la religion ${ }^{102}$.

Par ailleurs, ces personnes entretiennent un rapport distancié à l'institution médicale qu'on observe à travers le recours à des techniques corporelles, des médecines douces voire à une observance thérapeutique ${ }^{103}$ sélective.

\section{Un engagement religieux total?}

Les trois portraits à venir se caractérisent par une religiosité intense prenant parfois les formes de l'exclusivisme religieux.

\section{Spiritualité et réussite professionnelle}

Charlotte, la trentaine, n'a pas été surprise par l'annonce de sa séropositivité au VIH, en 1993. C'était une période où, dit-elle, elle vivait l'instant présent sans se soucier de l'avenir, tout en sachant que son ami était touché par le VIH. Son engagement religieux doit être envisagé à partir d'une passion amoureuse. Elle quitte amis, famille et études pour venir vivre à Paris avec son ami. Celui-ci est engagé dans un groupe néo-bouddhiste, la Sokka Gakaï.

Au départ, elle observe ces pratiques religieuses de loin avec une certaine circonspection ; elle adhère aux idées du groupe mais ne saisit pas bien le sens des pratiques, surtout le fait de réciter des mantras (courte phrase répétée indéfiniment) dans une langue inconnue (japonais). Après une réunion avec des membres de la Soka Gakkaï, Charlotte décide de s'engager davantage dans le groupe. Elle s'y plaît et continue à pratiquer. Elle obtient son Gohonzon en $1996^{104}$.

\footnotetext{
102 - F. Champion, M. Cohen, «Recompositions, décompositions. Le renouveau charismatique et la nébuleuse mystique-ésotérique depuis les années 1970 », Le débat, mai-août 1993, p. 81-89.

103 - M. Morin, « De la recherche à l'intervention sur l'observance thérapeutique : contributions et perspectives des sciences sociales », L'observance aux traitements contre le VIH/Sida. Mesure, déterminants, évolution, ANRS, coll. Sciences sociales et sida, décembre 2001, p. 5-20.

104 - Le gohonzon, est un petit parchemin, d'une vingtaine de centimètres, qui contient un mandala de Nichiren Daichonin, le fondateur de la Soka Gakkaï. Sur ce mandala figure, en caligraphie, au centre, le mantra Nam Myoho renge kyo, et autour des noms de divinités bouddhiques. Ce mandala est intégré à un autel domestique où sont placées diverses offrandes évoquant traditionnellement au Japon les cinq éléments, L. Hourmant, "'Transformer le poison en élixir'. L'alchimie du désir dans un culte néo-bouddhique, la Soka Gakkai française », De l'émotion en religion. Renouveaux et traditions, Fr. Champion et D. Hervieu-Léger (éds.), Centurion, Paris, 1990, 71-119.
} 
À la mort de son ami, en 1998, Charlotte trouve dans la Soka Gakkaï un réconfort; elle comprend que «la vie et la mort ne sont que les deux faces d'une même pièce » et que la mort n'est pas une fin en soi mais une étape vers une renaissance, selon le principe du karma.

«Le décès de mon copain, dit-elle, m'a fait un peu réfléchir sur la question, Nichiren Daichonin (le fondateur de la Soka Gallaï) dit un truc qui est vrai mais qui n'est pas toujours facile à comprendre, il dit, si vous voulez comprendre la vie, il faut d'abord commencer par comprendre la mort, avant tout chose ». Elle poursuit dans ces termes, la mort « c'est un cycle comme ça qui dure tout le temps donc quand tu dors c'est pas grave tu te reposes, mais tu repars avec de nouvelles bases et de nouvelles énergies pour la vie d'après donc la mort n'est pas un truc noir ou un truc triste, c'est juste la fin d'une aventure et le début d'une autre, donc le but c'est de profiter de la vie que tu as là aujourd'hui ».

Trois ans plus tard, Charlotte rencontre un nouveau compagnon et parvient à revivre une histoire amoureuse. Son engagement au sein de la Soka Gakkaï lui permet, entre autre, de réussir professionnellement. Assistante de production, elle parvient à avoir un rythme de travail qui lui convient et à décrocher des contrats intéressants. Au cours de l'entretien, elle raconte la manière dont elle procède pour obtenir un contrat :

«quand il faut que je parte en repérage, quand j'ai des rencontres importantes, je sais que je le fais avant (pratique du Gohonzon) pour me sentir bien, pour pas douter, que ça se passe bien, pour lâcher un peu l'angoisse parce que moi je fonctionne sur la trouille, je suis une trouillarde de première, c'est aussi mon moteur mais c'est aussi mon frein, j'essaye d'en faire plus un moteur qu'un frein mais pour ça je pratique beaucoup pour calmer la peur, et ça marche très bien, c'est à dire que j'arrive vraiment à relativiser (...) Là, en ce moment, je pratique (devant le Gohonzon) une heure tous les matins parce que je veux que la journée elle commence bien ». Dans la perspective de voir réaliser un projet de documentaire sur le Maroc, elle raconte qu'elle pratique « une heure (par jour) parce que j'ai vraiment envie que mon projet avance, parce qu'il va me falloir les producteurs et que je fasse le film parce qu'il n'y a pas assez de documentaires sur ce pays, et c'est pas facile, faut vraiment y croire, et j'y crois, (...) je suis un peu impatiente, et j'apprends aussi à avoir la patience, de me dire qu'il faut un temps pour tout, c'est comme toute chose, je pense que les gros projets sont des choses qui se font sur le long terme et arriver aussi, au jour le jour, à accepter que ça n'avait pas avancé hier mais que ça va avancer donc là en ce moment, parce que je suis ici et que je ne travaille pas et que j'ai de bonnes conditions, je pratique vraiment une heure tous les matins ».

En plus d'une pratique quotidienne, Charlotte se rend régulièrement aux réunions de « filles », données dans son quartier, une fois par semaine. Là, dit-elle, elle a pu nouer des liens précieux. Et l'on sent, à travers son discours, que le groupe fonctionne sur cette structure binaire qu'est le Nous (le groupe) et le Eux (de l'extérieur). 
«C'est vrai, dit-elle, que la conception de la vie que t'amène le bouddhisme fait que tu discutes vite fait de choses vachement intimes avec les gens (...) ça créé des liens incroyables parce que moi, je me suis fait des copines, enfin y'a des gens qui me tiennent vraiment beaucoup à coeur (...) Les réunions entre les filles, c'est vraiment être dans l'adversité à plusieurs en fait, ça créé des liens que tu n'as pas toujours avec les gens avec qui tu bosses et tu as beau être mal, tes collègues de travail, personne n'en a rien à foutre, ils essayent même plutôt de t'enfoncer parce que justement tu ne vas pas bien, et là, ça crée un lien où ça ne fonctionne pas pareil, et c'est vrai que ça crée des liens et moi je sais que j'ai toujours une pratique toutes les semaines à la maison (...) je sais que je suis plus attachée aux réunions qu'on fait avec des filles du quartier parce que c'est, je me suis vraiment fait des amitiés ».

Charlotte est consciente d'avoir placé sa réussite professionnelle au premier plan, dans sa pratique religieuse, et ce au détriment de sa santé, mais elle a envie de changer les choses.

Ma santé, dit-elle, «ça devrait être en première position, c'est encore en 23ème, c'est mieux qu'avant mais c'est pas encore normal, ça devrait être ma première préoccupation, je travaille dessus, et un jour ce sera gagné ».

Dernièrement, elle a été sollicitée par l'organisation Soka Gakkai pour prendre en charge un groupe de femmes, et ce malgré ses fréquents déplacements à l'étranger. L'objectif étant que « les filles dont on va me donner la charge, entre guillemets, se développent bien, ne se gourent pas, ne souffrent pas et que si elles ont un problème, qu'elles puissent m'appeler et que je sois disponible le jour où elles ont un souci ».

Charlotte préfère passer outre le fait que la Soka Gakkai soit qualifiée de « secte » dans les médias. Pour elle, le groupe auquel elle appartient ne fait pas de pression sur ses membres pour les retenir et ne les contraint pas à verser des sommes d'argent astronomiques. Quant à ses parents, catholiques, ils sont partagés car entre les reportages critiques qu'ils peuvent voir à la télévision et les descriptions que leur en donnent leur fille ; il leur est difficile de faire la part des choses.

On peut se demander si l'appartenance à un groupe structuré est liée au fait d'être femme et séropositive. Cette double caractéristique (femme et séropositive) peut être, au niveau de la société globale, un double « handicap » en terme d'évolution socioprofessionnelle. L'engagement au sein de ce type de groupe permettrait de lever/contourner ces « handicaps » dans la mesure où la réussite professionnelle y est valorisée.

\section{Oublier l'existence du VIH}

Angèle, la trentaine, a également trouvé dans le groupe religieux dans lequel elle s'est engagée un soutien sans faille, à la mort de son mari. Originaire des Antilles, elle arrive en métropole en 1985. Elle se marie deux ans plus tard, en sachant que son mari est séropositif. En 1991, il décède et elle apprend qu'elle est aussi séropositive. Elle reste seule avec le fils de son 
mari, qu'elle décide de garder. Ses parents, restés aux Antilles, et ses frères et sœurs, dont certains vivent en métropole, ne seront pas informés de sa séropositivité ; elle craint que cela fasse empirer la situation.

Angèle a été catholique jusqu'à l'âge adulte. Quelques années après son arrivée en métropole, elle délaisse le catholicisme et cherche ailleurs sa voie de salut. C'est une collègue de travail qui lui parle des Témoins de Jéhovah et l'invite à l'une de leurs commémorations. Angèle y trouve un lieu d'apaisement compte tenu de ce qu'elle vit au sein de son foyer ; la lente agonie et déclinaison de son mari. Celui-ci supporte difficilement cet engagement religieux; il a le sentiment qu'on lui «vole » sa femme. Même si Angèle tente un compromis en allant à une réunion sur deux, son engagement est encore important.

À la mort de son mari, Angèle trouve un réconfort dans la théodicée jéhoviste ; l'esprit de son mari ne viendra pas la tyranniser (croyance antillaise) mais reposera en paix et il aura la possibilité de ressusciter le jour du millénium. De même, les membres de son groupe lui manifesteront leur solidarité.

« À cette époque, dit-elle, ils (les jéhovistes) m'ont encouragée, ils m’ont beaucoup soutenu, après la mort de mon mari, pour son fils et tout ça, ce sont des personnes avec qui je peux parler librement, je pouvais pleurer quand j'en avais envie, ça ne posait aucun problème, et quand je vais faire mes analyses, ils me demandent les résultats, qu'est-ce que ça a donné, donc je donne des nouvelles, je suis contente, c'est vrai que c'est important de savoir qu'on a quand même cette aide, ce n'est pas spirituel, mais comment dirais-je, mental, si je peux m'exprimer ainsi, je sais que je peux compter sur eux, quoiqu'il arrive, je peux compter sur eux, à n'importe quel moment, je peux compter sur eux, c'est important».

L'engagement de Angèle devient plus intense au début des années 1990. Elle se convertit en 1990 et, deux ans plus tard, elle devient «pionnier auxiliaire ». Cela signifie qu'elle consacre soixante heures par mois pour prêcher la parole de Dieu. Quelques années plus tard, en 1996, elle passe «permanente »: le temps passé à la prédication est de soixante dix heures. Elle réorganise son emploi du temps pour se rendre disponible : elle ne travaille plus qu'à $80 \%$, et décide de passer un concours pour accéder un grade supérieur ce qui lui permet de compenser la perte de salaire occasionnée par la réduction de son temps de travail.

En plus du temps passé à prêcher, Angèle assiste aux cinq réunions organisées par le groupe, dans la semaine ; trois de ses soirées sont donc occupées par les réunions des Témoins de Jéhovah. Elle suit certaines de ces réunions dans un groupe linguistique pour pouvoir prêcher en espagnol. À terme, elle se demande si elle ne deviendra pas missionnaire mais d'abord, elle souhaite que son fils adoptif soit installé.

$\mathrm{Au}$ sein de son groupe religieux, Angèle n'a pas fait d'annonce publique de sa séropositivité même si certaines personnes le savent. Rétrospectivement, Angèle explique le rôle joué par son engagement auprès des Témoins de Jéhovah : 
«Je trouve que quand on a la foi, même si on est pauvre, je pense que ça aide beaucoup, ça nous permet de surmonter nos problèmes et de prendre beaucoup de choses sur nous-mêmes parce que c'est quelque chose qu'on a et que ça, on ne peut pas nous l'enlever, on ne peut pas nous l'enlever, et je pense que c'est important, pour moi, personnellement, c'est important, si sincèrement, je n'avais pas cette foi, si je n'avais pas cette dépense dans le culte, je pense que j'aurais baissé les bras, parce que y'a des moments où, deux ans après m'être mariée, j'ai fait une dépression, ça c'est normal, deux ans après, c'est sûr, ce sont des choses inconsciemment qui reviennent, ça fait partie de notre vie, qu'on ne peut pas effacer comme ça, et si on n'a rien pour se rattacher ou pour lutter, on coule, on coule, c'est important, pour moi c'est important, je vous dis, je suis très entourée et puis ça se passe très bien ».

\section{Réorienter sa vie}

Nina, âgée d'une vingtaine d'années, va également beaucoup s'investir dans son groupe religieux. Le jour où on lui annonce sa séropositivité, en 1993, elle passe la nuit à discuter avec une amie du sens de la vie. Quelques jours plus tard, elle décide de se rendre chez une autre amie dont la mère est membre du groupe Invitation à la Vie (IVI) et lui demande de « l'harmoniser ${ }^{105}$.

Nina passe le reste de ses vacances auprès de personnes faisant partie de ce groupe religieux. De retour sur Paris, elle décide de s'engager davantage notamment en faisant partie d'un groupe de prière ${ }^{106}$. Nina ne témoignera pas immédiatement de sa séropositivité ; elle préfère attendre de vraiment se sentir en confiance auprès des gens de ce groupe.

Progressivement, son engagement se fait plus intense. Toutes les semaines, elle se rend au centre IVI (situé à Boulogne, dans les Hauts de Seine) pour se faire harmoniser et avoir un entretien avec une personne de la Mission Écouter ${ }^{107}$, Elle participe aussi à la réunion mensuelle du groupe Vibrations ${ }^{108}$. En plus, elle se réunit avec son groupe de prière une fois par semaine.

Après voir rencontré IVI, Nina décide d'abandonner l'université où elle préparait un diplôme de langue chinoise et envisage de devenir psychomotricienne. Son engagement religieux

\footnotetext{
105 - Cette pratique, fortement répandue au sein de ce groupe, consiste en « un massage léger du corps d'une personne (restant revêtu et recouverte d'une étoffe) qui insiste aux endroits où la médecine asiatique a situé des centres énergétiques appelés chakras et qui se termine par un souffle au niveau du plexus solaire », R. Dericquebourg, Croire et guérir. Quatre religions de guérison, Dervy, Paris, 2001, p. 93.

106 - Le groupe de prière réunit des néophytes qui ont eu, au préalable, un entretien avec un responsable de l'association. Lorsqu'ils sont en nombre suffisant, ces néophytes constituent un groupe de prière : ils se réunissent toutes les semaines chez l'un d'entre eux. Après avoir récité le chapelet, ils écoutent un extrait d'une cassette de Yvonne Trubert (fondatrice du groupe) puis donnent des témoignages. Vient ensuite le moment de convivialité où ils dînent ensemble.

107 - «La mission Écouter est une équipe de personnes nommées par Yvonne Trubert pour recevoir, dans chaque centre, les personnes qui veulent confier un problème. Les personnes chargées de faire les entretiens sont tenues de garder le secret sur les confidences reçues », Idem, p. 101.

108 - «Faire des vibrations, écrit R. Dericqueebourg, consiste à prononcer des sons en chœur à la manière des chants de mantras. Le son et la voix unis provoqueraient des vibrations favorisant la rencontre des énergies telluriques et cosmiques dont le fidèle est le canal », Ibid., p. 96.
} 
est un peu à la mesure de ce que lui a apporté ce groupe : un équilibre de vie au travers d'amitiés, d'activités et de reconnaissance.

Quant à ses parents, catholiques, elle raconte qu'ils n'ont pas réagi de manière négative à son engagement au sein de IVI ; sa mère a même été la première personne que Nina a harmonisée. Et, alors qu'une amie de sa mère lui disait que sa fille faisait partie d'une secte, Nina raconte :

« ma mère, elle lui a toujours répondu que depuis que j'étais à Invitation à la vie j'étais de plus en plus heureuse, que j'avais l'air bien dans mes baskets, que la seule chose qui était importante c'était ça, personne ne me piquait mon argent, ce qui est quand même une caractéristique des sectes, personne ne m'obligeait à rien faire, que j'étais encore moi-même, que ça m'apportait quelque chose, que j'avais pas subi un lavage de cerveau ou je ne sais pas quoi, après c'est sûr que je suis très imprégnée mais parce que je l'ai décidé ».

À la différence de Angèle et Charlotte, Nina s'est engagée dans d'autres groupes ayant des pratiques thérapeutiques alternatives ou parallèles. Ainsi, elle fera partie de cette association, aujourd'hui morte, Parsifal. Elle n'y reste pas car, fréquentée majoritairement par des homosexuels, elle ne retrouve pas le vécu des femmes hétérosexuelles. Elle participera aussi à l'association Sidamour qui siège dans le Sud de la France et qui propose des alternatives au « tout thérapeutique »dans la gestion du VIH-Sida. Elle apprécie beaucoup les activités qui y sont données mais s'interroge sur la nécessité de créer des lieux spécifiques pour les séropositifs. Pour autant, c'est à travers ce groupe qu'elle a pris conscience qu'il existait d'autres lieux de croyances proches de celles qui existent au sein de IVI.

«j'aime bien (Sidamour) parce que ce sont des gens qui ne font pas partie d'Invitation à la vie, on n'est pas les seuls à croire en Dieu, à croire aux anges, et à croire qu'on est fait pour aimer sur terre ».

Il est difficile de qualifier le type d'organisations religieuses (secte, église, « cult») auxquelles appartiennent ces personnes dans la mesure où les observations que $\mathrm{j}$ 'ai pu y faire, au cours de l'enquête de terrain, restent parcellaires. Seul, un travail approfondi permettrait d'y répondre.

On peut néanmoins souligner le fait que l'engagement de ces personnes est relativement important (les heures passées au sein du groupe ne sont pas comptées) voire exclusif. On est parfois proche de ce que J.-M. Donégani appelle une tradition religieuse «intégraliste » c'est à dire, «quant toute la vision du monde est véritablement organisée autour d'une référence religieuse ${ }^{109}$. Pour autant, si l'on s'arrête sur l'emploi du temps d'autres personnes, notamment celles qui sont ou souhaitent devenir psychothérapeutes, on peut constater un engagement tout aussi important. En fait, la différence entre ces deux groupes de personnes tient surtout au fait que dans un cas elles appartiennent à une organisation structurée, et dans l'autre, ce sont les personnes, elles-mêmes, qui constituent, au gré de leurs rencontres, le corpus de leurs croyance et pratiques.

109 - J.-M. Donégani, La liberté de choisir. Pluralisme religieux et pluralisme politique dans le catholicisme français contemporain, Presses de la Fondation de Sciences Politiques, Paris, 1993, p. 241. 
Par ailleurs, il faut mentionner le lien qui existe entre le niveau socio-économique voire culturel des personnes et le type de groupe auquel elles s'affilient. Ainsi, alors que la Soka Gakkai est reconnue pour recruter auprès des classes moyennes et supérieures ${ }^{110}$, les Témoins de Jéhovah touchent plutôt les classes populaires ${ }^{111}$. Cette distinction est perceptible entre Charlotte (assistante de production) et Angèle (agent technique).

On peut aussi se demander si l'engagement de ces personnes au sein de ces groupes qui encadrent leur quotidien, ne tient pas au «déracinement» qu'elles ont vécu. Venues de province, ou de Guadeloupe pour s'installer en région parisienne, elles ont pu trouver, auprès de leurs groupes religieux, un réseau d'amitié et de sociabilité.

\footnotetext{
110 - Voir les travaux de L. Hourmant, notamment «Les nouveaux mouvements religieux japonais en France : entre laïcisation et euphémisation du sacré », Social Compass, 1995, n 42 (2), p. 207-220.

111 - Voir les travaux de R. Dericquebourg, notamment « Les Témoins de Jéhovah : vers une sortie de la logique sectaire », Sectes et démocratie, F. Champion et M. Cohen (dir.), Seuil, Paris, 1999, p. 105-125.
} 


\section{2 . La responsabilité de l'individu}

Les représentations du VIH-Sida peuvent être articulées autour de deux axes. Le premier envisage le VIH comme le signe d'une destruction de soi, consciente ou non; la démarche spirituelle étant alors conçue comme une sorte de renaissance, de découverte de soi. Le second axe prend davantage en considération la dimension sociale ou politique du contexte dans lequel est apparu le VIH-Sida.

\section{L’annonce du VIH et la découverte de soi}

Samson, âgé d'une trentaine d'années, a refusé pendant un certain nombre d'années toute médication. Quand ses défenses immunitaires tombent à cinq T4 et qu'il fait un cytomégalovirus, il révise ses positions et accepte de suivre un traitement médicamenteux. Il reste néanmoins convaincu que le VIH-Sida est un processus d'autodestruction. À ce moment de son existence, il se dit :

« je ne veux pas mourir bêtement sans savoir vraiment à quoi est dû ce processus d'autodestruction qui remonte, de toute façon, dès l'enfance, parce que c'est inconscient. Pour moi toute maladie dégénérative que ça soit le cancer, la leucémie, j'en passe et des meilleures, sclérose en plaques enfin toutes les maladies qui, a plus ou moins long terme, ont une échéance, où la mort est au bout, pour moi, c'est un signe que la personne, d'une manière ou d'une autre, s'autodétruit, ce n'est pas conscient, finalement, c'est un processus inconscient, c'est à la fois une épreuve dont on peut ressortir gagnant si on va chercher, justement, loin, loin, en soi, en tous les cas inconsciemment et qu'on fait remonter à la surface ».

Selon Samson, ce processus d'autodestruction tient à l'éducation qui réfrène la réalisation de son être véritable. «On ne peut plus écouter son cœur, dit-il, (...) on ne peut plus écouter son corps, on est vraiment séparé c'est à dire qu'on est complètement résigné, on ne peut plus écouter, parce qu'on a des rêves quand on est tout petit, seulement en grandissant, votre conditionnement, votre éducation, vous éloignent petit à petit de ces rêves, parce qu'on vous fait comprendre que vous n'êtes pas assez bien, on va dire pas assez bien, pas assez doué, vous êtes moche, trop grand, trop petit, vous n'en valez pas la peine, vous n'êtes pas digne de, etc., etc., et en fait, toute la bataille consiste, finalement, à redépasser tout ce conditionnement pour pouvoir à nouveau refournir de l'énergie dans les rêves que vous aviez étant plus jeune (...) Ca veut dire que les gens se coupent de ce qu'ils brûlent d'envie de faire, donc on met des barrières dans tous les sens et finalement, on se coupe complètement de son âme, on est vraiment séparé, c'est un état de séparation, et pour moi la maladie c'est ça, n'importe quelle maladie dans l'absolu c'est on est séparé de son cœur, de son âme ». 
Suivant son « intuition », il se rend compte que son avenir n'est pas dans la coiffure mais dans la psychothérapie. L'annonce du VIH a été l'élément déclencheur d'une anamnèse où certains évènements se révèlent être des « signes » de sa vocation professionnelle.

«C'est vrai, dit-il, que j'étais loin de m'imaginer ce que cette maladie allait pouvoir me révéler petit à petit à moi-même, à 17 ans je faisais de l'astrologie, c'est sûr que ça m'a aidé parce que c'est une forme d'astrologie qui permet de comprendre quel est le cheminement de la vie, votre programme, votre chemin et c'est vrai qu'à l'âge de 17 ans c'est vrai que j'ai lu pour la première fois, dans un livre, ce qui m'attendait, donc c'est clair que mon chemin prévoyait une maladie dont je pouvais m'en remettre si je savais développer en moi la foi, à cette époque-là, j'avais 17 ans, on ne parlait pas du tout du sida, ça n'était pas du tout apparu (...) Finalement à 18 ans j’ai commencé à accepter mon homosexualité, ça, ça a été vraiment un soulagement (...) J'ai abandonné mon ancien boulot, ça c'est pas un mal parce que à la fin je finissais par m'occuper des gens, plus à leur intérieur qu'à leur extérieur, parce que j'étais coiffeur, et c'est vrai que l'époque de la maladie n'a fait que me révéler à moi-même, et c'est vrai que il y a encore trois ans, penser que j'allais pouvoir être psychothérapeute c'était pour moi impensable, parce que justement tout mon conditionnement me disait mais tu es trop nul, tu n'arrives à rien, tu es bon à rien, etc., etc., et ça j'ai du apprendre à tout décortiquer, à tout défaire ».

Pour Nina, les choses semblent claires ; elle a été contaminée par le VIH parce qu'elle ne se respectait pas. Son engagement au sein du groupe Invitation à la Vie (IVI) lui permet de changer son mode de vie et son rapport à elle-même.

À l'époque où elle est contaminée, elle pense que « le terrain était là, le terrain favorable, enfin j'étais dans une démarche qui était une démarche de destruction si on peut dire, c'est à dire que je ne me respectais pas, je ne respectais pas mon corps, je ne me respectais pas du tout, donc mais c'est pas une punition, ce n'est pas un châtiment, ou une condamnation, ou Dieu m'a puni parce que je ne me suis pas respectée ou je ne sais pas quoi, mais plutôt ça a été, j’y serais encore, je faisais des études qui ne me plaisaient pas, j'avais une vie où je m'emmerdais, enfin la vie ce n'était pas marrant, c'était chiant, j'attendais je ne sais pas quoi, et j'ai l'impression que ça m'a réveillée, le fait de sentir que la vie pouvait être courte de toute façon, elle allait finir un jour, il fallait en profiter ». Le travail effectué avec une thérapeute consiste alors « à garder cette impulsion, comment réussir à la garder sans le prétexte de la séropositivité, parce que ça a été un moteur pour moi pendant très très longtemps, pour faire attention à moi, et j'en suis là aujourd'hui, je veux dire je n'ai pas fini, justement, c'est comment avoir vraiment ça en moi, sans me dire, oui il faut parce que comme je suis séropositive, on ne sait jamais, enfin mais avoir simplement la motivation de prendre soin de moi, de profiter de la vie, de m'aimer et d'aimer les autres simplement ». 
Quant à Charlotte, elle estime également que la contamination au VIH s'explique par le mode de vie qu'elle avait à cette époque. Sa rencontre avec la Soka Gakkai va lui permettre de comprendre cet état de fait.

«Je savais, dit-elle, que y'avait 99,9\% de chances que je le chope (le VIH) parce que je l'ai quasiment fait exprès, entre guillemets, on va dire, mais je pensais que moi, ça ne passerait pas par moi, de toute façon, moi, je suis plus forte que les autres, enfin bref, le test est arrivé quinze jours après, on m'a demandé confirmation, j'en ai refait un autre, celui-ci était confirmé, c'était sûr, et donc là j'ai compris que je m'étais fait des illusions, qu'on peut toujours croire qu'on est plus fort que toutes les choses, et que si on veut un truc, ça marchera comme ça et pas autrement, donc je l'ai un peu pris en pleine tête, en comprenant assez vite que quand même que c'était juste le résultat du non respect de ma propre vie qui correspondait aussi à ma prise de conscience que j'ai prise par rapport au bouddhisme où on vous explique, que vous êtes responsable de tout ce qui vous arrive et que aussi en changeant votre attitude vous pouvez aussi changer les choses ».

\section{Causes et conséquences sociales du VIH}

Aziz, la trentaine, établit un parallèle entre l'apparition du VIH et la libéralisation des mœurs. Né au milieu des années 1960, il pense avoir bénéficié des avantages liés à cette époque mais aussi de ses conséquences : le VIH. L'important, selon lui, est de pouvoir se libérer du carcan imposé par la société globale.

Quant à Solange, elle estime que les personnes meurent moins du sida que de l'absence de lien social.

«Le lien social, dit-elle, la perte du lien social, c'est ça qui tue les gens, parce que bien sûr on dit, sida = mort, mais c'est surtout parce qu'on a exclu les gens de la société, moi, cette année, je vis tout un tas de choses, je m'intéresse à ce que fait Tobie Nathan, je me suis toujours intéressée aux médecines traditionnelles et il explique les médecines traditionnelles, le sorcier, le guérisseur, le malade, ... tandis que nous, dans nos médecines, on renvoie le malade à ses symptômes, on l'isole complètement du groupe social ».

Quant à l'origine du sida, elle défend la thèse selon laquelle le VIH proviendrait d'un vaccin «fabriqué » en Afrique à partir de chimpanzés porteurs du VIS (Virus de l'Immunodéficience Simienne).

À partir de ces représentations du VIH-Sida, on peut noter la prédominance du modèle étiologique endogène. Cela signifie que les individus portent la responsabilité de leur contamination. La culpabilité n'est cependant pas un trait dominant dans leurs propos car elle est atténuée par d'autres représentations. Ainsi, le processus d'autodestruction dont parlent certains, provoqué par l'éducation parentale et/ou les contraintes de la société globale, n'est plus 
totalement porté par l'individu. La croyance en la réincarnation permet aussi de se libérer d'une certaine culpabilité.

\section{3 . Des pratiques thérapeutiques complémentaire et alternative}

$\mathrm{Au}$ sein de ce troisième groupe (les ruptures religieuses), le rapport à l'institution médicale occupe un spectre relativement large allant de l'acceptation au refus des traitements médicamenteux. Trois cas de figure vont permettre d'illustrer ces pratiques.

\section{Des pratiques religio-spirituelles complémentaires}

Le premier concerne des personnes qui suivent un traitement médical parce qu'elles estiment qu'elles ne peuvent pas faire autrement. En associant à la prise de médicaments des techniques parallèles diverses, elles ont le sentiment d'avoir prise, si ce n'est sur le virus HIV, au moins sur leur état d'être global. Cette autonomisation des pratiques thérapeutiques traduit, d'une certaine façon, une volonté de distanciation à l'institution hospitalière.

Angèle, Témoin de Jéhovah, est annoncée séropositive en 1991. Durant sept ans, elle reste sans traitement. Cela ne procède pas d'un choix religieux - en dehors des transfusions sanguines, les jéhovistes acceptent de se soigner avec les moyens offerts par la médecine - mais d'un état de santé relativement bon. Elle estime être restée asymptomatique durant toutes ces années grâce à ses prières et son engagement religieux. En 1998, alors que ses défenses immunitaires baissent, son médecin lui dit qu'elle doit suivre un traitement médicamenteux.

Pour accepter la trithérapie, dit-elle, «j'ai du faire un travail sur moi-même, et le fait d'avoir cette espérance, j'ai prié énormément, pour avoir l'aide et la force nécessaire pour pouvoir passer le cap parce que si je refusais ce traitement, le résultat n'aurait pas été bon donc il fallait que je fasse un travail intérieur, sur moi-même pour pouvoir accepter déjà, le fait de prendre ce médicament parce que dans ma tête, le médicament était lié à la déchéance, donc il fallait que je surmonte tout ça, et puis une fois le cap passé, ça s'est très bien passé, ça a très bien marché, et mon médecin me propose, peut-être d'arrêter, en alternance, le traitement, parce que je réagis bien et parce que, mentalement, je m'oblige à passer par dessus, et je suis entourée, je suis bien occupée, je suis occupée donc je ne pense pas à moi, je pense aux autres, donc ça m’aide énormément ».

Lorsque Aziz, ancien membre des Narcotiques Anonymes (NA), a connaissance de sa séropositivité, en 1984, aucun traitement n'existait. La mise sur le marché de l'AZT, ne l'emballe pas car en voyant mourir ceux qui le prennent, il se dit que cela n'a pas vraiment d'effet. Par ailleurs, une mésaventure avec un médecin d'un hôpital du Nord de Paris (celui-ci lui aurait dit qu'il était guéri de son hépatite $\mathrm{C}$ alors que ce n'était pas le cas) et les informations diffusées sur le VIH par des personnes qui fréquentaient les Narcotiques Anonymes l'amènent à être sélectif dans le choix d'un praticien. 
Aziz n'a pas accepté facilement de prendre un traitement médicamenteux mais son état de santé s'étant affaibli, il fait le choix de suivre une multithérapie et un traitement pour l'hépatite C. Pour gérer les effets secondaires de son traitement, il pratique intensivement du sport, surveille son alimentation et décide de se remettre à fumer du cannabis, qu'il vante pour ses vertus thérapeutiques,.

«Pour la déprime, dit-il, moi je n'ai pas envie de prendre des cachetons, et c'est vrai que de rentrer dans un truc d'antidépresseur, je ne m'y vois pas du tout alors ce qui est clair c'est que si je dois me réveiller le matin, prendre des cachetons, avoir la bouche pâteuse, d'être complètement somnambule, etc. j'arrêterais tout simplement les traitements VIH, ça c'est évident, et puis ce qu'il faut voir aussi, c'est que moi pendant des années j'ai arrêté de fumer du cannabis (...) J'ai compris qu'il fallait en passer par là pour que mon corps se régénère et qu'il fonctionne de mieux en mieux (...) C'est vrai que en ayant arrêté de fumer et en prenant des traitements avec de lourds effets secondaires, j'ai senti nettement la différence, et même physiquement, même biologiquement ça s'est ressenti au niveau de mes bilans sanguins, quand je me suis remis à fumer, j'ai tout de suite eu de bons résultats ».

Quant à Florent, s'il est resté asymptomatique depuis douze ans, il dit être fortement affaibli par le virus; il ressent une intense fatigue et a le sentiment de vivre comme une personne âgée alors qu'il a une trentaine d'années. Son engagement dans le bouddhisme l'a amené à s'intéresser de près à la médecine tibétaine. Il décide de suivre ce traitement durant deux mois mais n'y donnera pas de suite. Quant aux pratiques/techniques du bouddhisme, il apprécie le fait qu'elles donnent une approche globale de l'individu et apportent un mieux-être physique mais en aucun cas ils ne les envisagent dans une perspective de guérison.

«Quand je médite, dit-il, je ne me dis pas, tiens je vais me guérir, je me dis, je vais pratiquer, je vais pratiquer la méditation, je pense d'ailleurs que dans la mesure où ces techniques de méditation, on s'en rend compte aussitôt, se traduit par une régulation du souffle, de la respiration, avec une respiration profonde, d'emblée, c'est quelque chose qui apparaît comme extrêmement sain, je suis convaincu que, ça a été dit d'ailleurs, l'attention portée au souffle, un souffle profond plutôt qu'un souffle court, doit avoir des répercutions sur l'état de santé ».

\section{Un accommodement de survie}

Dans le second cas de figure, on est face à des personnes qui, compte tenu de leur état de santé, ont été contraintes de prendre un traitement médicamenteux. Leur refus de se prendre ce traitement s'inscrit dans une logique protestataire à l'égard de l'institution médicale. Le cas de Vincent viendra illustrer cette problématique.

Ce jeune homme fait partie du groupe Invitation à la Vie (IVI) depuis l'âge de 7-8 ans. Il apprend sa séropositivité au moment où il décide de se marier, en 1999. Les tests prénuptiaux 
qu'il effectue lui révèlent sa séropositivité au HIV ; ceux de sa femme également. Enceinte de deux mois, celle-ci va faire une fausse couche une semaine après cette annonce.

Assez rapidement, Vincent ressent des symptômes physiques ; il éprouve une grande fatigue et ses défenses immunitaires sont faibles. Il refuse de suivre une multithérapie et s'oriente vers des produits et pratiques parallèles. Ainsi, il essaye les produits Beljanski, fait des séances de kinésiologie $^{112}$. et sur les conseils de son médecin, également membre de IVI, il suit un traitement à base de curry. Parallèlement à ces démarches, Vincent recours aux pratiques de son groupe religieux : 1'harmonisation, les vibrations et la purification.

« Ma mère et ma soeur font aussi parties de l'association, raconte t-il, j'ai des amis très proches aussi, on est un groupe de jeunes, dans l'assos, dont j'ai mis certains au courant (de sa séropositivité et celle de sa femme), et on a créé une sorte de protection autour de nous (sa femme et lui), donc on recevait l'harmonisation très régulièrement, j'ai reçu un moment, une neuvaine d'harmonisation c'est à dire que tous les jours pendant neuf jours, je me faisais harmoniser, pour essayer de pallier la souffrance morale ». Pour les vibrations, il fait deux séances par semaine pendant deux mois et réitère l'expérience plusieurs fois de suite. Il tente de «se soigner» par ce biais. Quant à la purification, il explique qu'il s'agit «d'un procédé qui consiste à nettoyer aussi bien un lieu qu'une personne (...) On purifie par l'intermédiaire de phrases, entre guillemets, on dit à Satan de s'en aller (...) Ca permet justement de réinstaller une lumière à l'intérieur soit du lieu, soit de l'objet, soit de la personne».

Quelques mois plus tard, Vincent fait une gastroentérite. Les examens qu'il fait sont mauvais. Son médecin lui conseille de consulter à l'hôpital. Là, on lui prescrit une multithérapie qu'il se décide à prendre. Il reste cependant convaincu des bienfaits des thérapies parallèles. Il en veut pour preuve cette «expérience » qu'il a faite sur lui ; après avoir arrêté de prendre ses traitements parallèles, il a eu de fortes diarrhées. Il en conclut que ses traitements parallèles permettent de gérer certains effets secondaires. Et quand un praticien hospitalier lui dit que son traitement médical fonctionne bien, Vincent lui répond :

«non, pour moi ce n'est pas que ça, c'est tout, je ne peux pas retirer mon traitement en homéo, ce que me donne la kinésio(logie), ce que me donne Beljanski et les antirétroviraux, et plus tous les à-côtés, je ne peux pas dissocier tout ça, c'est un tout, si je prends juste les antirétroviraux, demain, je suis au fond de mon pieu avec la chiasse et compagnie, c'est une globalité si vous voulez ».

La vision qu'il a du système médical français est celle d'un monde gagné par l'argent.

112 - La kinésiologie est une thérapie manuelle qui prétend agir sur les plans physique, mental et énergétique. L'objectif étant de rétablir ou de renforcer la santé d'une personne en travaillant sur la tonicité des muscles. 
«Quand vous entendez parler un rhumatologue c'est que pour le pèse, c'est vraiment basé que sur l'argent, sur le pouvoir, sur le monopole d'un secteur de maladie et pour le fric ».

En dépit des résultats de ses examens biologiques, Vincent ne s'estime plus malade et pense qu'il le doit à sa démarche spirituelle. "Honnêtement, dit-il, je ne me sens plus malade, même si mes résultats ne sont pas forcément très bons ou ne le sauront pas après, intérieurement, je ne me sens plus malade, c'est pour moi le plus important, et en discutant avec mon médecin (iviste), elle me disait, j'ai certains confrères qui sont dans des états aussi avec des cancers et qui sont super bien (...) Je leur fais faire une batterie d'examens, ils sont dans un état physique pitoyable mais qui ont une vitalité, qui se sentent super bien mais qui, au niveau des résultats, qui seraient susceptibles de rentrer à l'hôpital mais qui sont dans un état de forme éblouissante, alors, allez expliquer ça, ce n'est pas compatible, en soi, donc ça veut dire que la spiritualité peut engendrer un état de mieux-être, d'enrichissement intérieur qui peut pallier tous les états, si c'est fait vraiment dans le bon sens, ça peut pallier à tout $»$.

À la différence des précédents cas de figure, Vincent se situe dans une logique de refus de prendre des traitements médicamenteux. Ce sont les mauvais résultats de ses examens médicaux qui l'ont conduit à les prendre. Il reste cependant persuadé que les marqueurs biologiques ne sont pas, en soi, une preuve de bonne ou mauvaise santé ; l'individu et son ressenti restant souverains.

\section{Absence de traitement médicamenteux}

Dans le troisième cas de figure, on est face à deux personnes, Julien et Thierry, qui refusent tout traitement médicamenteux. Le parcours de Julien ayant déjà été présenté, on s'attardera sur le cas de Thierry. Celui-ci apprend sa séropositivité, en 1986, alors qu'il est étudiant. Il achève ses études et trouve assez rapidement du travail.

Quelques années plus tard, il a le sentiment d'être dans une impasse. Il n'apprécie pas la manière dont est géré le cancer de l'un de ses collègues de travail. La relation qu'il a avec son compagnon de vie se dégrade, et il commence à ressentir certains symptômes au niveau des intestins. Il fait une dépression assortie d'une tentative de suicide. À la sortie de l'hôpital, il passe quinze jours à la montagne et prend un certain nombre de décisions dont celle de quitter son travail. Il retrouve, assez rapidement, un poste avec d'importantes responsabilités dans un laboratoire pharmaceutique.

C'est à cette période que Thierry renoue avec la spiritualité et s'engage dans des formes thérapeutiques parallèles. La première de ces expériences se passe avec la sœur de l'un de ses amis qui pratique l'une des techniques mises en place par Martin Brofman ${ }^{113}$, le Corps-Miroir.

\footnotetext{
113 - D'après le site Internet de la fondation Martin Brofman, « le Système du Corps-Miroir est une technique, un ensemble d'outils que tout le monde peut utiliser. Ces outils permettent d'explorer la relation entre votre corps, votre conscience, et votre vie et d'étudier les attitudes intérieures qui ont montré qu'elles encouragent le processus de guérison (...). Le Système du Corps-Miroir est basé sur l'idée que les parties de votre corps qui ne fonctionnent pas
} 
Cette première expérience le convainc de poursuivre dans ce domaine. Il se forme aux techniques de cette "guérisseuse », assiste à de nombreuses conférences, réalise des stages, ... Au cours de l'un de ces stages, il rencontre une personne qui deviendra son «maître spirituel ». Celui-ci a une formation d'ostéopathe et s'inspire des traditions bouddhiste et chrétienne. Thierry restera auprès de lui durant trois ans. À la suite de leur rupture, Thierry a la conviction qu'il doit devenir thérapeute. Il prendra une année sabbatique pour faire le point. Une formation d'accompagnant de mourants et l'ensemble des acquis engrangés au cours des dernières années permettent à Thierry de s'engager comme thérapeute; il a ses premiers clients et en 1998, il s'installe officiellement comme psychothérapeute.

Durant son année sabbatique (1995-96), Thierry a des contacts avec différentes traditions spirituelles. Il apprécie tout particulièrement les principes développés par un groupe d'origine indienne, le Shri Ram Chandra Jean. Il partira en Inde rencontrer le leader de ce groupe, Chari, et vivra des émotions fortes.

À cette époque, explique Thierry, «ma relation au sida c'était, y’avait vraiment quelque chose qui s'était passé, la façon dont je le formulerais le mieux, c'est que y'avait un endroit où il n'avait plus de prise sur moi, c'est à dire que ce virus était là, il était sans doute dans mon corps, mais il n'avait plus de prise sur moi, donc je ne faisais plus de suivi, y'avait plus rien ».

C'est l'époque où Thierry décide d'arrêter d'être suivi d'un point de vue médical et après une retraite spirituelle, dans un foyer catholique, il prend la décision suivante :

«Maintenant, il faut que ça soit ta foi qui te porte, et donc depuis ce jour-là, c'est comme ça que je vis c'est à dire que c'est pour moi, c'est la foi qui me porte, c'est le Christ qui est mon immunité, ça peut paraître complètement hallucinant, mais ça me réussit plutôt bien, mais c'est vraiment ça qui me porte, y'a quelque chose qui est de l'ordre d'une prière continuelle, et sachant que je dis toujours que c'est comme ça aujourd'hui, si demain je sens que ma santé vacille, je reverrai la question, si je sens que ça ne va pas bien, je reverrai la question, et chaque fois que j'ai voulu reprendre un suivi, y'a toujours eu quelque chose, quelqu'un dans la rue, un message, toujours quelque chose qui me disait, arrête ».

Finalement, sur les conseils d'un ami, il se rend dans une église orthodoxe qui lui laisse une certaine liberté d'action.

Thierry ne prétend pas être guéri du sida et ne cherche pas à le savoir dans la mesure où il a arrêté d'être suivi par un praticien. Pour autant, à la fin de l'entretien, il tient à signaler qu'un des derniers médecins qu'il a consulté était étonné des résultats de ses examens biologiques.

bien reflètent les parties de votre vie qui ne fonctionnent pas bien, et à propos desquelles vous ressentez des tensions dans votre conscience », informations trouvées sur le site Internet (http://www.healer.ch/f-Fondation.html), septembre 2002 . 
«Je me souviens, dit-il, d'un médecin qui était là, qui me faisait ses tests et qui me disait, ce n'est pas possible, ce n'est pas possible, vous avez une très légère trace de HIV, il me disait ce n'est pas possible, je n'ai quasiment jamais vu ça, vous avez une très légère trace du sida dans votre $A D N$, mais y'a rien, pour moi, vous êtes quelqu'un qui est en voie de guérison ».

Dans cette perspective, Thierry tend à penser que les sentiments peuvent outrepasser les lois biologiques.

«Il est vrai que quand je vois le gars avec qui je vivais quand j'ai appris que j'avais un problème par rapport au HIV, on a continué à avoir des relations non protégées pendant un an, après qu'on l'ai su, il n'a jamais été contaminé, et a priori, je n'ai jamais contaminé personne, même si, à certains moments, j'ai pris des risques, au fond de moi-même, dans mon coeur, je me dis que l'amour est plus fort que tout, mais pas un amour azimuté, pas un amour illuminé, un amour ancré, un amour raisonnable, un amour qui prend toutes les dimensions de l'être, corps, âme, esprit ». 


\section{Conclusion}

La rupture avec la religion d'origine s'effectue rarement dans un climat conflictuel dans la mesure où la prise de distance existait déjà, avant l'annonce de la séropositivité. L'apparition du VIH conduit la plupart des personnes à s'insérer dans de nouveaux réseaux de sociabilité/religiosité.

L'engagement spirituel sert à structurer et organiser une vie complètement bouleversée par l'annonce de la séropositivité. Il faut rappeler que ces personnes ont appris leur séropositivité avant l'arrivée des multithérapies et que la plupart d'entre elles avaient une vingtaine d'années lors de cette annonce.

À partir des engagements religieux des uns et des autres, on constate que la construction identitaire prend des formes différentes. Pour certains, on a vu que cela les conduisait à une nouvelle identité professionnelle (psychothérapeute), identité légitimée à partir de leur expérience de la maladie et de la mort mais aussi en tant que témoins et survivants d'une époque (avant les multithérapies).

D'autres personnes ont recours à des pratiques thérapeutiques parallèles ou alternatives qui leur permet de préserver une part de leur identité/intégrité corporelle en les sortant d'un cadre médical qu'ils considèrent comme trop restrictif, ne prenant pas assez en compte la dimension globale de l'individu.

D'autres, enfin, ont fait le choix de s'engager fortement au sein d'une organisation religieuse. Leur identité s'est vue redéfinie à travers cet engagement dans le sens où elle se construit à partir du groupe. 


\section{conclusion}

Pour conclure ce rapport, on reprendra les éléments avancés au cours de la construction de l'objet et ceux observés sur le terrain.

L'annonce de la séropositivité au VIH a été envisagée comme un moment de « crise » déstructurant l'identité de l'individu, aux niveaux de ses insertions sociales (famille, travail, sexualité,...) et de ses nouvelles attributions (séropositf, « malade » du sida). La perspective d'une reconstruction identitaire, pour des personnes engagées dans une démarche spirituelle, a été appréhendée autour d'une dialectique entre identité assignée et identité réelle. Le référent spirituel permettrait d'accepter, de s'accommoder, ou de dépasser cette identité de séropositif. Trois groupes ont été élaborés pour penser les formes de (re)construction identitaire, et ce en fonction du rapport à la religion/spiritualité. Chacun prend en compte d'une part le rapport à la religion/spiritualité, d'autre part les représentations du VIH, et enfin les pratiques religiothérapeutiques.

Le premier de ces groupes rassemble des personnes qui ont renoué ou conservé des liens avec leur religion d'origine. Ce retour ou cette continuité avec l'héritage religieux n'est pas sans poser un certain nombre de questions, notamment pour les homosexuels. Après avoir rompu avec le catholicisme, en raison de leur orientation sexuelle, ces derniers vont renouer avec leur religion d'origine, à l'annonce de la séropositivité ou suite à une déception amoureuse. Un certain nombre d'entre eux ont même envisagé de devenir prêtre ou moine. En fait, le dilemme vécu par ces personnes est de s'insérer au sein d'une institution dont ils savent qu'ils seront toujours mis à la marge (cf. l'église catholique ne condamne pas les homosexuels mais leurs pratiques sexuelles). L'acceptation de cette marginalisation fonctionne parce qu'elle est aussi, paradoxalement, une entreprise de normalisation (aux niveaux de la sexualité, des rapports à la famille,...).

La plupart de ces personnes envisage leur séropositivité de manière positive car cela les a conduit à renouer avec la religion et à changer leurs rapports à elles-mêmes et aux autres. Essentiellement catholiques, ces personnes se situent dans un rapport de sujétion à l'autorité médicale. De fait, peu d'entre elles ont un discours critique ou des pratiques alternatives à l'institution médicale.

Dans le second groupe, le religieux/spirituel est envisagé dans sa dimension culturelle. Il réunit des personnes originaires de l'Afrique sub-saharienne qui, pour la plupart, ont découvert leur séropositivité en France. À leur arrivée, ces personnes, souvent démunies de tout, vont être prises en charge par des services sociaux ; le statut qui leur est reconnu est celui de malade. Le référent spirituel/religieux apparaît alors comme un moyen de préserver une part de leur intimité mais aussi, voire surtout, de leur donner une identité autre que celle de malade. Cette identité « religieuse » leur est d'autant plus précieuse qu'ils n'ont pas la perspective de retourner dans leur pays d'origine.

Qu'ils s'agissent des protestants, des catholiques ou des musulmans, tous pratiquent la religion qu'ils avaient au pays. Cette continuité religieuse est une façon de maintenir un lien symbolique avec ceux restés au pays (femme, enfants, ...), même si, parfois, la pratique cultuelle est irrégulière. 
Leurs représentations du VIH, principalement exogènes (Satan, acte en sorcellerie, plan de Dieu, ...), traduisent la difficulté de dire et/ou de parler de la sexualité. Elles peuvent être comprises à partir de deux aspects. D'un point de vue individuel, elles permettent de donner un sens à une histoire souvent marquée par le malheur et l'infortune. D'un point de vue collectif, elles sont une forme de disculpation face à des pratiques sexuelles considérées comme déviantes au regard de l'éthique religieuse.

Les pratiques religio-thérapeutiques oscillent entre un pôle relativement attestataire (catholiques et musulmans) et un pôle plus protestataire (protestants). Dans le premier cas de figure, on trouve des pratiques thérapeutiques complémentaires (pèlerinage à Lourdes, lavements avec de l'eau contenant des versets du Coran, ...) à celles proposées par l'institution médicale. Dans le second cas de figure, on peut observer des croyances et pratiques allant à l'encontre du discours de la profession médicale (guérison du sida, jeûne, ...). Elles doivent être envisagées comme une forme de réappropriation symbolique du corps.

Le troisième groupe rassemble des personnes en rupture avec leur héritage religieux et qui ont engagé une démarche spirituelle à l'annonce de leur séropositivité. Trois formes de (re)construction identitaire peuvent être envisagées.

La première concerne des personnes qui ont changé d'identité professionnelle. Leur expérience du VIH les a conduites à vouloir devenir psychothérapeute. Alors que certaines vivent déjà de leur profession, d'autres sont encore en formation. L'efficacité de leur pratique est légitimée par leur expérience du VIH (survivants d'une époque où les multithérapies n'existaient pas) et celle d'un rapport avec le monde supraempirique. La seconde réunit des personnes à la recherche de pratiques/techniques ou d'autres voies spirituelles permettant une gestion du VIHSida pas seulement médicale. La troisième regroupe des personnes qui se sont fortement investies au sein d'une organisation religieuse ; leur identité personnelle est redéfinie en fonction de leur appartenance au groupe. Les liens communautaires y sont forts et permettent de restructurer/réorganiser le parcours des uns et des autres.

Les représentations du VIH sont d'ordre endogène et exogène. Pour certains, le VIH cristallise un mal-être auquel la spiritualité va pouvoir remédier, alors que pour d'autres, il est apparu à la suite de la libéralisation des moeurs. Quant aux pratiques religio-thérapeutiques, on oscille entre des pratiques complémentaires (taï chi, chi qong, ...) et des pratiques plus protestataires (rejet des traitements médicamenteux).

Selon l'appartenance religieuse/spirituelle des individus, il est possible d'observer, tendanciellement, un rapport plus ou moins attestataire à l'institution médicale. On a ainsi pu observer que les catholiques et musulmans (premier groupe) se conforment davantage aux prescriptions médicales que les protestants ou les personnes inscrites dans la mouvance New Age (second groupe). De fait, pour le premier groupe, la construction identitaire se réalise d'abord et avant tout dans le rapport à la spiritualité/religiosité (identité sexuelle, fatalité,...).

Alors que pour le second groupe, la construction identitaire passe davantage par un rapport distancié voire critique à l'institution médicale. On le perçoit, notamment, à travers 
l'existence d'un discours sur la «guérison» du VIH. La réalisation de cette "guérison » s'effectue néanmoins sur des modes différents. Dans le cas du New Age, on est face à une autoréalisation où le ressenti a valeur de «preuve » et où il s'agit de satisfaire des attentes suscitées par le modèle médical dominant (aller toujours plus loin dans le progrès). Le recours aux médecines parallèles, relativement fréquent pour ces personnes, permet d'envisager un rapport différent vis-à-vis du VIH et de l'institution médicale. Il donne le sentiment de pouvoir contrôler le virus mais aussi de ne pas être assujetti au modèle médical dominant.

Dans le cas des pentecôtistes, c'est le groupe qui accomplit le travail d'expulsion du «mal» (cf. le VIH provenant d'un acte de sorcellerie) et qui rejette ce qu'il perçoit être un rapport de domination/exploitation vis-à-vis de l'institution médicale (cf. se libérer du joug de la médecine des Blancs).

Il faut prendre en considération un troisième cas de figure, celui des organisations religieuses fortement structurées où l'identité se construit en référence à l'appartenance groupale.

De manière générale, on peut considérer que le référent spirituel/religieux permet une construction identitaire en ce sens qu'il permet de vivre différemment le rapport au VIH/Sida. 


\section{Bibliographie}

- Adam Ph.

1994 «Lutte contre le sida : vers une redistribution des rôles? », Panoramiques, Sois patient et tais-toi. Le pouvoir médical, in R. Lenoir, M. Tsikounas (éds), II (17) : 105-111. 1997 «Urgence sanitaire et liens sociaux : l'exceptionnalité du sida ? », avec C. Herzlich, Cahiers internationaux de sociologie, CII : 5-28.

- Aïach P.

1998 «Les voies de la médicalisation », in P. Aïach, D. Delanoë (éds), L’ère de la médicalisation. Ecce homo sanitas, Paris, Anthropos : 15-36.

- Aïach P., Fassin D. et Saliba J.

1994 «Crise, pouvoir et légitimité », in P. Aïach et D. Fassin (éds), Les métiers de la santé. Enjeux de pouvoir et quête de légitimité, Paris, Anthropos : 9-42.

- Aubrée M.

2000 «La diffusion du pentecôtisme brésilien en France et en Europe : le cas de l'I.U.R.D. », in C. Lerat et B. Rigal-Cellard (éds), Les mutations transatlantiques des religions, Bordeaux, PUB : 149-157.

- Bajoit G.

1999 « Notes sur la construction de l'identité personnelle », Recherches sociologiques, $2: 69-84$.

- Baszenger I.

1986 «Les maladies chroniques et leur ordre négocié », Revue Française de la Sociologie, XXVII : 3-27.

- Baubérot J.

1993 «Changements socio-religieux et restructuration identitaire : le protestantisme pentecôtiste et les tziganes », Ethnologie des faits religieux en Europe, Paris, C.T.H.S : 427-432.

- Benoist J.

1998 «Les médecines douces », in Ch. Bromberger (éd), Passions ordinaires. Du match de football au concours de dictée, Paris, Bayard : 523-541.

- Berger P.

2001 «La désécularisation du monde : un point de vue global », in P. Berger (éd), Le réenchantement du monde, Paris, Bayard : 13-36.

- Berger P. et Luckmann T.

1989 [1986] La construction sociale de la réalité, Paris, Méridiens Klincksieck.

- Bodart J.

1982 «Modernité et néo-clercs. À partir de l'image de soi du travailleur social », Social Compass, XXIX (4) : 283-295.

- Bonnet D.

2000 « Au-delà du gène et de la culture », Hommes et migrations. Santé, Le traitement de la différence, $1225: 23-38$.

- Borraz O. et Loncle-Moriceau P.

2000 «Permanence et recompositions du secteur sanitaire. Les politiques locales de lutte contre le sida », Revue Française de Sociologie, 41 (1) : 37-60. 
- Bourdieu P.

1985 «Champ religieux dans le champ de manipulation symbolique », in Histoire et société. Les nouveaux clercs. Prêtres, pasteurs et spécialistes de la santé, Genève, Labor et Fides, $6: 255-261$.

1986 «L'illusion biographique », Actes de la Recherche en Sciences Sociales, 62$63: 69-72$.

- Bulletin épidémiologique hebdomadaire

2001 «Surveillance du Sida en France. Situation au 31 mars 2001 », 24 : 1-4.

- Campiche R.

1993 «Individualisation du croire et recomposition de la religion », Archives de Science Sociales des Religions, 81 : 117-131.

1996 «Entre l'exemple et l'expérience : de la transmission par la famille d'une tradition à celle d'un éthos religieux », Figures des Dieux. Rites et mouvements religieux. Hommage à Jean Rémy, Paris-Bruxelles, De Boeck, coll. Ouvertures sociologiques : 147162.

- Carricaburu D. et Pierret J.

1992 Vie quotidienne et recompositions identitaires autour de la séropositivité, Paris, Rapport CERMES/ANRS.

- Champion F.

1999 «'Nouveaux mouvements religieux' et sectes », avec L. Hourmant, Sectes et démocratie, Paris, Seuil : 59-85.

1993 «La croyance en l'alliance de la science et de la religion dans les nouveaux courants mystiques et ésotériques », Archives de Sciences Sociales des Religons, 82 : 205222.

1993 «Recompositions, décompositions. Le renouveau charismatique et la nébuleuse mystique-ésotérique depuis les années 1970 », avec M. Cohen, Le débat : 81-89.

1992 «À propos des courants mystiques et ésotériques », Sortie des religions, retour du religieux, Lille, Astragale, coll. L'œuvre au Bleu : 151-169.

- Charmaz K.

1983 «Loss of self : a fundamental form of suffering in the chronically ill », Sociology of Health and Illness, 5 (2) : 168-195.

- Cohen M.

1995 «Les charismatiques et la santé. Offres religieuses de salut ou nouvelles médecines parallèles ? », in F. Lautman et J. Maître (éds), Gestions religieuses de la santé, Paris, L'Harmattan, coll. Santé, sociétés et cultures : 61-87.

1993 «Recompositions, décompositions. Le renouveau charismatique et la nébuleuse mystique-ésotérique depuis les années 1970 », avec F. Champion, Le débat : 81-89.

- Corten A.

1997 «Miracles et obéissance. Le discours de la guérison divine à l'Église Universelle », Social Compass, 44 (2) : 283-303.

- Cox H.

1995 (1994) Le retour de Dieu. Voyage en pays pentecôtiste, Paris, Desclée de Brouwer. 
- Davie G.

1996 «Le déferlement spirituel des nouveaux mouvements religieux », avec D. Hervieu-Léger, in D. Hervieu-Léger, G. Davie (éds), Identités religieuses en Europe, Paris, La Découverte : 269-289.

- Dericquebourg R.

2001 Croire et guérir. Quatre religions de guérison, Paris, Dervy.

1999 «Les Témoins de Jéhovah : vers une sortie de la logique sectaire », in M. Cohen, F. Champion (éds), Sectes et démocratie, Paris, Seuil : 105-125.

1997 «La guérison par la religion », Revue Française de Psychanalyse, 3 : 965-979.

- Donegani J.-M.

1993 La liberté de choisir. Pluralisme religieux et pluralisme politique dans le catholicisme français contemporain, Paris, Presses de la Fondation des Sciences Politiques.

- Élias N. 1991 [1987] La société des individus, Paris, Fayard.

- Fainzang S.

2001 Médicaments et société. La patient, le médecin et l'ordonnance, Paris, PUF, coll. Ethnologies, Controverses.

- Fassin D.

1994 «Le domaine privé de la santé publique. Pouvoir, politique et sida au Congo », Annales, 49 (4) : 745-775.

1996 L'espace politique de la santé. Essai de généalogie, Paris, PUF, coll. Sociologie d'aujourd'hui.

1999 «Santé et immigration. Les vérités politiques du corps », Cahiers de l'URMIS, $5: 69-76$.

1999 «Santé : des inégalités sociales sans droit de cité », Mouvements, 4 : 49-57.

1999 «L'indicible et l'impensé : la 'question immigrée' dans les politiques du sida », Sciences sociales et santé, 17 (4) : 5-35.

2000 «Les politiques de l'ethnopsychiatrie. La psychée africaine, des colonies africaines aux banlieues parisiennes », L'homme, $153: 231-250$.

2002 «Sida, immigration et inégalité : nouvelles réalités, nouveaux enjeux », Sida, immigration et inégalités. Nouvelles réalités, nouveaux enjeux, Paris, ANRS, coll. Science sociales et sida : 1-11.

- Fath S.

2001 «L'autorité charismatique au cœur de l'église : pentecôtisme et débat sectaire », Etudes théologiques et religieuses, 3 : 371-390.

- Faure O.

1993 Les Français et leur médecine au XIX siècle, Paris, Belin.

- Friedman D.

1981 Les guérisseurs. Splendeurs et misères du don, Paris, Métailié.

- Guérin A.

1999 Médecines parallèles et sida, avec B. Paillard, Paris, Rapport de l'Agence Nationale de Recherches sur le Sida, Paris. 
- Hervieu-Léger D.

1990 «Renouveaux émotionnels contemporains. Fin de la sécularisation ou fin de la religion ?», in $\mathrm{D}$. Hervieu-Léger, F. Champion (éds), De l'émotion en religion. Renouveaux et traditions, Paris, Centurion : 217-248.

1996 «Le déferlement spirituel des nouveaux mouvements religieux », avec G. Davie, in D. Hervieu-Léger, G. Davie (éds), Identités religieuses en Europe, Paris, La Découverte : 269-289.

1996 «La religion des Européens : modernité, religion, sécularisation », in D. HervieuLéger et G. Davie (éds), Identités religieuses en Europe, Paris, La Découverte : 9-23. 1999 Le pèlerin et le converti. La religion en mouvement, Paris, Flammarion.

- Herzlich Cl.

1997 «Urgence sanitaire et liens sociaux : l'exceptionnalité du sida », avec P. Adams, Cahiers internationaux de sociologie, CII : 5-28.

- Hourmant L.

1990 «'Transformer le poison en élixir'. L'alchimie du désir dans un culte néobouddhique, la Soka Gakkai française », in $\mathrm{F}$. Champion et D. Hervieu-Léger (éds), De l'émotion en religion. Renouveaux et traditions, Paris, Centurion : 71-119.

1995 « Les nouveaux mouvements religieux japonais : entre laïcisation et euphémisation du sacré », Social Compass, 42 (2 : 207-220.

1999 «'Nouveaux mouvements religieux' et sectes», avec F. Champion, Sectes et démocratie, Paris, Seuil : 59-85.

- Hours B.

2001 «Introduction. Pour une anthropologie de la santé en société », in B. Hours (éd), Systèmes et politiques de santé. De la santé publique à l'anthropologie, Paris, Karthala : 5-40.

- Jauffret M.

1997 «L'auto-support des usagers de drogues en France», Toxibase, $4^{\mathrm{e}}$ trimestre : 1522.

- Lalouette J.

1991 «Expulser Dieu : la laïcisation des écoles, des hôpitaux et des prétoires », Mots. Les langages du politique, 27.

- Lambert Y. 1995 «Une définition plurielle pour une réalité en mutation », Cahiers Français. Religions et société, 273 : 3-12.

- Laplantine F. 1999 «Maladie, guérison et religion dans les mouvements pentecôtistes latinoaméricains contemporains », Anthropologie et Sociétés, 23 (2) : 101-115.

- Lévy J.

2002 «Religion et spiritualité et nouvelles thérapies face au VIH/Sida », in R. Massé et J. Benoist (éds), Convocations thérapeutiques du sacré, Paris, Karthala, coll. Médecines du monde : $165-182$.

- Maître J.

1987 «Régulations idéologiques officielles et nébuleuses d'hétérodoxies. À propos des rapports entre religion et santé », Social Compass, XXXIV (4) : 353-364. 
- Massé R.

2001 «La santé publique comme projet politique et projet individuel », in B. Hours (éd), Systèmes et politiques de santé. De la santé publique à l'anthropologie, Paris Karthala : 41-64.

- Monlouis-Félicité A.

1998 «Au plus proche de la vie familiale», Informations sociales. Sida : les nouvelles donnes, $71: 48-53$.

- Morin M.

2001 «De la recherche à l'intervention sur l'observance thérapeutique : contributions et perspectives des sciences sociales », L'observance aux traitements contre le VIH/Sida. Mesure, déterminants, évolution, Paris, ANRS, coll. Sciences sociales et sida : 5-20.

- Nedelec F.

1993, « Notes de terrain », Sociétés, 42 : 367-371.

- Paillard B.

1999 Médecines parallèles et sida, avec A. Guérin, Paris, Rapport de l'Agence Nationale de Recherches sur le Sida, Paris.

- Pollak M.

1993 Une identité blessée. Étude de sociologie et d'histoire, Paris, Métailié.

- Rocchi V.

2000 «Du Nouvel Âge aux réseaux psychomystiques », Ethnologie Française, XXX : 583-590.

- Savignoni A.

1999 Situation du Sida dans la population étrangère en France, avec A. Laporte, F. Lot, J. Pillonel, Paris, Institut de Veille Sanitaire.

- Séguy J.

1980 Christianisme et société. Introduction à la sociologie de Ernst Troeltsch, Paris, Cerf, Coll. Sciences Humaines et Religions.

- Théry I.

1998 «e silence, le secret et l'itinéraire de la confidence », Informations sociales. Sida : les nouvelles donnes, 71 : 66-75.

- Trincaz J.

1975 «Le pouvoir thérapeutique des Ba-Pena (Casamance). Initiation et pouvoir libérateur », Psychopathologie africaine, XI (3) : 323-362.

- Vigarello G.

1993 Le sain et le malsain. Santé et mieux-être depuis le Moyen Âge,

Paris, Seuil, coll. L'Univers Historique.

- Weber M.

1990 [1920] L'éthique protestante et l'esprit du capitalisme, Paris, Plon, coll. Agora.

- Willaime J.-P.

1999 «e pentecôtisme : contours et paradoxes d'un protestantisme émotionnel », Archives des Sciences Sociales des Religions, 105 : 5-28.

1999 «Les définitions sociologiques de la secte », in F. Messner (éd), Les sectes et le droit, Paris, P.U.F : 21-46. 
- Zempléni A.

1985 «La 'maladie' et ses 'causes'. Introduction», L'ethnographie. Causes, origines et agents de la maladie chez les peuples sans écritures, 96-97 (2 et 3) : 13-44. 


\section{Annexes}

\section{1) Données Socio-démographiques}

\begin{tabular}{|l|c|}
\hline \multicolumn{1}{|c|}{ Religions - Spiritualités } & Nombre \\
\hline Catholique & 10 \\
\hline Protestante & 6 \\
\hline Musulmane & 3 \\
\hline Bouddhiste & 4 \\
\hline New Age & 9 \\
\hline Autres & $\mathbf{5}$ \\
Orthodoxe & 2 \\
Invitation à la vie & 2 \\
Témoin de Jéhovah & 1 \\
Divers & 1 \\
\hline
\end{tabular}

\begin{tabular}{|l|c|c|c|}
\hline \multicolumn{1}{|c|}{ Age } & Homme & Femme & Total \\
\hline $20-29$ ans & 2 & 2 & $\mathbf{4}$ \\
\hline $30-39$ ans & 6 & 4 & $\mathbf{1 0}$ \\
\hline $40-49$ ans & 15 & 4 & $\mathbf{1 9}$ \\
\hline $50-59$ ans & 2 & 1 & $\mathbf{3}$ \\
\hline 60 ans et + & 2 & 0 & $\mathbf{2}$ \\
\hline Total & $\mathbf{2 7}$ & $\mathbf{1 1}$ & $\mathbf{3 8}$ \\
\hline
\end{tabular}

\begin{tabular}{|l|c|}
\hline \multicolumn{1}{|c|}{ Sexe } & Nombre \\
\hline Homme & $\mathbf{2 7}$ \\
\hline Femme & $\mathbf{1 1}$ \\
\hline
\end{tabular}

\begin{tabular}{|l|c|c|c|}
\hline \multicolumn{1}{|c|}{ Professions } & Homme & Femme & Total \\
\hline Artisans-Commerçants & 2 & 0 & $\mathbf{2}$ \\
\hline Professions libérales et cadres supérieurs & 5 & 1 & $\mathbf{6}$ \\
\hline Cadres moyens & 5 & 1 & $\mathbf{6}$ \\
\hline Employés & 1 & 0 & $\mathbf{1}$ \\
\hline Personnel de service & 1 & 2 & $\mathbf{3}$ \\
\hline Retraité & 2 & 0 & $\mathbf{2}$ \\
\hline Sans Profession & 11 & 7 & $\mathbf{1 8}$ \\
\hline Total & $\mathbf{2 7}$ & $\mathbf{1 1}$ & $\mathbf{3 8}$ \\
\hline
\end{tabular}




\begin{tabular}{|l|c|c|c|}
\hline \multicolumn{1}{|c|}{ Niveau d'étude } & Homme & Femme & Total \\
\hline École primaire & 0 & 1 & $\mathbf{1}$ \\
\hline CAP/BEP & 2 & 0 & $\mathbf{2}$ \\
\hline Collège, BEPC et avant le BAC & 3 & 4 & $\mathbf{7}$ \\
\hline BAC & 8 & 2 & $\mathbf{1 0}$ \\
\hline BAC-BAC+2 & 3 & 1 & $\mathbf{4}$ \\
\hline BAC+3-BAC+4 & 6 & 1 & $\mathbf{7}$ \\
\hline BAC+5 et + & 4 & 2 & $\mathbf{6}$ \\
\hline Autres & 1 & 0 & $\mathbf{1}$ \\
\hline Total & $\mathbf{2 7}$ & $\mathbf{1 1}$ & $\mathbf{3 8}$ \\
\hline
\end{tabular}

\begin{tabular}{|l|c|}
\hline \multicolumn{1}{|c|}{ Statut matrimonial } & Nombre \\
\hline Vivant en couple & $\mathbf{7}$ \\
\hline Vivant seul & $\mathbf{2 9}$ \\
\hline Sans réponse & $\mathbf{2}$ \\
\hline
\end{tabular}

\begin{tabular}{|l|c|c|c|}
\hline Date de l'annonce de la séropositivité & Homme & Femme & Total \\
\hline$[1983-1996[$ & 23 & 6 & $\mathbf{2 9}$ \\
\hline$[1996-2000[$ & 4 & 5 & $\mathbf{9}$ \\
\hline
\end{tabular}

\begin{tabular}{|l|c|c|c|}
\hline \multicolumn{1}{|c|}{ Pays d'origine } & Homme & Femme & Total \\
\hline France & 18 & 5 & $\mathbf{2 3}$ \\
\hline Afrique & 6 & 6 & $\mathbf{1 2}$ \\
\hline Autres & 3 & 0 & $\mathbf{3}$ \\
\hline
\end{tabular}

\begin{tabular}{|l|c|c|c|}
\hline \multicolumn{1}{|c|}{ Pratiques sexuelles } & Homme & Femme & Total \\
\hline Hétérosexuel(le) & 13 & 11 & $\mathbf{2 4}$ \\
\hline Homosexuel(le) & 12 & 0 & $\mathbf{1 2}$ \\
\hline Bisexuel(le) & 1 & 0 & $\mathbf{1}$ \\
\hline Non réponse & 1 & 0 & $\mathbf{1}$ \\
\hline
\end{tabular}

\begin{tabular}{|l|c|c|c|}
\hline \multicolumn{1}{|c|}{ Mode de contamination } & Homme & Femme & Total \\
\hline Sexuelle & 18 & 7 & $\mathbf{2 5}$ \\
\hline Voie intraveineuse & 5 & 1 & $\mathbf{6}$ \\
\hline Autres & 4 & 3 & $\mathbf{7}$ \\
\hline
\end{tabular}




\section{2) Grille d'entretien}

Trois thématiques ont été abordées au cours des entretiens :

- Annonce de la séropositivité et ses incidences tant d'un point de vue professionnel, que familial, spirituel, médical, etc. ;

- La démarche spirituelle : l'annonce de la séropositivité au VIH a-t-elle une incidence sur la démarche spirituelle : s'agit-il d'une conversion religieuse, d'une pratique sans rupture, .... Quelle est cette démarche spirituelle, quel type de pratique a la personne : se rend-elle régulièrement dans un groupe religieux, dans quelle mesure le groupe religieux ou la démarche spirituelle a une incidence sur les pratiques thérapeutiques, etc. ;

- Les rapports à l'institution médicale : quels types de rapports entretient la personne avec l'institution hospitalière, son médecin, ... Existe-t-il un lien entre les pratiques religieuses et les pratiques thérapeutiques ? 